Universidade DE SÃo PAUlo

INSTITUTO DE FÍsicA

\title{
Distinguindo a Composição dos Raios Cósmicos Extremamente Energéticos
}

\author{
NÍKOLAS KeMmerich \\ Orientadora: Prof ${ }^{A}$. Dra ${ }^{\mathrm{A}}$. Ivone Freire da Mota e Albuquerque \\ DisSERTAÇÃo DE MESTRADO APRESENTADA AO \\ INSTITUto DE FísicA PARA A OBTENÇÃO DO \\ título de Mestre EM CiÊnCIAS.
}

Comissão Examinadora:

Prof $^{a}$. Dra ${ }^{a}$. Ivone Freire da Mota e Albuquerque (IFUSP)

Prof $^{a}$. Dr ${ }^{\mathrm{a}}$. Carola Dobrigkeit Chinellato (UNICAMP)

Prof. Dr. Philippe Gouffon (IFUSP)

São Paulo

2013 


\section{Agradecimentos}

Gostaria de agradecer a todas as pessoas que me ajudaram na elaboração desta dissertação, em especial ao Prof. Dr. Vitor de Souza e do seu grupo por disponibilizar o cluster de São Carlos para simular os chuveiros atmosféricos extensos. Também ao Prof. Dr. Philippe Gouffon pelos seus auxílios nas análises estatísticas. Aos Drs. Washington Rodrigues de Carvalho Junior, Diogo Tridapalli e Carlos José Todero Peixoto e ao doutorando Denis Robertson Sotelo pelas discussões e as várias dúvidas respondidas.

À minha orientadora Prof ${ }^{\mathrm{a}}$. Dr ${ }^{\mathrm{a}}$. Ivone Freire da Mota e Albuquerque, sempre atenciosa. Nunca esquecerei o seu carinho e amor pela ciência. Com certeza é minha referência como pesquisador para o resto da vida.

Aos meus amigos e familiares, principalmente meu pai, Luceno Kemmerich, referência de caráter.

Ao CNPq pela bolsa de estudos e ao Instituto de Física da Universidade de São Paulo pelos ótimos cursos, pelo espaço e infraestrutura oferecida para a realização desta dissertação. 


\section{Resumo}

As pesquisas em Raios Cósmicos de Ultra Alta Energia conectam várias áreas da ciência, desde a física de partículas elementares até a estrutura do universo. Compreender a sua composição pode elucidar muitos enigmas interdisciplinares. O foco de nosso trabalho será a elaboração de métodos para distinguir a composição dos raios cósmicos com energia $E>5 \times 10^{19} \mathrm{eV}$ usando dois parâmetros, o $X_{\max }$ e a densidade de múons. Em particular, temos como objetivo discriminar chuveiros iniciados por fótons daqueles por núcleos ou nucleons. Iremos basear nosso método em simulações de chuveiros atmosféricos extensos que geraremos através do código AIRES. Iremos analisar as principais características dos chuveiros iniciados por núcleos, nucleons e fótons procurando por sinais que possibilitem a discriminação com alta estatística. 


\section{Abstract}

The subject of Ultra High Energy Cosmic Rays connects scientific fields, from elementary particle physics to the structure of the universe. Understanding the composition of UHECR can elucidate many interdisciplinary enigmas. Our work is focused on the elaboration of methods to distinguish the composition of cosmic rays at energies $5 \times 10^{19} \mathrm{eV}$ using two parameters, $X_{\max }$ and muon density. In particular, we want to discriminate extensive air showers initiated by photons from those initiated by nucleus and nucleons. We base our work on simulations of extensive air showers using the AIRES package. We analyze proton, nucleus and gamma showers looking for signals to discriminate them using large statistics. 


\section{Sumário}

$\begin{array}{lll}1 & \text { Introdução } & 1\end{array}$

1.1 Descoberta dos Raios Cósmicos . . . . . . . . . . . . . . . 2

1.2 Descoberta dos Chuveiros Atmosféricos Extensos. . . . . . . . 5

1.3 Espectro de Energia dos Raios Cósmicos . . . . . . . . . . . 8

1.4 Propagação e o Corte GZK . . . . . . . . . . . . . . . . . . . 10

1.5 Fontes e Mecanismos de Aceleração dos UHECR . . . . . . . . . 13

1.5 .1 Cenários Top-Down . . . . . . . . . . . . . . . . . . . . . . . . . 14

1.5.2 Cenários Botton-Up. . . . . . . . . . . . . . . . . . . 14

1.6 Antigos Experimentos $\ldots \ldots \ldots \ldots$

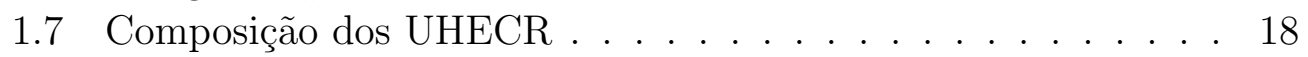

\begin{tabular}{|lll}
2 & EAS e Técnicas de Observação & 21
\end{tabular}

2.1 Chuveiros Atmosféricos Extensos . . . . . . . . . . . . . . . . 22

2.1 .1 Cascata Eletromagnética . . . . . . . . . . . . . . . 22

2.1 .2 Cascata Hadrônica . . . . . . . . . . . . . . . . . . 25

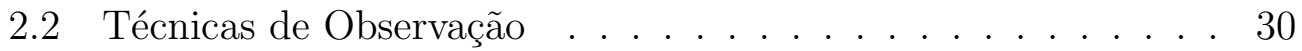

$2.2 .1 \quad$ Detectores de Superfície . . . . . . . . . . . . . 30

2.2 .2 Detectores de Fluorescência $\ldots . . . . . . .34$

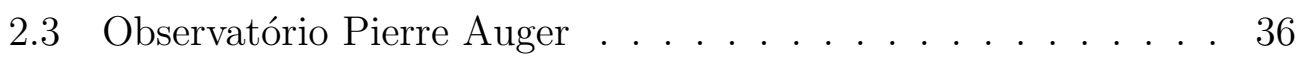

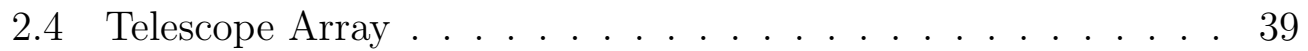

\begin{tabular}{lll}
\hline & Simulação dos EAS & 41
\end{tabular}

3.1 Simulações através do Método MC . . . . . . . . . . . . . . 42

3.2 SIBYLL . . . . . . . . . . . . . . . . . . . . . . . . . . . . 44

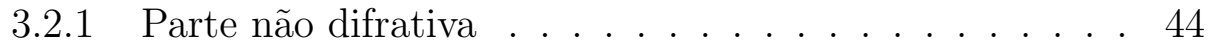

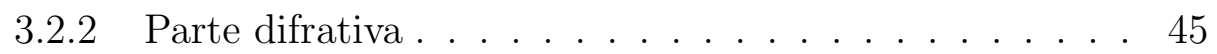

3.2 .3 Minijets . . . . . . . . . . . . . . . . . . . . 46

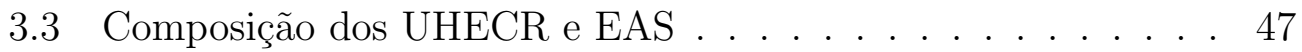

$3.4 X_{\max } \operatorname{dos} \mathrm{EAS} \ldots \ldots \ldots \ldots \ldots$. . . . . . . . . . . . . 47

3.5 Densidade de Múons . . . . . . . . . . . . . . . . . . . 50 
4 Método de distinção dos EAS $\quad 57$

4.1 Cortes Individuais e Vinculados . . . . . . . . . . . . . . . . 59

4.2 Fator de qualidade e Otimização dos Cortes Vinculados . . . . 63

4.3 "Blind" Analysis . . . . . . . . . . . . . . . . . . . 66

$4.3 .1 \quad$ Erros Inerentes à Análise $\ldots \ldots \ldots$

4.3 .2 Resultados . . . . . . . . . . . . . . . . . . . 71

$\begin{array}{lll}5 \text { Conclusões } & 73\end{array}$

\begin{tabular}{ll}
\hline Referências Bibliográficas & 75
\end{tabular} 


\section{Capítulo 1}

\section{Introdução}

Nesta dissertação investigaremos a composição dos raios cósmicos de ultra alta energia (Ultrahigh Energy Cosmic Rays - UHECR) que possuem energia $E>10^{18} \mathrm{eV}$. Os UHECR são estudados indiretamente através dos chuveiros atmosféricos extensos (Extensive Air Showers - EAS), que são cascatas de partículas iniciadas no topo da atmosfera que se estendem até a superfície da Terra. Diversos parâmetros dos EAS podem assinalar a natureza primária dos UHECR.

O foco de nossa investigação será a composição dos eventos mais energéticos no espectro dos UHECR, buscando métodos que possibilitem distinguir EAS iniciados por diferentes tipos de partículas. Em particular, temos como objetivo discriminar chuveiros iniciados por fótons daqueles iniciados por núcleos ou nucleons. Um fluxo de fótons atingindo a atmosfera pode caracterizar processos físicos bastante distintos dos caracterizados pelos fluxos de núcleos ou nucleons. Esses processos podem ser descritos tanto pelo Modelo Padrão de física de partículas (Standard Model-SD), como por extensões deste. Os baixos limites no fluxo de fótons estimado por experimentos, tais como o Observatório Pierre Auger (OPA) [1, 2] e Telescope Array (TA) [3], têm excluído muitos dos modelos exóticos. Porém, o limite superior da fração de fótons continua significativo para a componente mais energética $(\sim 30 \%$ para $E>10^{19.5} \mathrm{eV}$ ). Um eventual fluxo de fótons, mesmo menor do que a componente principal dos UHECR, formada por núcleos e nucleons, pode indicar sinais de extensão. Por isso, desenvolver técnicas de distinção da componente primária dos EAS é sempre importante, tanto para o fluxo da fração principal quanto para testar parâmetros de modelos exóticos.

Nosso método busca selecionar uma amostra de eventos com a melhor pureza possível de fótons. Os métodos de distinção serão baseados em duas técnicas de observação de EAS: os detectores de superfície (Surface Detector - SD) e os detectores de fluorescência (Fluorescence Detectors - FD). O pri- 
meiro detecta o sinal dos EAS na superfície da Terra, enquanto o segundo observa a luz fluorescente emitida durante o desenvolvimento do chuveiro na atmosfera. Ambos os métodos são utilizados no Observatório Pierre Auger (OPA), localizado na cidade de Malargüe, na região Pampa Amarilla ( $-35.47^{\circ}$ latitude e $-69.58^{\circ}$ longitude, $1416 \mathrm{~m}$ a.n.m.) na província de Mendoza, Argentina. Quando as duas técnicas são utilizadas simultaneamente, formam o modo híbrido cuja principal vantagem está na redução dos erros sistemáticos dos parâmetros reconstruídos nos EAS.

Buscamos métodos que distingam a partícula que inicia o EAS (primário do chuveiro) através do método Monte Carlo, utilizando o programa AIRES [4]. Investigaremos as principais características dos chuveiros gerados procurando determinar as melhores formas de distinguir os chuveiros iniciados por fótons daqueles iniciados por prótons e núcleos.

Neste capítulo faremos uma breve introdução sobre os raios cósmicos (RC), depois apresentaremos o seu espectro de energia construído a partir dos dados de diversos experimentos. Exploraremos as características deste espectro, principalmente na região mais energética onde se encontram os UHECR. Listaremos os modelos de propagação e origem dos UHECR e o quanto eles são altamente dependentes da composição. Faz 100 anos desde a descoberta dos RC e mais de 70 anos dos EAS. Através dos chuveiros se pode revelar RC extremamente energéticos, e embora muito se tenha avançado na direção de desvendar os mistérios das partículas mais energéticas do universo, as principais questões concernentes à sua natureza e origem ainda não foram respondidas.

\subsection{Descoberta dos Raios Cósmicos}

No final do século XIX e início do século XX, o poder de penetração de "raios" ejetados por elementos radioativos estavam sendo investigados. Estes foram classificados em $\alpha, \beta$ e $\gamma$, respectivamente em ordem crescente de poder de penetração. Não se conhecia partícula com poder de penetração maior do que os raios $\gamma$.

Nesta época, eletroscópios eram utilizados para medir o grau de ionização dos elementos radioativos e, com isso, determinar a natureza dos raios emitidos. Os eletroscópios eram preenchidos com um gás neutro e na passagem dos raios $\alpha, \beta$ e $\gamma$ o gás era ionizado. Em 1900, C.T.R Wilson investigou um fenômeno bem conhecido na época: a ionização espontânea dos eletroscópios. O fenômeno ocorria mesmo blindando os eletroscópios com chumbo e sem têlos submetido a qualquer tipo de radiação. Wilson supôs que esta ionização do gás era uma consequência da radioatividade natural da Terra e assumiu 
que o agente da radioatividade eram os raios $\gamma$, dado que os outros tipos de partículas ionizantes eram facilmente blindados.

Wulf, em 1910, teve uma ideia para verificar a hipótese de Wilson. Se a radioatividade era emanada da Terra, então a ionização nos eletroscópios diminuiria com a altitude. Ele comparou a ionização na base e no topo da Torre Eiffel $(330 m)$, onde a ionização esperada seria zero. A radioatividade pareceu diminuir com a altitude, mas apenas pela metade quando comparada com aquela ao nível do solo e, assim, a questão necessitou de mais verificações.

Wulf aperfeiçoou os eletroscópios da época (vide Figura 1.1), permitindo medidas mais precisas. Ao invés de usar folhas de ouro, ele usou fios metalizados de fibra de sílica. Isto possibilitava observar a ionização do eletroscópio através de um microscópio acoplado ao mesmo.

Para resolver a questão ainda em aberto, Victor Hess realizou, entre 1911 e 1912, uma série de medidas da ionização na atmosfera. Para isto, realizou experimentos em altitudes de até $5 \mathrm{~km}$, no qual atingia em balões, levando consigo os eletroscópios de Wulf. A Figura 1.2 mostra uma fotografia de Hess em um de seus experimentos. Surpreendentemente, ele constatou que a ionização ao invés de diminuir havia dobrado, mostrando que a causa da ionização natural era de origem extraterrestre. Vitor Hess recebeu o Prêmio Nobel de física em 1936 pela descoberta dos raios cósmicos em seus experimentos em 1912. Werner Kolhörster confirmou as conclusões de Hess ao realizar observações a altitudes de até $9 \mathrm{~km}$, medindo uma radiação ainda maior. Na época, os cientistas não se convenceram dos resultados de Hess e preferiram hipóteses alternativas sobre a origem da radiação. Uma delas era a hipótese de que havia elementos radioativos na atmosfera terrestre.

Bruno Rossi [6] destaca a importância dos trabalhos de Robert A. Millikan e seu grupo devido aos experimentos que realizaram entre 1923 e 1926. Millikan era um dos físicos mais céticos quanto à teoria da radiação ionizante vinda do espaço e, por isso, ele e seus colaboradores decidiram verificar se os dados de Hess e outros estavam corretos. Ele dissipou suas dúvidas sobre a existência dos RC com os resultados dos experimentos realizados nos Lagos Muir e Arrowhead em San Bernardino no Sul da Califórnia, localizados a altitudes de 11.800 pés $(3,6 \mathrm{~km})$ e 5.100 pés $(1,55 \mathrm{~km})$ respectivamente. A Figura 1.3 ilustra o experimento realizado.

A diferença de altitude entre o Lago Arrowhead e Muir é de $2,05 \mathrm{~km}$, o que equivale a uma coluna vertical de 1,8 $\mathrm{m}$ de água por unidade de área. No experimento os eletroscópios foram colocados na superfície do lago Arrowhead ("E"na figura), e a 1,8 m abaixo da água no lago Muir. Desta forma, para atingir os detectores, a radiação atravessa a mesma quantidade de matéria quando vinda de cima. 


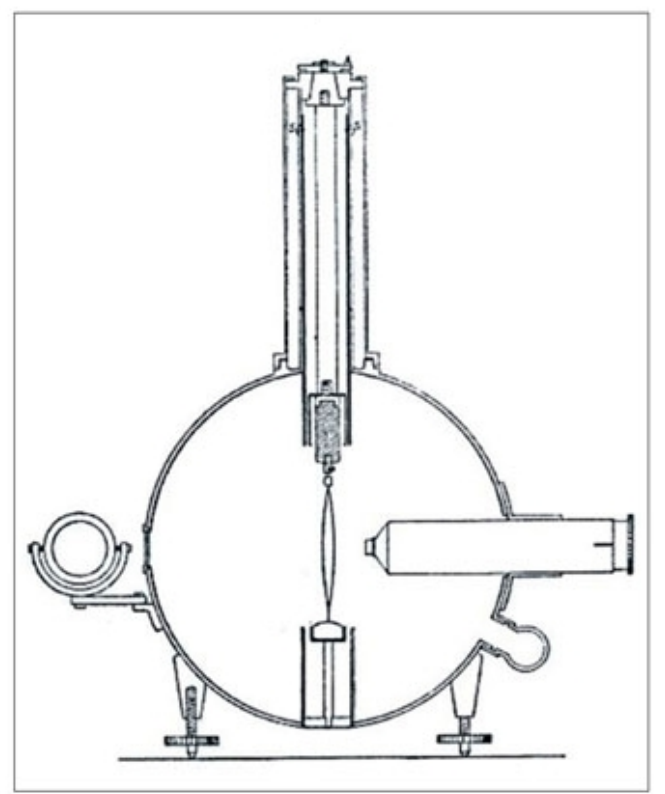

Figura 1.1: Ilustração do eletroscópio de Wulf. Figura extraída de [5].

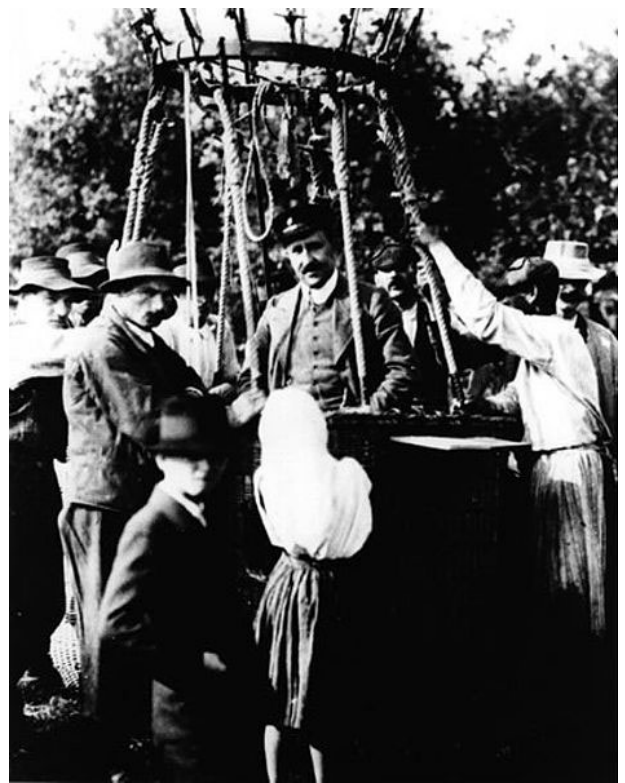

Figura 1.2: Fotografia de Hess em um dos seus experimentos com balões. Figura extraída de [5].

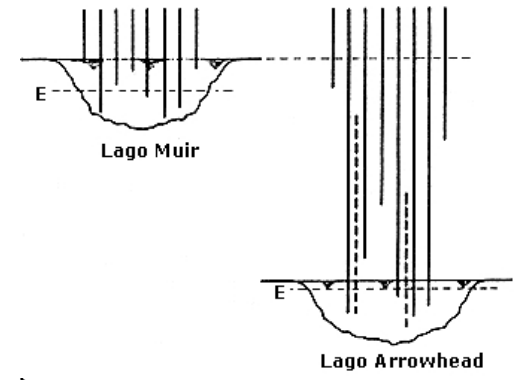

Figura 1.3: Representação esquemática do experimento feito por Millikan e colaboradores. Extraída de [6].
Assim, se a radiação fosse originada fora da Terra ela deveria ionizar os eletroscópios na mesma intensidade. Se a radiação fosse originada por elementos radioativos, digamos na atmosfera (linhas tracejadas), haveria diferenças na ionização produzida nos eletroscópios. Millikan pode verificar que os eletroscópios eram ionizados da mesma forma, concluindo que a radiação não era originada por elementos radioativos na atmosfera.

Millikan também inovou os experimentos feitos em balões [7]. Ele conseguiu desenvolver aparelhos que não necessitavam da presença do homem nos voos, o que permitiu maior segurança nos experimentos, além de possibilitar medir a radiação a maiores altitudes na atmosfera. Millikan foi o primeiro a dar o nome de "Cosmic Rays" à radiação vinda de fora da Terra. 


\subsection{Descoberta dos Chuveiros Atmosféricos Extensos}

Um desenvolvimento técnico importantíssimo para estudar RC foi inventado por Walter Bothe [8] no final de 1920. Era a chamada técnica de coincidência e, por essa invenção, ele recebeu o Prêmio Nobel em 1954. A técnica se baseava em contadores Geiger-Müller (G-M), uma das ferramentas mais usadas na física experimental no século XX. Bothe e Kohlhörster substituíram os eletroscópios por dois contadores G-M. Eles notaram que, quando os contadores eram colocados um em cima do outro, a pequenas distâncias, eles disparavam simultaneamente. A frequência com que os disparos simultâneos ocorriam decrescia com o aumento da distância de separação entre os contadores G-M.

Este aparato foi usado para determinar a natureza dos RC. Robert Millikan, por exemplo, acreditava que estes eram compostos por fótons de altas energias criados na síntese de elementos, tais como o hélio, no meio interestelar. A razão para Milikan ter pensado nos fótons como radiação ionizante se baseava no fato de ser a partícula com o maior poder de penetração e o seu caminho livre médio no ar ser de centenas de metros. Cálculos teóricos relativos aos fótons de altas energias prediziam um aumento no caminho livre médio com a energia, permitindo sua detecção na superfície da Terra.

Após investigarem as possíveis causas dos disparos nos contadores G-M, blindando o aparato, eles chegaram à conclusão de que os RC não deveriam ser compostos majoritariamente por fótons, mas sim por partículas carregadas. Apesar das tentativas de estimar a natureza dos RC, nenhum resultado foi conclusivo e a questão a respeito da composição continuou em aberto.

O experimento de Bothe foi o arquétipo para outros que vieram. Rossi não demorou muito para construir o seu próprio detector de coincidência aperfeiçoado, que incluía vários canais [9]. Por volta de 1933, Rossi realizou experimentos de coincidência com contadores G-M em um arranjo triangular e blindados com 1 metro de chumbo. Ficou surpreso em ainda assim detectar RC. Observou também que, ao aumentar a espessura de chumbo na parte superior, a frequência de coincidência entre os contadores aumentava. Esta só diminuía após a blindagem de certo valor limite. Os resultados deste estudo foram mostrados através das curvas da taxa de coincidência em função da matéria atravessada pela radiação, ou profundidade atmosférica, para espessuras de chumbo fixas. Estas ficaram conhecidas como curvas de transição de Rossi. Rossi concluiu corretamente que partículas secundárias eram produzidas pelos RC ao atravessarem o chumbo. Ao aumentar a espessura de chumbo a absorção das partículas secundárias aumentava e, por 
isso, a queda na frequência de coincidências. A Figura 1.4 mostra à esquerda uma ilustração do aparato de Rossi e à direita, as curvas de transição.
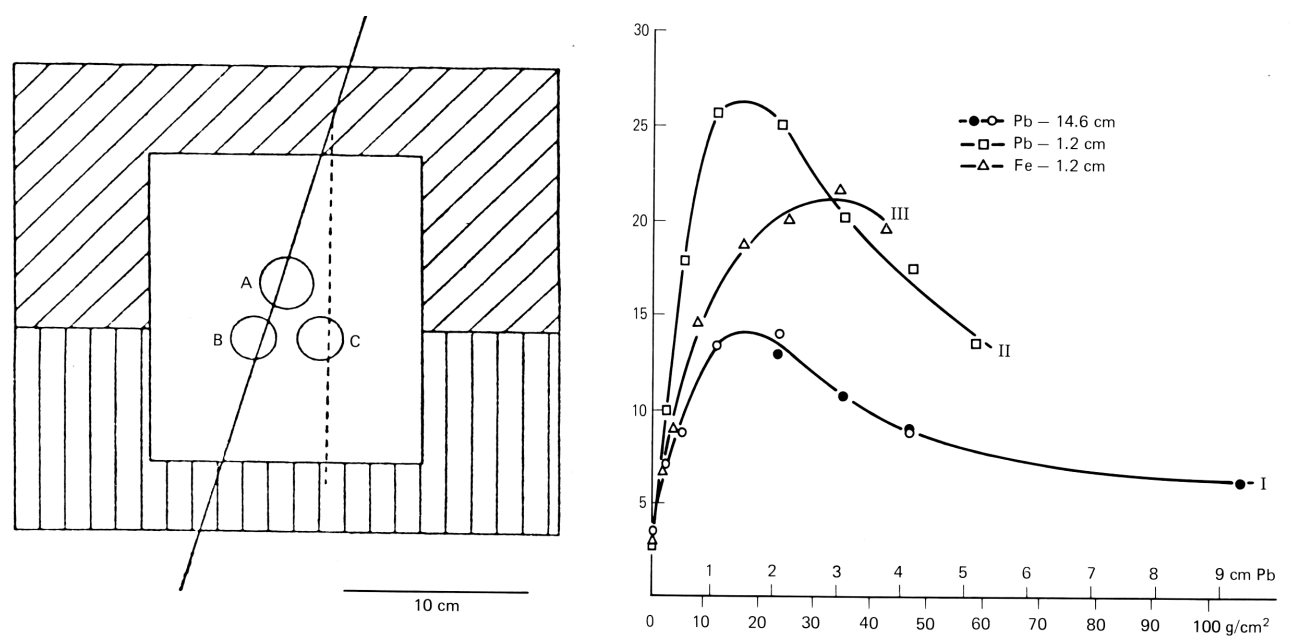

Figura 1.4: À esquerda, o arranjo triangular dos contadores G-M representados por A, B e C e abaixo a escala do desenho. À direita, curvas de transição de Rossi, que mostram a taxa de coincidência em função da quantidade de matéria atravessada pela radiação (fazendo variar a altura dos contadores G-M) para uma determinada quantidade de blindagem de chumbo, como indicado na figura. Extraídas de [10].

Em 1934, Regener e Pfotzer encontraram um fenômeno parecido em medidas da intensidade de RC utilizando o detector de coincidência tripla na estratosfera, a $28 \mathrm{~km}$ de altitude. Eles constataram que a intensidade da radiação era máxima a uma altitude de $14 \mathrm{~km}$. Esta intensidade ficou conhecida como o máximo de Pfotzer. Reneger interpretou o fenômeno como a multiplicação de elétrons na atmosfera que ele chamou de "Schauer" (do alemão - chuveiro) como sugerido nos trabalhos de eletrodinâmica quântica de Bhabha e Heitler [11].

Paralelamente aos trabalhos de Rossi e outros, Blackett e Occhialini na metade dos anos 30 acoplaram uma câmara de nuvens (inventada por Wilson, em 1900) entre os contadores G-M [12]. Quando uma partícula carregada passava pelo contador superior, a câmara disparava permitindo observar diretamente as trajetórias das partículas. A técnica permitiu observar as supostas produções de elétrons e pósitrons (partículas conhecidas na época) de forma eficiente e foi uma das ferramentas chaves para o desenvolvimento da física nuclear e da física de partículas elementares. Blackett recebeu o Prêmio Nobel em 1948 pelo desenvolvimento da técnica e suas descobertas. A Figura 1.5 mostra uma das fotografias tiradas por este tipo de aparato [13], onde 
é possível apreciar a beleza do resultado obtido pelo aparato de Blackett. Ela revela que as hipóteses feitas por Rossi e outros estavam corretas, existindo de fato uma multiplicação de partículas secundárias. As características visíveis na Figura 1.5 são similares aos chuveiros atmosféricos desenvolvidos quando partículas extremamente energéticas entram no topo da atmosfera da terrestre.

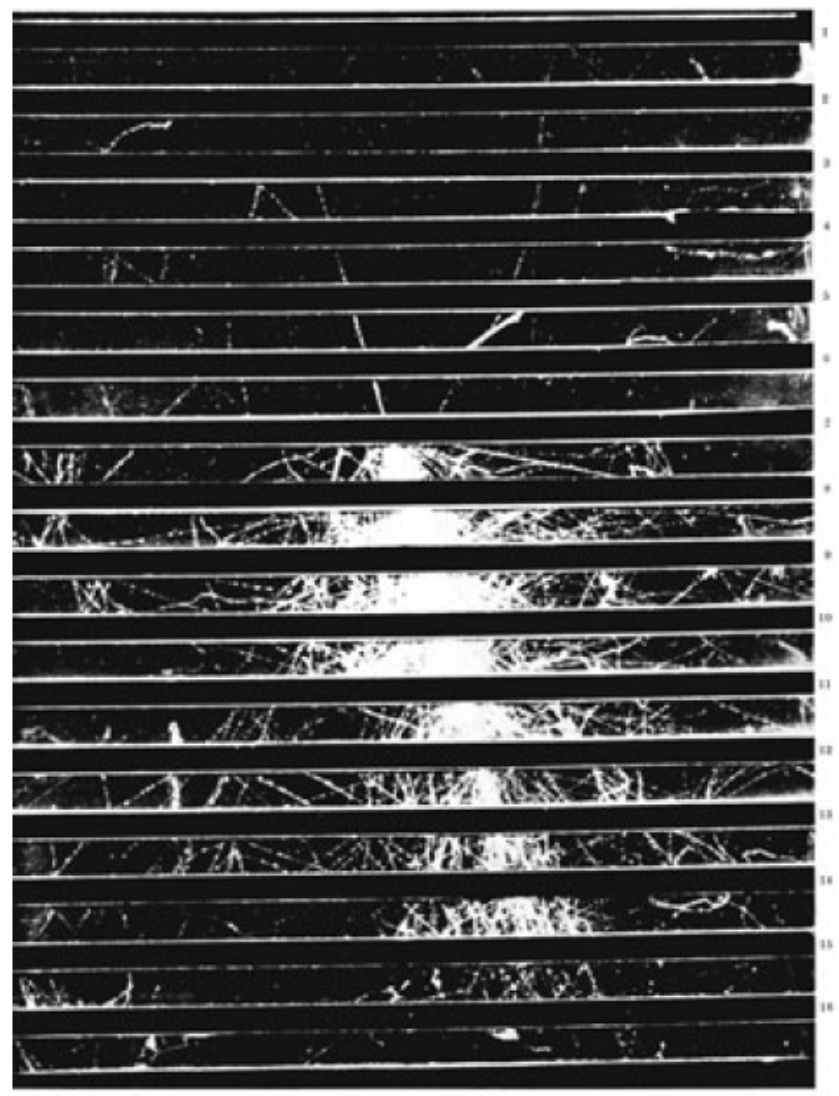

Figura 1.5: Imagem da cascata de partículas em uma camara de nuvens, preenchida com placas de chumbo, a $3027 \mathrm{~m}$ de altitude. As medidas indicam que um próton teria dado origem a essa cascata. Figura extraída de [13].

Bruno Rossi em suas observações na Eritrea, em 1934 [14], notou que os sinais da chegada das partículas em detectores espalhados numa superfície estavam correlacionados. Com isso descobriu o fenômeno dos chuveiros atmosféricos, ao qual nas suas publicações deu o nome do fenômeno de "sciami" (do italiano enxames). Anos mais tarde, Bothe e Schmeiser analisaram as curvas de transição de Rossi e apontaram que elas implicavam na ocorrência de chuveiros de partículas no ar e mostraram que as partículas que 
compunham um chuveiro estavam separadas a uma distância de até $40 \mathrm{~cm}$. Kolhörster, de forma independente, chegou à mesma conclusão ao analisar a taxa de coincidência em função da distância entre os detectores. Embora Rossi tivesse feito as descobertas anteriormente, parece que Bothe e Kolhörster desconheciam suas publicações. Naquela época Rossi não pode continuar seus trabalhos antes de deixar a Itália, devido à ascenção do fascismo, indo para os Estados Unidos em 1939 onde assumiu uma posição provisória na Universidade de Chicago.

A descoberta dos chuveiros atmosféricos extensos foi creditada a Pierre Auger e colaboradores em 1939. Roland Maze melhorou a eletrônica dos detectores conseguindo diminuir o tempo de resolução dos sinais dos circuitos de coincidência para $5 \mu$ s. Com esta resolução Auger notou que o sinal obtido por detectores afastados de até $300 \mathrm{~m}$ ainda coincidiam e estas coincidências deviam estar conectadas de alguma forma, que era justamente através da cascata de partículas.

O resultado mais impressionante do trabalho de Auger que o distingue dos de Rossi, Bothe e outros, foi em ter estimado a energia da partícula primária que deu origem ao chuveiro. Chegou a medir um chuveiro de $10^{15}$ $\mathrm{eV}$, que na época era difícil imaginar como uma partícula poderia chegar a tal energia. Hoje, eventos com energia excedentes a $10^{20} \mathrm{eV}$ foram observados. Identificar as fontes e os mecanismos pelos quais foram acelerados ainda é um desafio a ser alcançado.

\subsection{Espectro de Energia dos Raios Cósmicos}

O espectro de energia dos RC fornece o fluxo de partículas por área, tempo, ângulo sólido em função da energia do chuveiro, se estendendo por várias ordens de magnitude. A Figura 1.6 mostra este espectro de energia, onde se pode identificar três quebras chamadas de knee $\left(E \sim 4 \times 10^{15} \mathrm{eV}\right)$, um segundo knee $\left(E \sim 10^{17} \mathrm{eV}\right)$ e ankle $\left(E \sim 4 \times 10^{18} \mathrm{eV}\right)$, bem como uma queda brusca representando o corte GZK $\left(E>5 \times 10^{19} \mathrm{eV}\right)$. Também estão indicadas as técnicas utilizadas para a observação dos RC, classificadas como métodos diretos e indiretos. Os diretos envolvem detectores a bordo de balões e satélites e indiretos, detectores na superfície da Terra que observam os EAS.

Este espectro pode ser descrito por leis de potência $E^{-\alpha}$ onde: abaixo do knee $\alpha=2,7$, no intervalo entre este e o segundo knee $\alpha=3,1$, do segundo knee até o ankle $\alpha=3,3$ e acima do ankle $\alpha=2,7$.

A intensidade dos $\mathrm{RC}$ com energia $\simeq 1 G$ eV é correlacionada com ciclo de atividade solar de 11 anos, indicando que são originados no Sol. A energias mais altas que $1 \mathrm{GeV}$, os RC que chegam à Terra exibem uma anticorrelação 


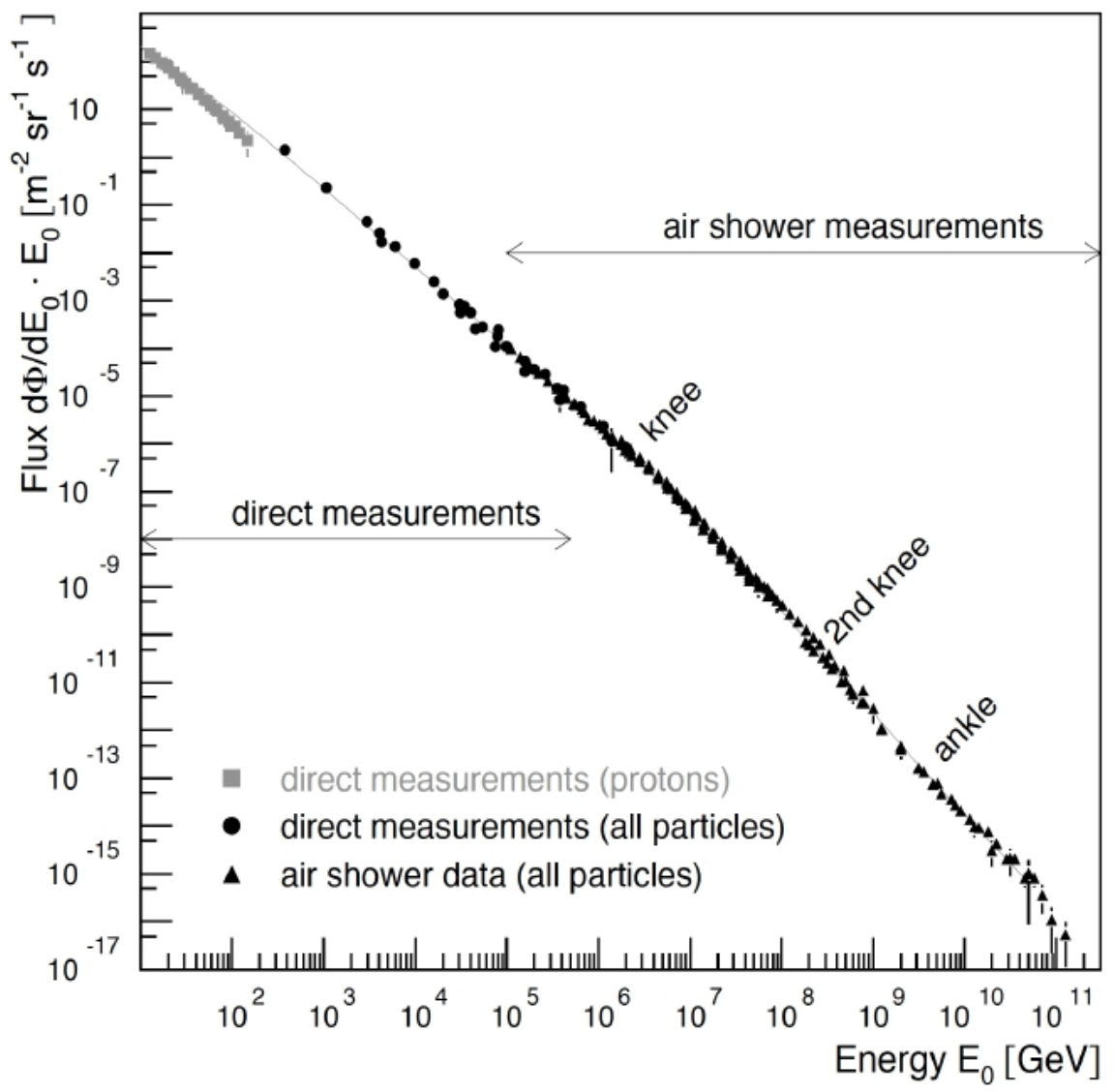

Figura 1.6: Espectro de Energia dos Raios Cósmicos. Extraída de [15].

temporal com a atividade solar. O fluxo diminui quando o campo magnético solar aumenta e vice-versa, indicando que são originados fora do sistema solar.

Há evidências de que a maior parte dos $\mathrm{RC}$ de $1 \mathrm{GeV}$ até a região do knee sejam originados na nossa galáxia em remanescentes de supernovas [16]. A luminosidade total dos RC na galáxia é de $L_{c r} \sim 1,5 \mathrm{erg} / \mathrm{s}$, cerca de $10 \%$ da potência total estimada na forma de energia cinética do material ejetado em supernovas na galáxia. As quebras no índice espectral estão relacionadas ao máximo de energia com que os sítios astrofísicos podem acelerar as partículas e podem também indicar uma transição na sua composição. A quebra no knee seria a energia máxima alcançada por prótons nas fontes, enquanto núcleos de ferro poderiam alcançar energias até $10^{18} \mathrm{eV}$.

A região do ankle pode ser interpretada como o cruzamento com a galáctica e extragaláctica. É esperado que os RC com energias acima de $1 \mathrm{EeV}$ tenham uma origem extragaláctica devido à sua aparente isotropia. 
Uma característica importante no espectro de energia é a supressão que ocorre em torno de $5 \times 10^{19} \mathrm{eV}$, chamado "corte GZK". Esta é esperada devido à interação dos UHECR com a radiação cósmica de fundo (Cosmic Microwave Background - CMB) e foi observado tanto pelo OPA como pelo HiRes [17, 18]. Abaixo descreveremos essa supressão com mais detalhes.

\subsection{Propagação e o Corte GZK}

Greisen, [19] Zatsepin e Kuz'min [20] mostraram que RC compostos por prótons, com energias acima $5 \times 10^{19} \mathrm{eV}$, perderiam gradualmente sua energia ao se propagar até a Terra no CMB. As interações com radiação de rádio (Radio Background-RB) e infravermelho (Infrared Radiation BackgroundIR) também são importantes.

Entre os principais processos que causam a perda de energia de nucleons em sua propagação até a Terra, está a fotoprodução de píons, dado pelas reações

$$
\begin{aligned}
p+\gamma_{C M B} & \rightarrow \pi^{o}+p \\
\rightarrow & \pi^{+}+n \\
n+\gamma_{C M B} & \rightarrow \pi^{o}+n \\
& \rightarrow \pi^{-}+p,
\end{aligned}
$$

onde $p$ e $n$ representam, respectivamente, o próton e o nêutron, $\pi^{o}$ e $\pi^{ \pm}$, os píons neutros e os carregados e $\gamma$, os fótons do CMB.

Abaixo do limiar da fotoprodução de píons, o processo de perda de energia dominante é a produção de pares $p \gamma \rightarrow p e^{+} e^{-}$. Outro processo significativo de perda de energia para prótons de altíssimas energias é devido à expansão adiabática (redshift) do universo.

Estimaremos de forma simplificada a energia limiar para a fotoprodução de píons. Considere o sistema de laboratório, onde os quadrivetores momento do fóton e do próton são dados por

$$
\begin{array}{r}
p_{\gamma}^{\mu}=\left(\epsilon, \overrightarrow{p_{\gamma}}\right) \\
p_{p}^{\mu}=\left(E_{p}, \overrightarrow{p_{p}}\right) .
\end{array}
$$

O invariante $s$, que está relacionado com a energia total no centro de massa por $E_{C M}^{2}=s$, no referencial do laboratório é

$$
\begin{gathered}
s=\left(E_{p}+\epsilon\right)^{2}-\left(\vec{p}_{p}+\vec{p}_{\gamma}\right)^{2} \\
s=m_{p}^{2}+2 E_{p} \epsilon(1-\beta \cos \theta),
\end{gathered}
$$


onde usamos $E^{2}=m^{2}+p^{2}$, tomando $c=1$. O ângulo $\theta$ é formado pelos vetores momento do fóton e próton e $\beta$ é a velocidade do próton em relação à velocidade da luz. Para que o processo de fotoprodução de píons aconteça,

$$
E_{C M}^{2} \geqslant\left(m_{p}+m_{\pi}\right)^{2} .
$$

Considerando uma colisão frontal $\left(\theta=180^{\circ}\right)$, a velocidade do próton $\beta \approx 1$ e a energia média dos fótons do $\mathrm{CMB} \epsilon=6,3 \times 10^{-4} \mathrm{eV}$, a energia limiar do próton para que este processo ocorra é dado por

$$
E_{p, t h}=\frac{m_{\pi}}{4 \epsilon}\left(m_{\pi}+2 m_{p}\right) \simeq 10^{20} \mathrm{eV} .
$$

Levando-se em conta a distribuição da energia do CMB, que segue a distribuição de radiação do corpo negro, esta energia limiar se encontra em $\sim 5 \times 10^{19} \mathrm{eV}$.

O caminho livre médio $\lambda_{p}$ do próton com energia $E=10^{20} \mathrm{eV}$, ao se propagar pelo $\mathrm{CMB}$, é dado por

$$
\lambda_{p}=\left(n \sigma_{\gamma, p}\right)^{-1}=8,1 M p c
$$

onde $\sigma_{\gamma, p}=10^{-28} \mathrm{~cm}^{2}$ é a seção de choque de interação fóton-próton e $n=400 \mathrm{~cm}^{-3}$ é a densidade média de fótons nesta energia.

A inelasticidade $k_{\text {inel }}$ é um parâmetro importante e representa a fração de energia perdida em uma interação. Ela é dependente da energia e sua relação com o caminho livre médio é dada por

$$
L_{\text {loss }}=\lambda / k_{\text {inel }},
$$

é chamada comprimento de atenuação. A Figura 1.7 mostra o $L_{l o s s}$ de prótons, fótons e núcleos em vários processos de interação com o $\mathrm{CMB}$ em função da energia. As três curvas inferiores referem-se ao fóton, enquanto as linhas superiores mais destacadas mostram separadamente os processos de fotoprodução de píons e de pares para o próton. As linhas pontilhadas referem-se ao núcleo de ferro.

No limiar da fotoprodução de píons, os prótons perdem cerca de $20 \%$ da sua energia em uma interação[21]. Com o aumento da energia do centro de massa, a $k_{\text {inel }}$ aumenta em até $50 \%$. A Figura 1.8 mostra a perda de energia dos prótons (somente fotoprodução de píons) ao se propagarem pelo CMB, determinada através de simulações [22]. Cada curva representa a energia do próton na fonte, indicando que os UHECR devem ter sido produzidos dentro de uma esfera de raio limitado pelo horizonte GZK ( $100 \mathrm{Mpc})$ para serem detectados na Terra com aproximadamente a mesma energia. Se as fontes 


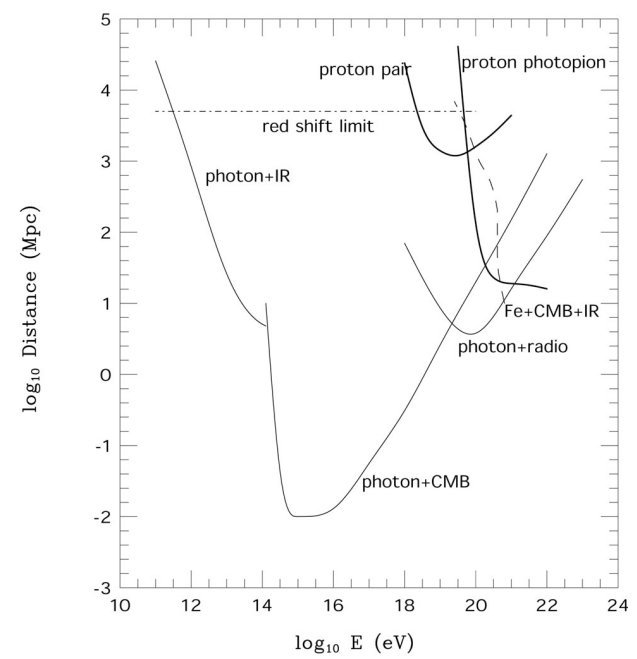

Figura 1.7: Comprimento de atenuação para prótons, núcleos e fótons. Extraída de [23].

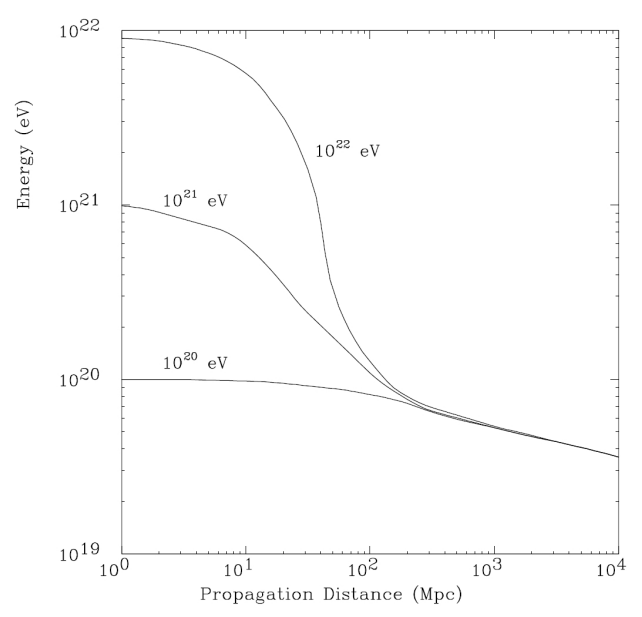

Figura 1.8: Energia média dos prótons em função da sua distância percorrida através do CMB. Extraída de [22].

que produzem os UHECR estiverem fora do raio GZK, os prótons perderiam a maior parte da sua energia antes de chegar à Terra.

Os núcleos com massa atômica $A$ perdem sua energia através dos processos de fotodesintegração e produção de pares, ambos devidos à sua interação com o CMB e IR. A fotodesintegração consiste na perda de um ou mais nucleons durante a propagação, que ocorre quando a energia de centro de massa excede a energia associada com a frequência de excitação coletiva do núcleo, chamada ressonância dipolar gigante. As reações para os processos são

$$
\begin{aligned}
A+\gamma_{C M B, I R} & \rightarrow(A-1)+N \\
& \rightarrow(A-2)+2 N \\
& \rightarrow A+e^{+}+e^{-}
\end{aligned}
$$

onde $N$ representa um nucleon.

A perda de energia na propagação dos núcleos não pode ser calculada diretamente do caminho livre médio como para os prótons porque os núcleos perdem massa após a primeira fotodesintegração.

Na Figura 1.9 temos um panorama geral das possíveis interações dos RC de diferentes composições químicas com o CMB [24]. 


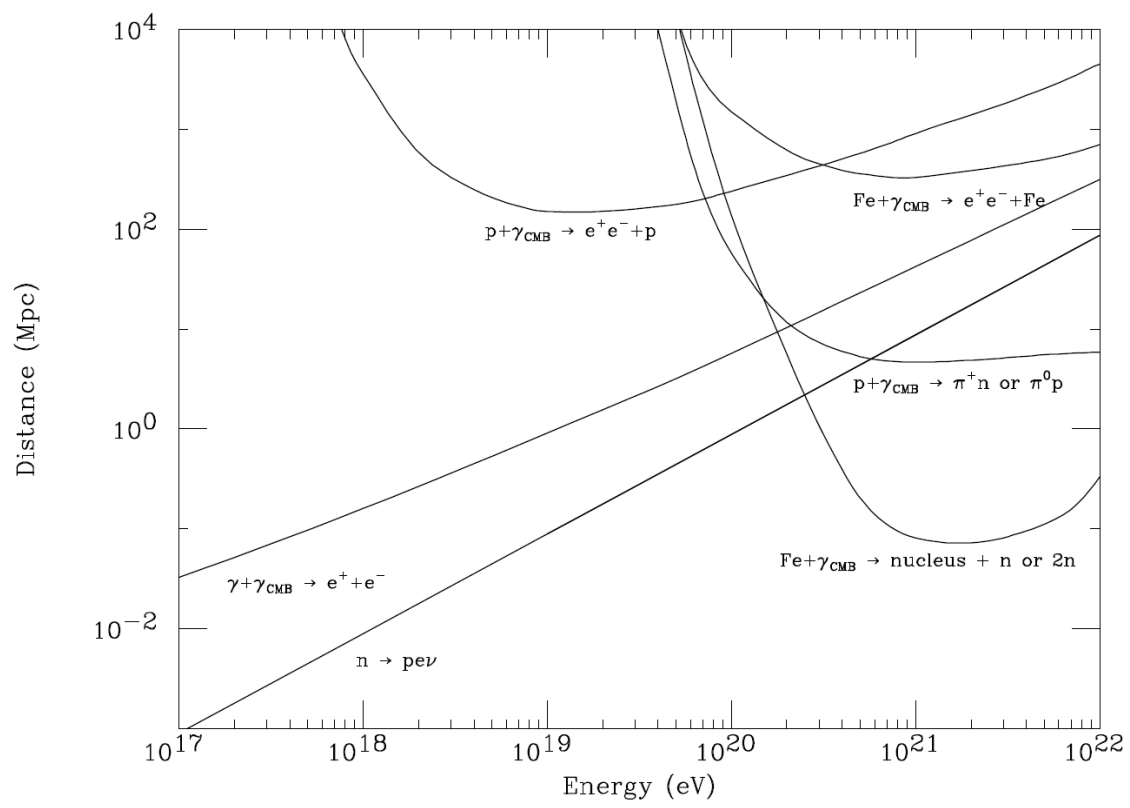

Figura 1.9: Panorama das possíveis interações dos RC com o CMB. As curvas marcadas com $p+\gamma_{C M B} \rightarrow e^{-} e^{+}+p$ e $F e+\gamma_{C M B} \rightarrow e^{-} e^{+}+F e$ são comprimentos de atenuação do próton e do ferro para produção de pares. A curva marcada por $p+\gamma_{C M B} \rightarrow \pi^{+}$ou $\pi^{o}$ representa o caminho livre médio para a fotoprodução de píons pelos prótons no CMB. Já $F e+\gamma_{C M B} \rightarrow$ nucleus $+n$ ou $2 n$ representa o caminho livre médio para a reação de fotodesintegração em que um ou dois nucleons são ejetados do núcleo e $\gamma+\gamma_{C M B} \rightarrow e^{+} e^{-}$para o caminho livre médio dos fótons de altas energias. O comprimento de decaimento médio do nêutron é

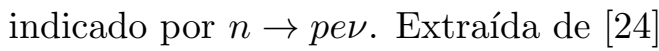

\subsection{Fontes e Mecanismos de Aceleração dos UHECR}

A origem dos UHECR ainda permanece um grande mistério, bem como os mecanismos pelos quais são acelerados a energias extremamente altas. Existem dois tipos de cenários que poderiam explicar a energia dos UHECR, os chamados Top-Down e Bottom-Up. No primeiro, os UHECR resultam do decaimento de partículas exóticas, como, por exemplo, relíquias supermassivas do Big Bang ou do colapso de defeitos topológicos. O segundo se baseia em mecanismos de aceleração nos quais os RC ganham energia através de campos eletromagnéticos intensos ou por ondas de choque difusas. Abaixo descreveremos as principais características de cada um destes cenários. 


\subsubsection{Cenários Top-Down}

Nestes cenários os problemas relacionados à aceleração dos UHECR é contornado ao postular a existência de novas partículas massivas originadas de processos físicos ocorridos no início do universo. Em tais modelos estas partículas massivas decairiam produzindo os UHECR. Uma discussão detalhada dos cenários Top-Down pode ser encontrada em [25].

As partículas massivas viriam do colapso ou do decaimento de defeitos topológicos, tais como monopolos magnéticos ou cosmic strings, associados com a teoria da grande unificação (GUT). Poderiam também ser partículas metaestáveis supermassivas de longa vida, relíquias produzidas no início do universo e que estão decaindo na época atual.

Embora os cenários Top-Down sejam muito interessantes por conter modelos de física nova, estes, em sua maioria, preveem um alto fluxo de fótons que não estão sendo observados pelos experimentos de UHECR, tais como o OPA. Isso reduz a possibilidade destes modelos serem as fontes dos UHECR.

\subsubsection{Cenários Botton- $U p$}

Nestes cenários as partículas carregadas são aceleradas nos sítios astrofísicos, onde os modelos de aceleração dependem dos objetos astrofísicos em consideração. Como mencionamos antes, dois mecanismos principais podem ocorrer neste cenário: aceleração por ondas de choque difusas e aceleração direta devido a campos eletromagnéticos intensos.

Na aceleração direta, campos elétricos podem existir devido à alta rotação de estrelas de nêutrons compactas magnetizadas (pulsares) ou por discos de acreção devido a campos magnéticos. Os detalhes do processo de aceleração e a energia máxima alcançada dependem da situação física particular em consideração. Por apresentar discordâncias entre autores sobre detalhes cruciais de vários modelos e principalmente pela dificuldade do mecanismo direto em obter as características da lei de potência do espectro, este mecanismo de aceleração não é favorecido [25].

O mecanismo de aceleração por ondas de choque difusas é um modelo estocástico baseado no mecanismo de aceleração de Fermi [26]. Neste, a aceleração ocorre devido à interação de partículas carregadas com nuvens interestelares magnetizadas. A aceleração difusa se dá próxima às ondas de choque no meio interestelar, onde as partículas carregadas são espalhadas repetidamente por campos magnéticos irregulares. A aceleração por choques é muito mais rápida do que o mecanismo original de Fermi.

O modelo de aceleração por ondas de choque [27, 28, 29, 30] é o que melhor explica a origem dos RC galácticos. Há evidências de que os RC galácticos se- 
jam acelerados em remanescentes de supernovas [16] e a sua energia máxima depende da velocidade do choque $\beta$ e da sua extensão, do valor absoluto do campo magnético médio e da carga da partícula, com núcleos acelerados a uma energia $Z e$ maior do que o prótons. A questão da composição se torna uma fator importante na aceleração dos RC e os modelos são altamente dependentes do parâmetro $Z e$. Da mesma forma que os $\mathrm{RC}$ galácticos, os UHECR devem ser acelerados em objetos astrofísicos que comportem as condições físicas necessárias para que alcancem energias acima de $1 \mathrm{EeV}$.

Uma das principais vantagens do mecanismo de aceleração por choques difusos é que ele resulta no espectro de lei de potência com o índice espectral dentro dos limites de medidas experimentais. Dependendo da geometria do choque e da natureza relativística, a combinação do ganho de energia no cruzamento das partículas nas ondas de choque e da probabilidade de escape, esse mecanismo leva a uma lei de potência com o índice espectral 2,0 no caso de um choque não relativístico em um gás ideal e índices entre 2,1 e 2,4 para choques relativísticos [31].

Através de argumentos dimensionais, Hillas [32] mostrou que a energia máxima alcançada por uma partícula carregada com carga $Z e$ é

$$
E_{\text {max }}=\beta Z e\left(\frac{B}{1 \mu G}\right)\left(\frac{R}{1 k p c}\right) E e V
$$

onde $\beta$ representa a velocidade da onda de choque, $B$ o valor absoluto do campo magnético e $R$ a extensão da região de aceleração. Através desta relação, ele relacionou os objetos astrofísicos com o potencial para acelerar RC a energias $E>10^{20} \mathrm{eV}$. A Figura 1.10 mostra o gráfico de Hillas [32] com as condições necessárias, mas não suficientes, para potenciais sítios aceleradores. A linha verde na parte inferior do gráfico mostra o valor do campo magnético mínimo para acelerar núcleos de ferro a energias $E>10^{20} \mathrm{eV}$ em função do tamanho do objeto, enquanto as linhas tracejadas e contínuas superiores em azul o valor mínimo para prótons, para diferentes velocidades de choque.

Enquanto o espectro de energia e a composição dos UHECR fornecem pistas sobre os aceleradores astrofísicos, a identificação de suas fontes pode somente ser alcançada usando a sua direção de chegada. Além dos processos de perda de energia, a trajetória dos UHECR até a Terra é afetada por campos magnéticos interestelares. Para uma partícula com carga $Z e$ em um campo magnético $B(\mu G)$, o raio de Larmor em $k p c$ é dado por [33]

$$
R_{L} \simeq 1 K p c \frac{E[E e V]}{Z B[\mu G]} .
$$

O $R_{L}$ das partículas com enegia maior do que $1 E e V$ e $B \sim 1 \mu G$ excede as 


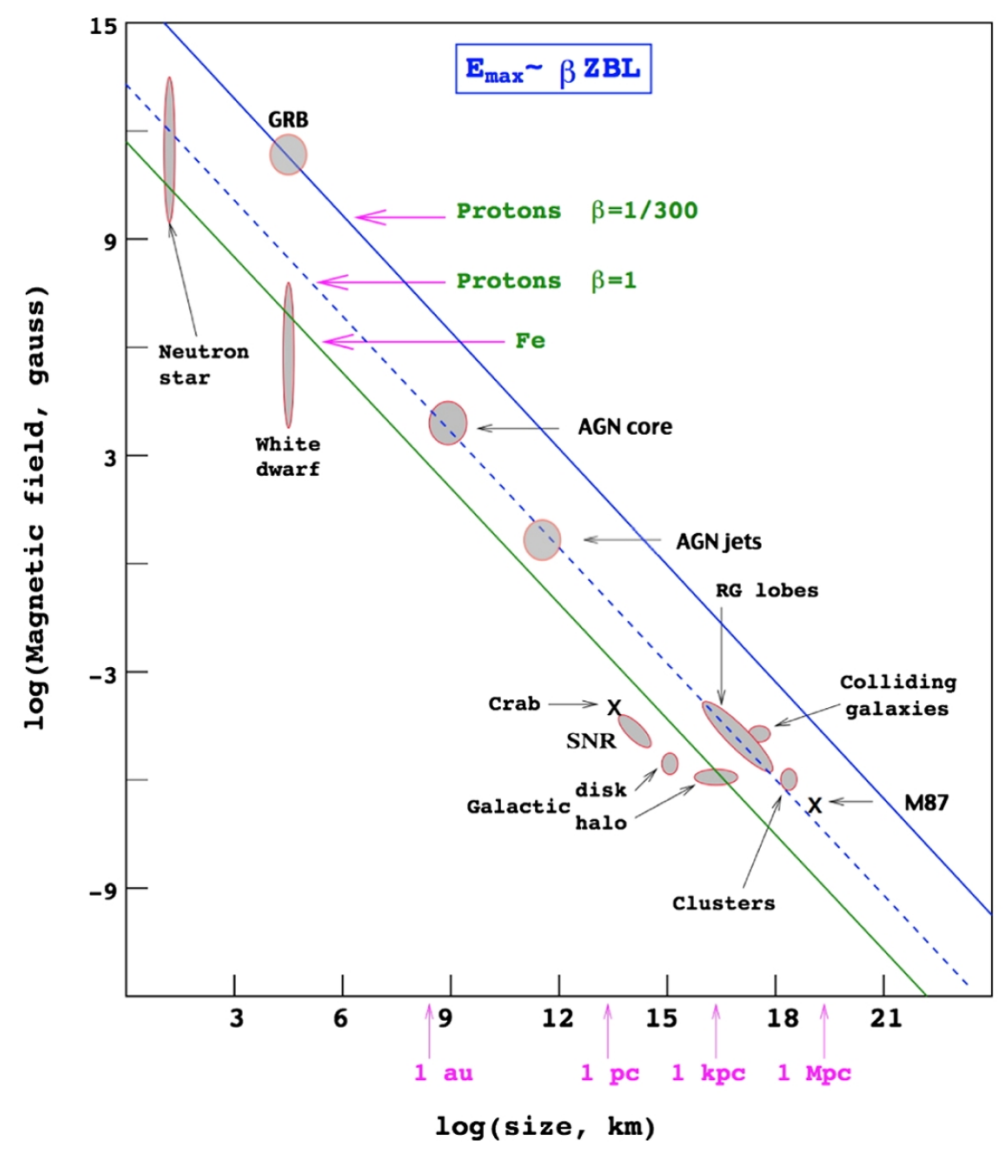

Figura 1.10: Gráfico de Hillas para candidatos a sítios de aceleração. Para acelerar uma partícula específica a energias $E>100 \mathrm{EeV}$, o objeto astrofísico deve estar acima da linha correspondente a prótons ou ao núcleo de ferro. Extraída de [31.

dimensões da galáxia. Assim, os UHECR têm rigidez suficiente para manter a direção de origem dentro de alguns graus na sua propagação dentro da Via Láctea. Se todos os RC fossem originados dentro desta, eles teriam uma tendência de vir do plano galáctico. Dado que não há evidências significativas de virem desta direção, é razoável pensar que partículas com energias $E>$ $10^{19} \mathrm{eV}$ são de origem extragaláctica.

\subsection{Antigos Experimentos}

Experimentos antigos observaram alguns eventos de UHECR que excediam em muito a energia do corte GZK, se tornando um grande enigma e colocando 
em dúvida a presença da supressão no espectro de energia. Entre os antigos experimentos encontram-se Volcano Ranch, Haverah Park, AGASA e HiRes.

O experimento Volcano Ranch foi construído em 1959, no Novo México, EUA , sob a coordenação de J. Linsley. Consistia de detectores de cintilação de $3 \mathrm{~m}^{2}$ separados por $900 \mathrm{~m}$ e cobrindo um total de $8 \mathrm{~km}^{2}$ de superfície. Foi com este experimento que o primeiro evento de energia $E=10^{20} \mathrm{eV}$ foi detectado [37.

O experimento Haverah Park estava localizado em North Yorkshire, no norte da Inglaterra. Utilizava tanques de água que detectavam a luz Cherenkov emitida pelas partículas em sua passagem pela água. Vários tamanhos de tanques foram utilizados e foram espalhados por $12 \mathrm{~km}^{2}$ de área. O experimento tomou dados por quase 20 anos, até o seu desligamento em 1987.

Akeno Giant Air-Shower Array - AGASA foi o maior observatório de chuveiros atmosféricos antes do OPA. Utilizava 111 detectores de cintilação de 2,2 $\mathrm{m}^{2}$ separados por uma distância média de $1 \mathrm{~km}$ cobrindo uma área de $100 \mathrm{~km}^{2}$. O AGASA mediu 11 eventos com energias acima de $10^{20} \mathrm{eV}[38]$ e obteve um espectro de energia que não apresentava o decréscimo no fluxo devido ao efeito GZK.

HiRes foi um observatório pioneiro em usar detectores de luz fluorescente para medir EAS. Foi instalado em Dugway, Utah, EUA, sob o nome de Fly's Eye e tomou dados de 1983 a 1993. HiRes mediu o evento mais energético de $\mathrm{RC}$, com energia de $3,2 \times 10^{20} \mathrm{eV}$ [39]. Uma versão ampliada foi desenvolvida e chamada de High Resolution Fly's Eye ou HiRes, que tomou dados de 1997 até 2006 .

Atualmente, o Observatório Pierre Auger é o maior observatório já construído e operante, tendo sido finalizado em 2008 e adquirindo dados desde 2004. É um experimento híbrido que combina detectores de fluorescência e detectores de superfície. Estes últimos são separados por 1,5 $\mathrm{km}$ de distância e cobrem uma área de $3000 \mathrm{~km}^{2}$, equivalente a 42.000 campos de futebol.

A Figura 1.11 mostra o espectro de energia de $\mathrm{RC}$ medidos por diversos observatórios. Pode-se notar que os eventos mais energéticos detectados pelo OPA e HiRes mostram o decréscimo no fluxo de RC acima de $10^{19} \mathrm{eV}$, consistentes com o efeito GZK, ao contrário dos eventos medidos pelo AGASA. O experimento Telescope Array-TA é o mais novo experimento de UHECR e está localizado em Utah, EUA, operando desde 2009. É um detector híbrido que utiliza tanto detectores de cintilação como detectores de fluorescência, mas cobrindo uma área bem menor que o OPA. 


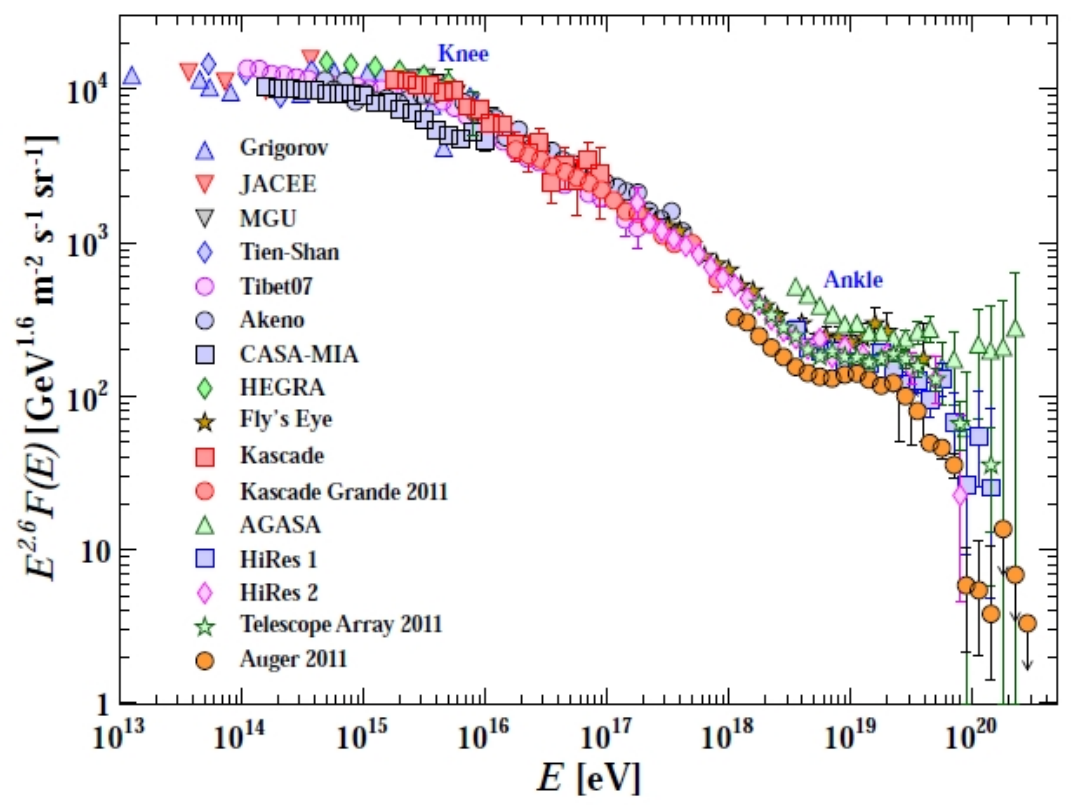

Figura 1.11: Espectro de energia dos $\mathrm{RC}$ medido por diversos observatórios, conforme a legenda. Extraída de [40].

\subsection{Composição dos UHECR}

Um grande mistério envolve a origem e a composição dos UHECR. Estes são investigados indiretamente através dos EAS. Dois dos principais parâmetros para investigar a composição são a profundidade de máximo do chuveiro e a densidade de múons no solo, que descreveremos detalhadamente nos Capítulos 2 e 3. As flutuações intrínsecas destes parâmetros também pode ajudar na determinação da composição primária.

Resultados do OPA para a composição dos UHECR com energia acima de $10^{19} \mathrm{eV}$ indicam uma tendência para elementos mais pesados [41], enquanto o HiRes [42] indica um tendência para prótons. Outra análise do OPA investiga que se os eventos mais energéticos forem constituídos por elementos mais pesados deveria existir um fluxo anisotrópico de elementos mais leves à energias $E / Z$ menor. O OPA buscou este fluxo na direção de Centauro A e não os encontrou [43].

As partículas mais energéticas também podem encontrar explicação em modelos de física nova, tal como em partículas exóticas [25, 44]. Estas partículas poderiam viajar por distâncias maiores no CMB, além do horizonte GZK, ou estarem dentro do horizonte, onde decairiam gerando um fluxo de partículas conhecidas. Assim, chuveiros poderiam ser produzidos a 
partir de novas partículas ou do decaimento de partículas desconhecidas. Os sinais deixados por estas partículas na Terra podem ser investigados através de simulações de EAS [45, 46]. Fótons extremamente energéticos poderiam ser parte dos produtos destes decaimentos e poderiam, a princípio, contribuir com uma pequena fração dos UHECR [47].

Limites superiores para a fração dos UHECR composta por fótons foram determinados pelo OPA e recentemente pelo TA. Através dos dados dos FD do OPA estimou-se que os limites superiores da fração de fótons para energias maiores do que 2, 3, 5 e $10 \mathrm{EeV}$ são respectivamente de $3.8 \%, 2.4 \%, 3.5 \%$ e $11.7 \%$ (com $95 \%$ de nível de confiança) [1]. Já com os dados do SD, foi determinado que primários com energia maior do que 1,2 e $4 \times 10^{19} \mathrm{eV}$ têm um limite superior, respectivamente, de $2 \%, 5,5 \%$ e $31 \%$ [2]. Um trabalho recente da colaboração TA estimou o limite da fração de fótons em 6,2\% para $E_{\gamma}>10^{19} \mathrm{eV}$ e $28,5 \%$ para $E_{\gamma}>10^{19,5} \mathrm{eV}[3]$. 


\section{Capítulo 2}

\section{EAS e Técnicas de Observação}

Os EAS são formados quando uma partícula primária incide no topo da atmosfera e colide com os seus constituintes. Esta colisão gera partículas secundárias que, por sua vez, geram outros secundários, iniciando, assim, um processo de multiplicação de partículas. Este processo continua até que as partículas que compõem o chuveiro têm sua energia degradada de tal forma a não produzirem mais partículas. Neste ponto, que caracteriza o máximo do chuveiro, as partículas não se multiplicam mais e apenas perdem energia por ionização.

Uma partícula primária com energia $E=10^{20} \mathrm{eV}$ gera cerca de $10^{11}$ partículas secundárias deixando sinais na superfície da Terra, onde detectores espalhados podem medir este sinal e, com isso, reconstruir o evento ocorrido. Dois métodos de detecção são utilizados para observar os EAS: um através dos detectores de superfície e outro através de fluorescência. Estes permitem extrair a direção de incidência e a energia do primário.

A utilização simultânea dos dois métodos é chamada de modo híbrido, permitindo combinar as informações vindas de ambos os detectores e, desta forma, reduzir as incertezas das medidas. O OPA [23] e o TA [50] são experimentos que utilizam este modo.

Neste capítulo, apresentaremos um modelo simples para descrever os EAS e os principais parâmetros que os caracterizam. Em seguida, detalharemos os métodos utilizados para detectá-los e para analisar os dados coletados. Por último, descreveremos as principais características dos observatórios OPA e TA. 


\subsection{Chuveiros Atmosféricos Extensos}

Apesar da complexidade dos EAS, é possível construir modelos simples que determinam suas principais características. Estes modelos descrevem os chuveiros pela superposição do desenvolvimento de dois tipos de cascatas: a eletromagnética e a hadrônica, tendo a atmosfera terrestre como um calorimetro natural.

A profundidade atmosférica é uma medida da quantidade de matéria que o chuveiro atravessa e é definida como [4]

$$
X_{v}(h)=\int_{h}^{\infty} \rho(z) d z
$$

onde $\rho(z)$ é o perfil de densidade da atmosfera em função da altura e $h$ corresponde a uma determinada altitude do solo. É padrão medi-la em $\mathrm{g} / \mathrm{cm}^{2}$ e definir sua origem no topo da atmosfera. Assim, seu valor aumenta à medida em que a altitude em relação ao nível do mar diminui. A quantidade de matéria atravessada por um chuveiro depende do ângulo de incidência (ângulo zenital $\theta$ ). Às vezes é conveniente transformar a profundidade atmosférica vertical $X_{v}$ em profundidade atmosférica atravessada ao longo do eixo do chuveiro, chamada profundidade atmosférica slant. Estas estão relacionadas por $X_{\text {slant }}=X_{v} / \cos \theta[4]$.

$\mathrm{Na}$ primeira interação entre a partícula primária e a atmosfera, parte da energia inicial é transferida para as várias partículas secundárias criadas, principalmente píons neutros e carregados. Píons carregados continuam interagindo com os núcleos da atmosfera contribuindo para a cascata hadrônica. A cada interação, 1/3 da energia inicial é transferida para os píons neutros que decaem imediatamente em fótons alimentando a cascata eletromagnética. A Figura 2.1 ilustra a distribuição espacial das partículas geradas em um EAS.

A cascata hadrônica se concentra no centro do chuveiro formando seu núcleo (core), constituído principalmente por múons e, em menor quantidade, por prótons e nêutrons. O ângulo de espalhamento dos múons é pequeno quando comparado com da cascata eletromagnética. Uma fração dos muons decaem, porém sua maioria chega à superfície terrestre.

Abaixo descreveremos com mais detalhes modelos simples para a cascata eletromagnética e hadrônica.

\subsubsection{Cascata Eletromagnética}

Um modelo simplificado para descrever a evolução de uma cascata eletromagnética pura foi construído por Heitler [51] e está esquematizado na Fi- 


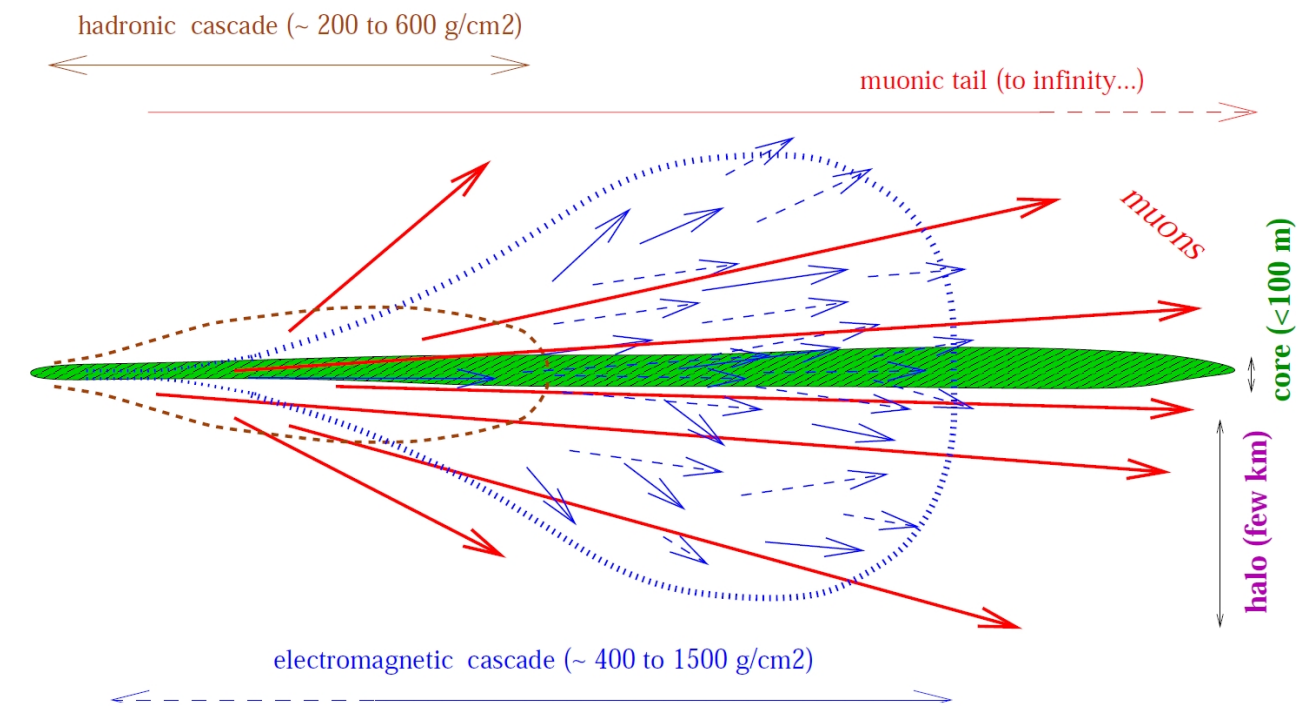

Figura 2.1: Esquema da extensão espacial dos EAS. Extraído de [52.

gura 2.2. Nesse processo, múltiplos fótons $(\gamma)$, elétrons $\left(e^{-}\right)$e pósitrons $\left(e^{+}\right)$ são gerados, onde o fóton inicial dá origem a um par $e^{-} e^{+}$. A cada passo de distância fixa $d$, este par perde metade da energia ao interagir com moléculas da atmosfera produzindo dois fótons via processo de Bremsstrahlung.

A distância $d$ é o comprimento de interação no qual o elétron perde metade de sua energia, que é dado em termos do comprimento de radiação do meio $\lambda_{r}$ : $d=\lambda_{r} \ln 2\left(\lambda_{r}=32 \mathrm{~g} / \mathrm{cm}^{2}\right.$ no ar $)$. O fóton de Bremstrahlung ao atravessar $d$ produz um novo par $e^{+} e^{-}$. Após $n$ interações, a cascata eletromagnética produz $2^{n}$ partículas e alcança uma profundidade atmosférica dada por

$$
X=n \lambda_{r} \ln 2,
$$

onde o número de partículas produzidas é então $N=2^{n}=e^{\frac{X}{\lambda_{r}}}$. O processo de multiplicação cessa quando a energia das partículas cai abaixo da energia crítica $\xi_{c}^{e}=85 \mathrm{MeV}$ (no ar), a partir da qual a perda de energia por radiação torna-se menor do que a perda por ionização.

A cascata alcança seu tamanho máximo quando todas as partículas alcançam a energia crítica $\xi_{c}^{e}$, sendo a energia da cascata dada por

$$
E_{o}=\xi_{c}^{e} N_{\max }
$$

A profundidade atmosférica onde o chuveiro atinge o número máximo de partículas carregadas $X_{\max }$ é obtida ao determinarmos o número de in- 


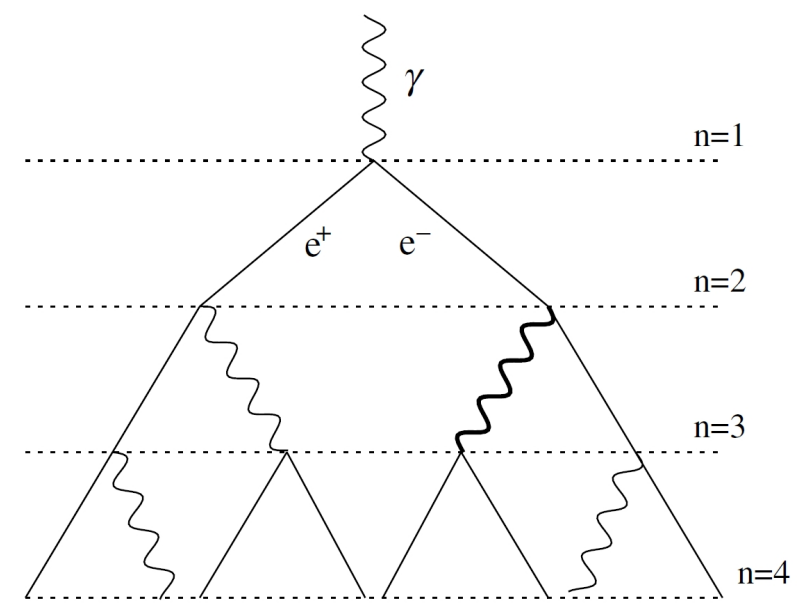

Figura 2.2: Esquema de uma cascata eletromagnética segundo o modelo de Heitler. Cada partícula dá origem a duas subsequentes com metade da energia da partícula inicial. Extraída de [53].

terações $n_{c}$ requeridas para cada partícula alcançar a energia $\xi_{c}^{e}$. Usando

$$
\begin{gathered}
\frac{E_{o}}{\xi_{c}^{e}}=N_{\text {max }}=2^{n_{c}} \\
\ln \left[\frac{E_{o}}{\xi_{c}^{e}}\right]=n_{c} \ln 2
\end{gathered}
$$

e a relação 2.2, obtemos

$$
X_{\max }=\lambda_{r} \ln \left[\frac{E_{o}}{\xi_{c}^{e}}\right]
$$

A taxa de elongação é definida como a taxa de aumento do $X_{\max }$ com a energia do primário $E_{o}$,

$$
\Lambda \equiv \frac{d X_{\max }}{d \log _{10} E_{o}}
$$

Utilizando a expressão 2.6 , obtemos $\Lambda=2,3 \lambda_{r}=85 \mathrm{~g} / \mathrm{cm}^{2}$, indicando que a cada aumento de uma ordem de magnitude na energia inicial do chuveiro, o $X_{\max }$ aumenta em $85 \mathrm{~g} / \mathrm{cm}^{2}$ para a cascata puramente eletromagnética.

Nesse modelo, a seção de choque de todos os processos é independente da energia e as perdas de energia por colisões são ignoradas. Comparações do modelo de Heitler com modelos mais detalhados e com dados experimentais mostram uma diferença no número de partículas no máximo e na razão do número de elétrons e fótons desenvolvidos. No modelo de Heitler o número total de partículas no máximo $N_{\max }$ é cerca de uma ordem de magnitude 
maior e a razão entre o número de $e^{ \pm}$e o de fótons é de 2, enquanto se esperaria uma razão da ordem de 1/6 [53].

Apesar das suas limitações, o modelo de Heitler reproduz três propriedades das cascatas eletromagnéticas: a proporcionalidade da energia primária com o número de partículas no máximo (equação 2.3), a evolução logarítmica do $X_{\max }$ com a energia (2.6) e a taxa de elongação proporcional ao comprimento de radiação do meio, sendo cerca de $85 \mathrm{~g} / \mathrm{cm}^{2}$ no ar.

O tratamento matemático mais detalhado da cascata eletromagnética envolve a solução de uma equação de transporte que inclui termos de produção e perda de partículas e pode ser encontrado em [54].

\subsubsection{Cascata Hadrônica}

Apresentaremos agora um modelo para a cascata hadrônica [53], o qual, apesar de bastante simplificado, nos possibilita descrever suas propriedades básicas. Começaremos com um chuveiro gerado por prótons e depois generalizaremos os resultados para núcleos mais pesados.

A Figura 2.3 abaixo ilustra o processo de uma cascata iniciada por um próton. Cada interação das partículas ocorre a uma distância fixa de profundidade atmosférica $d=\lambda_{I} \ln 2$, onde $\lambda_{I}$ é o comprimento de interação de partículas fortemente interagentes. Ao atravessar a espessura de matéria, o próton produz $N_{c h}$ partículas carregadas e $N_{c h} / 2$ píons neutros que decaem quase que imediatamente em fótons, alimentando a cascata eletromagnética. Os píons carregados continuam interagindo, formando outros píons neutros e carregados até degradar sua energia à crítica, que tomaremos como $\xi_{c}^{\pi}=20$ $G e V$. A partir desse ponto, eles têm maior probabilidade de decair do que de interagir.

Os parâmetros mantidos constantes são a multiplicidade de píons e o comprimento de interação $\lambda_{I}$. No intervalo de energia entre $1 \mathrm{GeV}$ e 10 $T e V$, a multiplicidade de píons carregados $N_{c h}=10$ é uma boa aproximação $\left(N_{\pi^{o}}=5\right)$. Com isso, a cada interação, $1 / 3$ da energia é depositada na parte eletromagnética e, quanto maior o tempo para que os píons alcancem a energia crítica, maior será a componente eletromagnética do EAS.

Considerando que todos os píons carregados decaem em múons, o número de múons $N_{\mu}$ produzidos no chuveiro é igual ao número de píons carregados. Depois de $n$ interações haverá $N_{\pi^{ \pm}}=\left(N_{c h}\right)^{n}$ píons carregados, com energia total de $(2 / 3)^{n} E_{o}$. A energia de cada píon carregado na n-ésima camada de interação é

$$
E_{\pi^{ \pm}}=\left(\frac{2 / 3}{N_{c h}}\right)^{n} E_{o}
$$




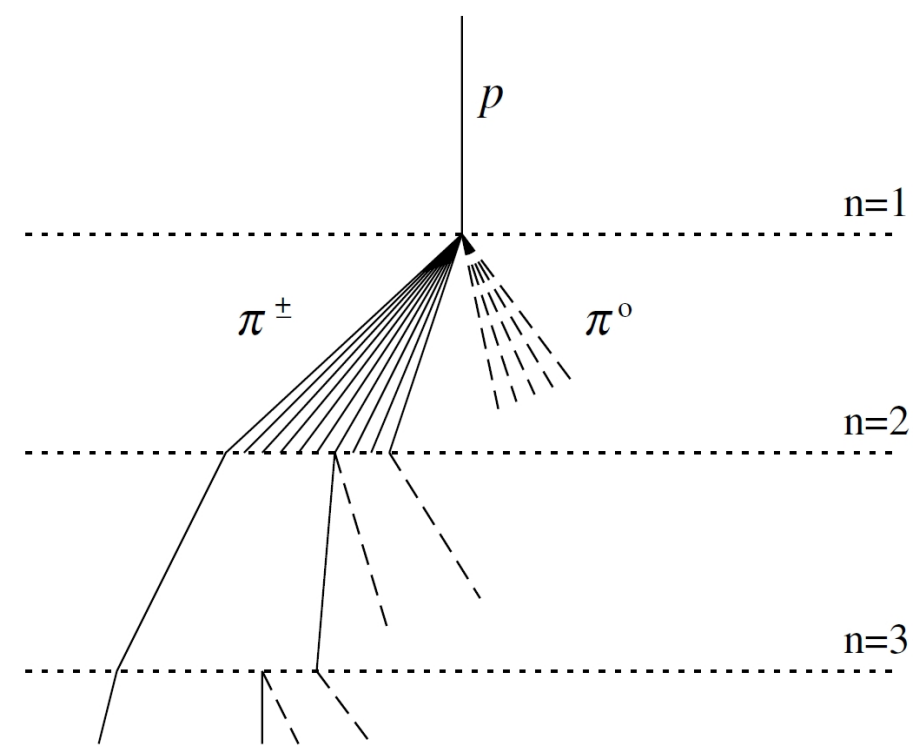

Figura 2.3: Esquema de uma cascata hadrônica, segundo um modelo parecido com de Heitler. As linhas tracejadas indicam píons neutros que decaem em fótons alimentando a cascata eletromagnética. Os píons carregados continuam interagindo até sua energia se degradar o suficiente para passarem a decair. Extraída de [53].

e, após $n_{c}$ interações, os píons alcançam a energia crítica

$$
\xi_{c}^{\pi}=\frac{E_{o}}{\left(3 / 2 N_{c h}\right)^{n_{c}}}
$$

Isolando $n_{c}$ e usando $N_{\mu}=N_{\pi^{ \pm}}=\left(N_{c h}\right)^{n_{c}}$ obtemos

$$
\ln N_{\mu}=\ln N_{\pi^{ \pm}}=n_{c} \ln N_{c h}=\beta \ln \left(E_{o}\right) /\left(\xi_{c}^{\pi}\right)
$$

onde

$$
\beta=\frac{\ln \left(N_{c h}\right)}{\ln \left(3 / 2 N_{c h}\right)}=0,85
$$

e encontramos

$$
N_{\mu}=\left(\frac{E_{o}}{\xi_{c}^{\pi}}\right)^{\beta} .
$$

Diferentemente do número de elétrons e de pósitrons no modelo de Heitler, a multiplicidade de múons não cresce linearmente com a energia primária, mas com uma taxa menor relacionada a $\beta$, que depende da multiplicidade de píons e da inelasticidade das interações dos hádrons. Neste modelo simples 
$\beta=0,85$, porém estudos detalhados usando simulações Monte Carlo encontram $\beta$ no intervalo de 0,9 a 0,95 [55]. A questão da não linearidade da multiplicidade de múons com a energia primária tem importantes consequências para a modelagem de chuveiros iniciados por nucleos mais pesados.

A energia total pode ser escrita como

$$
E_{o}=\xi_{c}^{e} N_{\max }+\xi_{c}^{\pi} N_{\pi^{ \pm}}
$$

onde a energia primária é dividida entre $N_{\pi^{ \pm}}$píons e $N_{\max }$, partículas eletromagnéticas. Reescrevendo a equação acima onde substituimos $N_{\max }=10 N_{e}$ de forma a corrigir o número de partículas no desenvolvimento máximo estimada pelo modelo de Heitler, temos

$$
E_{o} \approx 0,85 G e V\left(N_{e}+24 N_{\mu}\right),
$$

onde usamos $\xi_{c}^{e}=85 \mathrm{MeV}$.

A fração de píons e partículas eletromagnéticas é regulada pela suas respectivas energias críticas. A importância desse resultado é que a energia primária pode ser calculada através do número de múons $N_{\mu}$ e do número de partículas carregadas $N_{e}$, que podem ser medidos com os detectores de superfície e de fluorescência.

A determinação do $X_{\max }$ ao modelar chuveiros hadrônicos é mais complexa do que nos modelos puramente eletromagnéticos, mas podemos estimálo a partir dos $\gamma \mathrm{s}$ produzidos na primeira interação. É esperado que a seção de choque maior e o alto valor da multiplicidade de píons faça como que o $X_{\max }$ hadrônico seja reduzido, alterando também a taxa de elongação.

Uma boa aproximação para a taxa de elongação pode ser obtida a partir da dependência da seção de choque e da multiplicidade com a energia primária. Estas aumentam com a energia e, numa estimativa grosseira, a primeira interação acontece em $X_{o}=\lambda_{I} \ln 2$, onde o $\lambda_{I}$ é o comprimento de interação do próton primário. Usando a seção de choque próton-ar de 550 $m b$ a $E=10^{18} \mathrm{eV}$ e um aumento de $50 \mathrm{mb}$ por ordem de grandeza na energia [56],

$$
\lambda_{I} \simeq 90-9 \log \left(E_{o} / E e V\right) g / \mathrm{cm}^{2} .
$$

A primeira interação produz $N_{c h} / 2$ píons neutros que decaem em $N_{c h}$ fótons. Cada fóton inicia um chuveiro eletromagnético com energia $E_{o} / 3 N_{c h}$. A produção de partículas carregadas na primeira interação pode ser parametrizada como $N_{c h}=41,2\left(E_{o} / 1 P e V\right)^{1 / 5}$, segundo dados de colisões prótonpróton [57].

A profundidade do máximo atingida é obtida como no modelo de Heitler, mas deslocada da profundidade inicial $X_{o}$ e considerando a energia inicial 
dos fótons produzidos:

$$
X_{\max }^{p}=X_{o}+\lambda_{r} \ln \left[E_{o} / 3 N_{c h} \xi_{c}^{e}\right] .
$$

A taxa de elongação para chuveiros de prótons será dada por [31]

$$
\Lambda^{p}=\frac{d X_{\max }}{d \log E_{o}}=\frac{d\left(\lambda_{I} \ln 2+\lambda_{r} \ln \left[E_{o} / 3 N_{c h} \xi_{c}^{e}\right]\right)}{d \log E_{o}}
$$

$\mathrm{Ou}$

$$
\Lambda^{p}=4 / 5 \Lambda^{\gamma}-9 \ln 2 \simeq 62 \mathrm{~g} / \mathrm{cm}^{2} .
$$

A rápida taxa de transferência de energia em chuveiros hadrônicos foi notada por Linsley [58], que introduziu o teorema da taxa de elongação. Este diz que a $\Lambda^{\gamma}$ é um limite superior para a $\Lambda^{p}$ e que os chuveiros hadrônicos nunca vão ter uma taxa de elongação maior que a dos chuveiros eletromagnéticos. Esta é uma consequência da multiplicidade dos píons, que aumenta a taxa de conversão da energia primária em secundários.

Resta agora obter a taxa de elongação para núcleos pesados. Esta pode ser obtida a partir do modelo de superposição, em que um núcleo com número de massa $A$ e energia total $E_{o}$ gera um chuveiro equivalente à superposição de $A$ chuveiros de nucleons, cada um com energia $E_{o} / A$. A energia de cada píon neutro é $E_{o} /\left(3 A N_{c h}\right)$, conforme o mesmo procedimento anterior. Chuveiros de núcleos pesados irão desenvolver um $X_{\max }$ menos profundo e irão ter rápido desenvolvimento, onde

$$
\begin{array}{r}
X_{\text {max }}^{A}=X_{o}+\lambda_{r} \ln \left(\frac{E_{o}}{3 A N_{c h} \xi_{c}^{e}}\right) \\
X_{\text {max }}^{A}=X_{\text {max }}^{p}-\lambda_{r} \ln A,
\end{array}
$$

que pode ser dado em termos do $X_{\max }^{p}$. Assim, um chuveiro gerado por um núcleo pesado terá o seu $X_{\max }^{A}$ numa posição $\lambda_{r} \ln A$ menor que um chuveiro gerado por um próton. O chuveiro de núcleos pesados se desenvolve mais rapidamente do que o de núcleos leves, pois pelo modelo de superposição os píons degradam sua energia mais rapidamente. Também, o número de píons é maior devido à superposição e é esperado um maior número de múons. Pela equação 2.12 temos $A$ prótons de energia $E_{o} / A$ gerando $A N_{\mu}^{p}$ muons,

$$
\begin{array}{r}
N_{\mu}^{A}=A\left(\frac{E_{o} / A}{\xi_{c}^{\pi}}\right)^{\beta} \\
N_{\mu}^{A}=N_{\mu}^{p} A^{1-\beta} .
\end{array}
$$

Um chuveiro iniciado por um núcleo de ferro vai ter $(56)^{0,08}=1,4$ mais múons que um chuveiro de próton para a mesma energia primária (usamos $\beta=0,92)$. 
O modelo apresentado para chuveiros iniciados por núcleos apresenta uma característica interessante, que é reproduzida em modelos mais detalhados: a evolução da seção de choque da primeira interação e da multiplicidade com a energia para qualquer núcleo é a mesma que para prótons. Como consequência, diferentes núcleos irão ter taxas de elongação idênticas.

Vamos comparar os resultados qualitativos obtidos pelos modelos apresentados com os resultados das simulações Monte Carlo dos EAS. A Figura 2.4 mostra um gráfico da taxa de elongação para prótons e ferro utilizando diferentes modelos de interação de hádrons na simulação dos EAS1 e os dados obtidos por diferentes observatórios, tais como Auger e HiRes. Diversos modelos de interação resultam em taxas de elongação do próton e do ferro muito próximas umas às outras. Desta figura é possível notar que, a altas energias, enquanto os dados do OPA indicam uma tendência de uma composição mais próxima do Fe, o HiRes indica que esta parece ser de prótons.

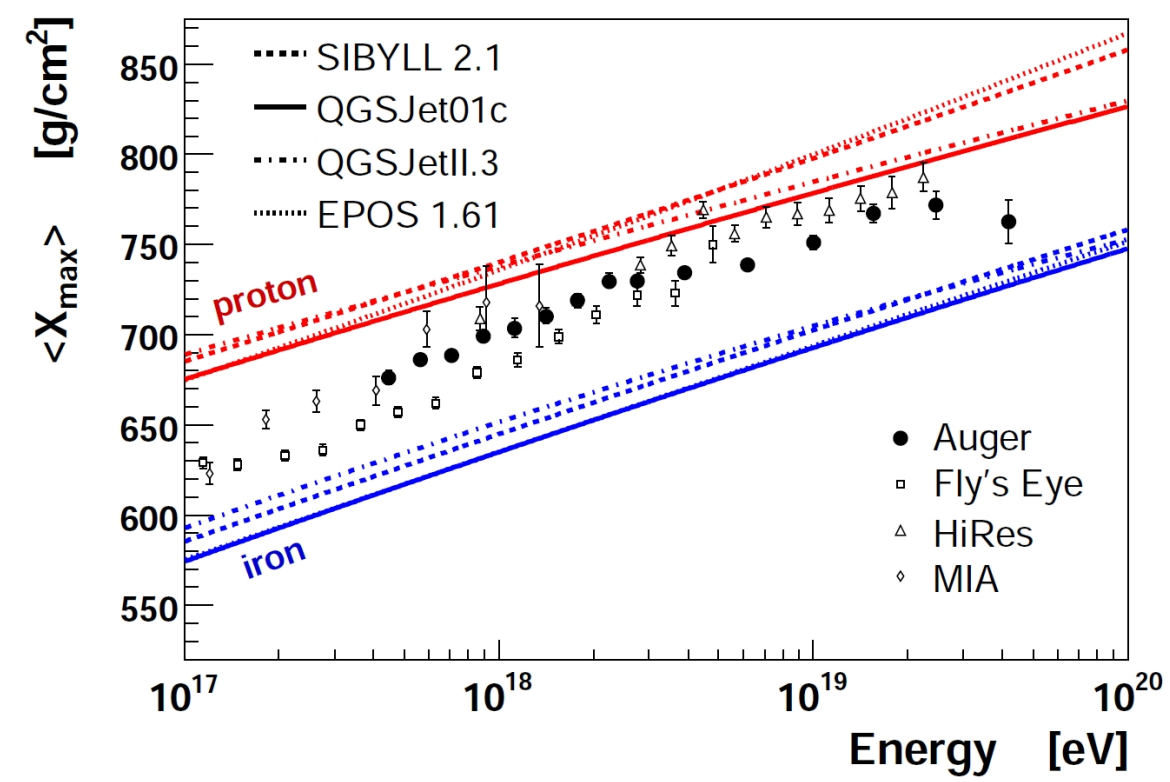

Figura 2.4: Gráfico da taxa de elongação para o próton e ferro simulados com diferentes modelos de interação de hádrons e dados de observatórios. Extraída de [59].

O desenvolvimento dos EAS é bastante influenciado pela flutuação natural da primeira interação, causando flutuações no número de múons e na

\footnotetext{
${ }^{1}$ É importante salientar que estas simulaçoes, como veremos no Capítulo 3 utilizam modelos de interação bem mais elaborados do que os aqui descritos, bem como levam em conta as flutuações inerentes dos chuveiros.
} 
profundidade do máxiomo de partículas carregadas. As flutuações naturais somada com as incertezas dos modelos dificultam a distinção da componente que inicia os EAS. Voltaremos a esta questão no capítulo 3, onde descreveremos o programa de simulação Monte Carlo dos chuveiros atmosféricos que utilizaremos.

\subsection{Técnicas de Observação}

Os RC com energia $E>10^{15} \mathrm{eV}$ devem ser estudados com detectores na superfície da Terra, não podendo ser detectadas diretamente. Através dos sinais dos EAS medidos no detectores, a direção de chegada e a energia do primário devem ser determinadas. Estes parâmetros são reconstruídos através de duas técnicas principais de observação, os detectores de superfície (SD) e os detectores de fluorescência (FD).

Os SD amostram a radiação e as partículas que alcançam o solo, tais como $\mu \mathrm{s}, \gamma_{\mathrm{s}}$ e $e^{ \pm} \mathrm{s}$. Existem diferentes tipos de $\mathrm{SD}$ e os mais frequentemente usados são os detectores de cintilação e os de luz Cherenkov em tanques de água.

Luz fluorescente é emitida quando as partículas carregadas do chuveiro interagem na atmosfera, sendo esta observada pelos telescópios FD.

Cada técnica apresenta vantagens e desvantagens. A reconstrução da energia do chuveiro com SD depende dos modelos de interação de hádrons, enquanto o FD observa diretamente a luz fluorescente, sendo esta proporcional à energia do primário. O problema da técnica de fluorescência é que ela permite somente medidas em noites escuras. Como o fluxo dos UHECR é muito baixo, é importante ter um detector que tenha um ciclo de trabalho de $100 \%$. O SD oferece este ciclo, enquanto o FD oferece somente $\sim 10 \%$.

\subsubsection{Detectores de Superfície}

Detectores de cintilação usualmente são feitos de plásticos cintiladores. São sensíveis a todas as partículas carregadas e medem principalmente a parte eletromagnética dos EAS no solo. Porém, a eficiência destes detectores cai muito em função do ângulo zenital, sendo pequena para $\theta>45^{\circ}$.

Tanques de água que medem luz Cherenkov, gerada pela passagem das partículas carregadas do chuveiro, foram bem sucedidas em experimentos com grandes áreas de detecção. Os tanques com água pura devem ter excelente proteção contra contaminação e necessitam de mais cuidado do que com os cintiladores. Dependendo da geometria do tanque, em média os múons 
podem depositar dez vezes mais luz do que um elétron. Os tanques permitem melhor detecção de chuveiros inclinados dos que detectores de cintilação.

A área a ser coberta pelos SD na superfície da Terra depende da energia do primário e o espaçamento entre eles depende de quantos SD queremos acionar em um evento. A experiência mostra que para estudar UHECR é necessário uma área de milhares de $\mathrm{km}^{2}$, com detectores espaçados numa distância da ordem de $1 \mathrm{~km}$.

Independentemente do tipo de SD utilizado, os detectores amostram o número de partículas dos EAS que alcançam o solo em função do tempo. Com este sinal temos que reconstruir a energia e direção do primário, buscando também características que identifiquem sua composiçao primária. Assumimos, para isto, que os EAS têm simetria no plano perpendicular ao seu eixo. Esta simetria é mantida para ângulos de incidência até $60^{\circ}$ em relação ao eixo zenital. Acima disso as partículas são defletidas pelo campo geomagnético e os UHECR que chegam com ângulos acima de $75^{\circ}$ deixam um sinal na forma característica de uma borboleta no plano perpendicular ao eixo.

A direção do primário está relacionada com a geometria do chuveiro, que é determinada pela diferença temporal do sinal da frente do chuveiro registrada nos diferentes detectores no solo. Com isso pode-se determinar o eixo do chuveiro e sua direção.

A energia do primário é determinada a partir da distribuição da densidade do sinal em função da distância lateral ao eixo. A posição dos detectores é projetada no plano perpendicular ao eixo e uma função, chamada de Função Distribuição Lateral (LDF), é ajustada. A LDF depende das características do sítio de observação. Estas funções dependem de parâmetros provenientes de simulações Monte Carlo. Como exemplo, o OPA utiliza 60, 61] a função NKG (Kamata and Nishimura [62] e Greisen[63])

$$
f(r)_{N K G}=S_{1000}\left(\frac{r}{r_{1000}}\right)^{\beta}\left(\frac{r_{700}+r}{r_{1700}}\right)^{\beta+\gamma}
$$

onde $S_{1000}$ é um parâmetro de normalização ajustado, $r_{1000}, r_{700}$ e $r_{1700}$ são as distâncias, resctivamente, de 1000, 700 e $1700 \mathrm{~m}$, $\gamma$ é quase zero e beta leva a dependência angular,

$$
\beta=a(E)+b \sec \theta .
$$

Os valores $a$ e $b$ são valores derivados de simulações Monte Carlo, onde a distribuição dos detectores é levada em consideração.

Com a função ajustada, calculamos o sinal a uma distância ótima $r_{\text {otm }}$, que é utilizado para determinar a energia do primário. A distância ótima $r_{\text {otm }}$ foi proposta por Hillas em 1970 [65], sendo definida no ponto onde a soma 
das flutuações naturais e estatísticas vindas da amostragem das partículas seriam minimizadas. No OPA o sinal reconstruído a $r_{1000}=r_{\text {otm }}$ é o $S_{1000}$. A energia se relaciona com a LDF calculada em $r_{\text {otm }}$ como

$$
E \propto S(1000)
$$

onde a proporcionalidade da energia com o S(1000) depende dos modelos de interação de hádrons utilizada.

A Figura 2.5 mostra um evento real observado pelo SD do OPA, para o qual a energia primária foi estimada em $E=4.1 \pm 1.4 \mathrm{EeV}$. A Figura (a) mostra os detectores SD acionados, onde as cores identificam a intensidade do sinal em escala logarítmica. A seta indica a direção de incidência do primário (zenite $=54,5^{\circ} \pm 0,1^{\circ}$, azimute $=20,9^{\circ} \pm 0,1^{\circ}$ ). Em (b) temos os dados ajustados com a LDF. O sinal é medido em VEM (Vertical Equivalent Muon), onde 1 VEM é o sinal médio depositado quando um muon vertical atravessa a região central do detector.

A reconstrução da composição do primário não é fácil, pois o SD não tem acesso direto ao $X_{\max }$. Um indicador de composição pode ser a densidade de múons dos EAS em dada amostragem. Separar os sinais de $\gamma \mathrm{s}$ e $e^{ \pm} \mathrm{s}$ dos de $\mu$ s nos SD não é uma tarefa fácil e pode ser estimado através de simulação Monte Carlo. Porém, comparações entre dados e simulações mostram uma diferença nos múons esperados, onde as simulações subestimam o número de múons. A diferença pode ser devido aos modelos de interação de hádrons ou aos métodos utilizados para medir os múons. Combinar as duas grandezas das observação, a densidade de muons e o $X_{\max }$, contribui bastante para determinar a composição dos UHECR. 


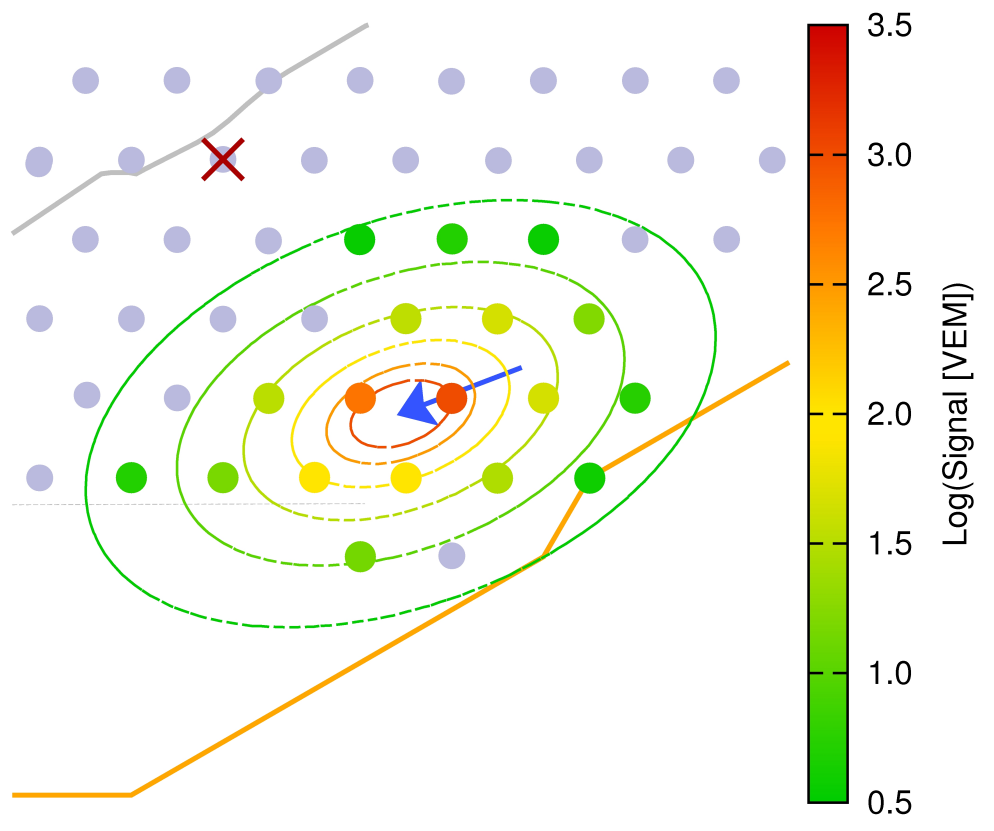

(a)

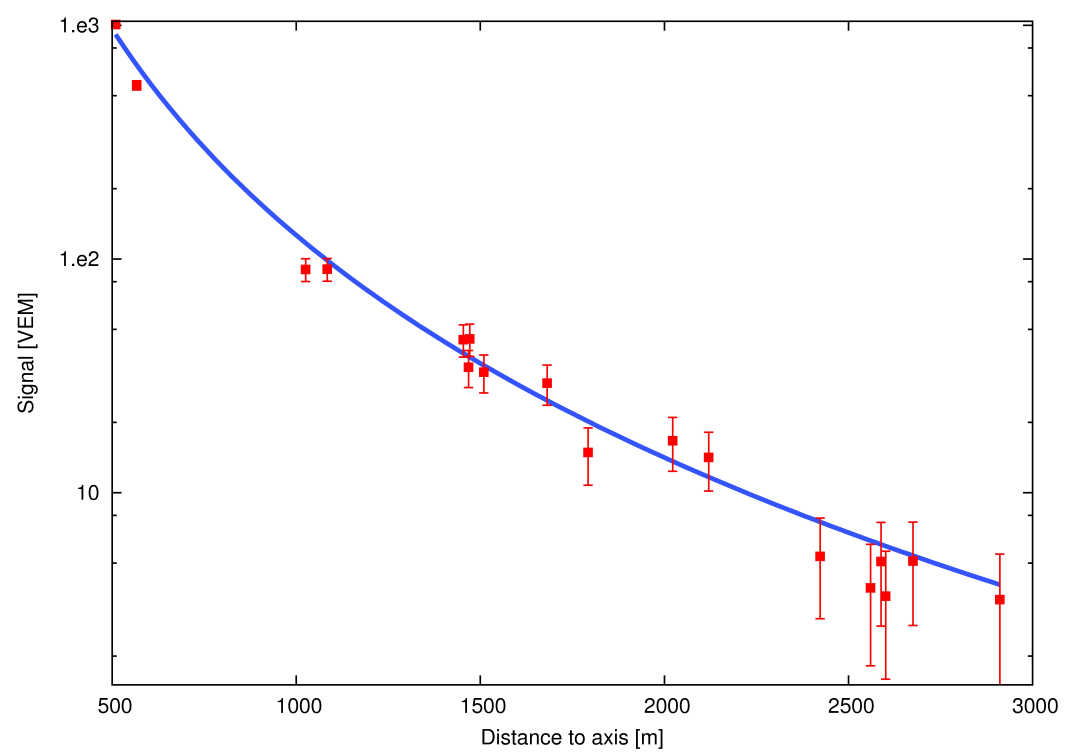

(b)

Figura 2.5: Exemplo de um evento detectado pelo SD do OPA. Em (a) temos os tanques de água de luz Cherenkov acionados no evento. As cores representam a intensidade do sinal deixado em cada detector. Em (b) temos a função LDF ajustada aos dados. Extraída de 64]. 


\subsubsection{Detectores de Fluorescência}

Os FD são telescópios que captam a luz emitida na interação das partículas carregadas dos EAS com as moléculas de nitrogênio $\left(N_{2}\right)$ da atmosfera no intervalo de comprimento de onda $(300-450) \mathrm{nm}$. A emissão ocorre devido à desexcitação das moléculas de nitrogênio. A técnica de FD é a mais apropriada para medir a energia do primário, dado que a luz fluorescente emitida é proporcional à energia depositada na atmosfera. Outra vantagem é que a técnica mede diretamente o $X_{\max }$ do chuveiro na atmosfera, parâmetro importante na determinação da composição primária.

Cada telescópio é composto basicamente por um espelho esférico que reflete a luz recebida para o plano focal, onde se encontra um conjunto de pequenas fotomultiplicadoras (PMT). O telescópio só pode ser utilizado em noites escuras e sem núvens, o que implica num ciclo de trabalho de $\sim 10 \%$.

Várias correções devem ser feitas para eliminar a luz de outras fontes, como por exemplo a radiação Cherenkov que também é gerada pela passagem de partículas carregadas através da atmosfera. O sinal destas fontes devem ser subtraídas do sinal original. Também é necessário constante monitoramento da atmosfera e das suas condições ópticas, bem como o conhecimento preciso da geometria do chuveiro.

A reconstrução dos parâmetros começa com a geometria do chuveiro, tal como ilustrada na Figura 2.6, onde os parâmetros geométricos relativos aos FD são definidos no plano de detecção do chuveiro (SDP). $R_{p}$ é a distância de maior proximidade do eixo do chuveiro ao telescópio, $t_{o}$ é o tempo no qual este eixo atinge a máxima aproximação e $\chi_{o}$ é o ângulo externo entre este eixo e a superfície.

O SDP é definido a partir da distância do eixo do chuveiro ao FD e os parâmetros $R_{p}, t_{o}$ e $\chi_{o}$ são obtidos através do seguinte ajuste

$$
t_{i}=t_{o}+\frac{R_{p}}{c} \tan \left(\frac{\chi_{o}-\chi_{i}}{2}\right)
$$

onde os tempos $t_{i}$ e ângulos $\chi_{i}$ são determinados pelos pixels e intensidade do sinal das câmeras que compõem o FD.

A Figura 2.7 exemplifica o sinal obtido pelas câmeras do FD do OPA. À esquerda temos os pixels (PMTs) onde o sinal inicial está em azul indo para o vermelho num tempo posterior. Cada pixel tem um ângulo $\chi_{i}$ de visão. À direita temos a resposta dos pixels selecionados (pontos pretos na figura à esquerda) em função do tempo (100ns por bin).

Às vezes o sinal do FD não fornece um único ajuste para a equação acima. Uma maneira de contornar este problema seria usar eletrônica rápida nos FD para alcançar boa precisão nos parâmetros $t_{i}$ e $\chi_{i}$. Outra maneira 


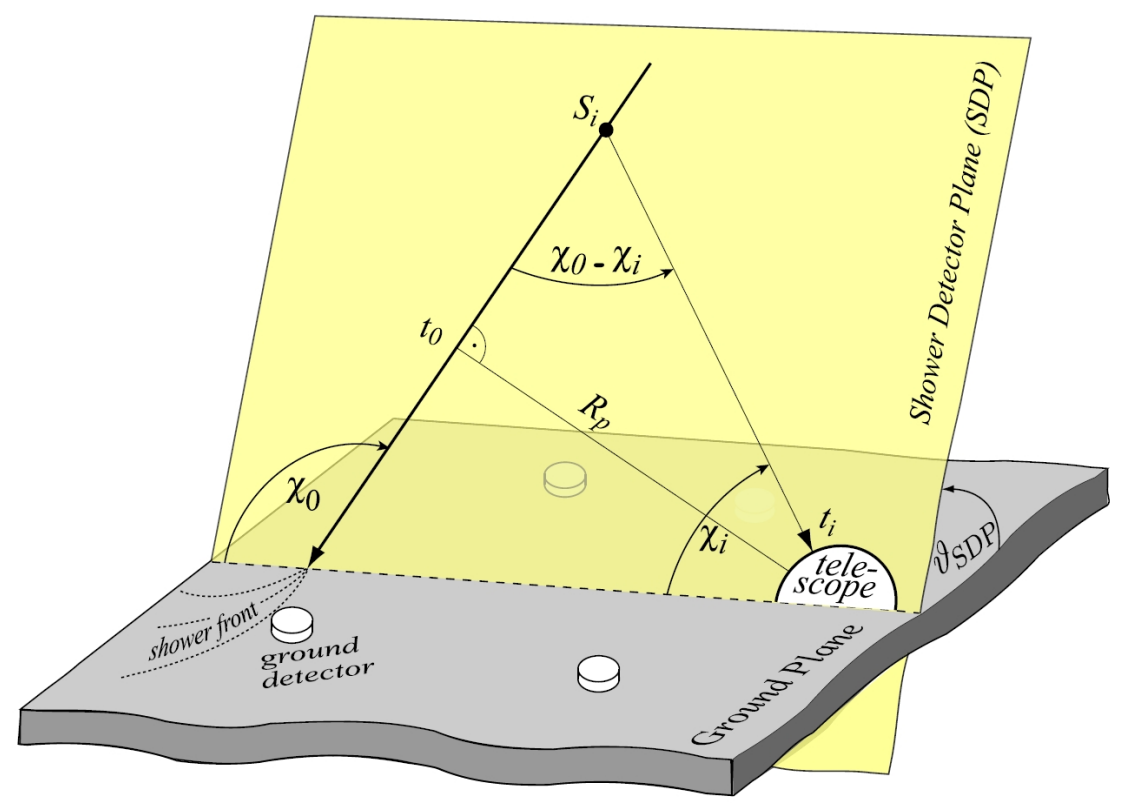

Figura 2.6: Geometria da detecção de um EAS por um FD. Extraída de 66]

seria analisar os dados de outros FD que observam o mesmo chuveiro em diferentes ângulos, reconstruindo os eventos em modo estéreo, o que é feito quando possível. Pode-se também utilizar o tempo de chegada da frente do chuveiro usando os SD e vincular o parâmetro $t_{o}$. Esta é a técnica híbrida usada pelo OPA e TA, que permite reconstruir a geometria do chuveiro dentro de uma fração de um grau.

Uma vez determinada a geometria do chuveiro, é possível determinar o seu $X_{\max }$. O número de partículas carregadas $N_{c}(X)$ na profundidade atmosférica $\left(\mathrm{g} / \mathrm{cm}^{2}\right)$ determinada pelo perfil longitudinal, geralmente é dado pela função Gaisser-Hillas (GH) [68],

$$
N_{c}(X)=N_{\max }\left(\frac{X-X_{0}}{X_{\max }-X_{0}}\right)^{\frac{X_{\max }-X_{0}}{\lambda}} e^{\frac{X_{\max }-X}{\lambda}}
$$

onde $N_{\max }$ é o número de partículas carregadas no máximo do chuveiro, $X_{0}$ é um parâmetro livre e $\lambda$ é o caminho livre médio da partícula (para o próton $\lambda=70 \mathrm{~g} / \mathrm{cm}^{2}$ ). Estes três parâmetros e o $X_{\max }$ são determinados no ajuste da função distribuição GH. A Figura 2.8 mostra o perfil da função G-H ajustada aos dados simulados para um chuveiro de próton com $E=1 \times 10^{20}$ $\mathrm{eV}$. 


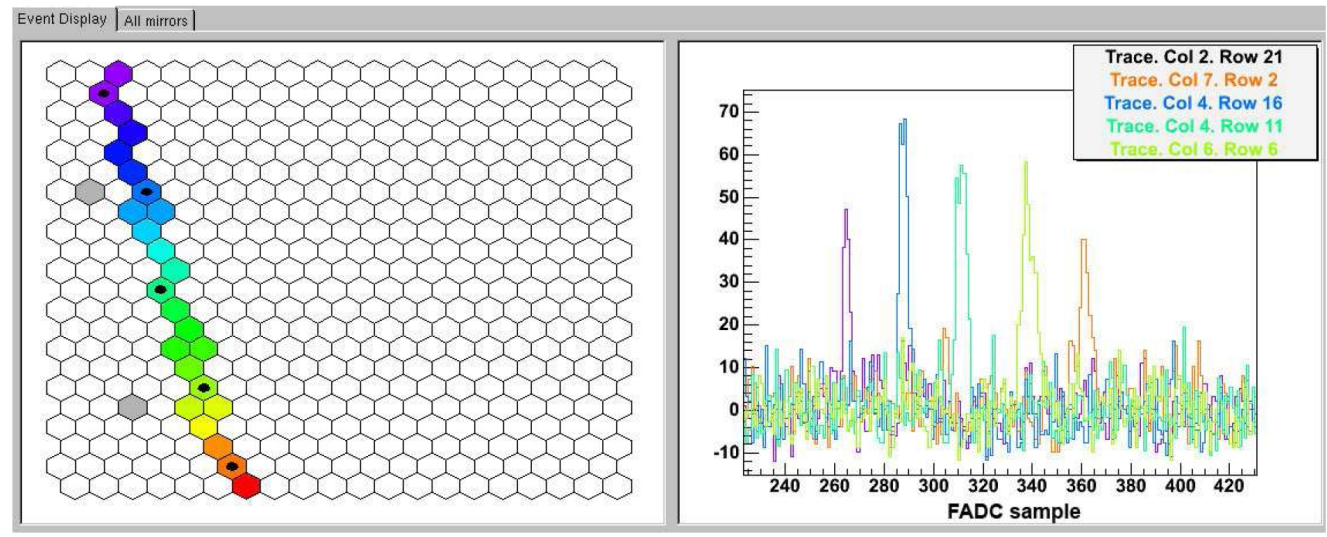

Figura 2.7: Exemplo do sinal deixado nas fotomultiplicadoras que compõem o FD no OPA. À esquerda os pixels acionados e à direita a resposta destes em função do tempo. Extraída de [66].

A integral do perfil longitudinal determina a energia eletromagnética total do chuveiro atmosférico,

$$
E_{e m}=2.2 M e V / g / \mathrm{cm}^{2} \int_{0}^{\infty} N_{c}(X) d X
$$

onde a constante $2,2 \mathrm{MeV}$, corresponde à energia média depositada por uma partícula carregada a cada intervalo de $1 \mathrm{~g} / \mathrm{cm}^{2}$ de profundidade.

A energia eletromagnética da cascata corresponde à maior parcela da energia da partícula inicial. Uma menor parcela da energia é transportada por partículas que não depositam sua energia na atmosfera como os neutrinos, os hádrons e os múons e esta deve ser determinada através de simulação Monte Carlo. Um primário de núcleo de ferro com $E=10^{18} \mathrm{eV}$ tem $80 \%$ da energia primária depositada em luz fluorescente (90\% para prótons), enquanto que o mesmo primário com $E=10^{20} \mathrm{eV}$ deposita $88 \%$ (94\% para prótons) [31]. Variações de modelo a modelo podem chegar a 50\% [69].

A composição primária pode ser estimada a partir do $X_{\max }$. Porém, uma separação evento a evento é difícil devido às flutuações intrínsecas deste parâmetro.

\subsection{Observatório Pierre Auger}

O Observatório Pierre Auger é o maior observatório de RC já construído e foi projetado para detectar UHECR de forma híbrida, ou seja, utilizando SD e FD simultaneamente. Está localizado próximo à cidade de Malargüe, na 


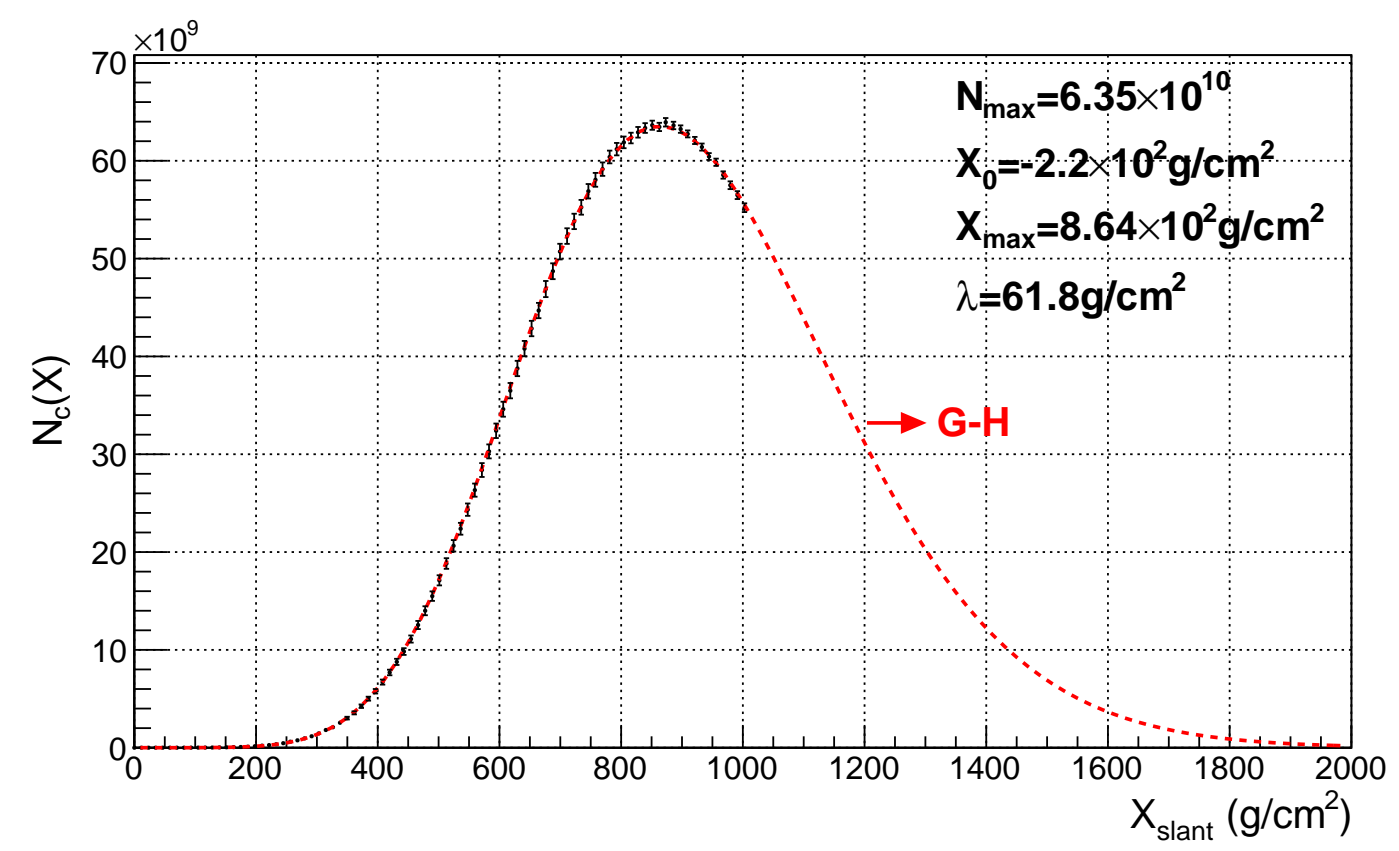

Figura 2.8: Função Gaisser-Hillas ajustada aos dados simulados para um chuveiro de próton com $E=1 \times 10^{20} \mathrm{eV}$. A energia calorimétrica é proporcional à área sob a curva.

província de Mendoza, Argentina, na região "Pampa Amarilla" $\left(35,1^{\circ}-35,5^{\circ}\right.$ $\mathrm{S}, 69,0^{\circ}-69,6^{\circ} \mathrm{O}$ a $1300-1400 \mathrm{~m}$ de altitude).

O OPA começou a operar em 2004 com 100 estações de tanques de água de luz Cherenkov cobrindo uma área de $150 \mathrm{~km}^{2}$. Sua construção foi finalizada em 2008, totalizando 1600 estações SD e 24 telescópios de fluorescência. Os SD são separados por $1,5 \mathrm{~km}$, garantindo investigar eficientemente UHECR com $E>3 \times 10^{18} \mathrm{eV}[70]$.

A Figura 2.9 mostra um esquema do OPA, onde cada ponto branco pequeno representa uma estação SD. As linhas contínuas indicam o campo de visão dos $24 \mathrm{FD}$ localizados nos quatro pontos brancos maiores na periferia (Coihueco, Loma Amarilla, Los Leones e Los Morados). Na região central encontra-se o Central Laser Facility (CLF) de onde são disparados pulsos de laser na atmosfera para calibrar os detectores de fluorescência. Próximo à estação Coihueco, na área com maior densidade de pontos brancos, encontrase o infill array consistindo de SD mais próximos entre si, que estendem as observações de UHECR para regiões de mais baixas energias (0,1 a 1) EeV (Auger Muon and Infill for the Ground Array - AMIGA). Com o mesmo objetivo que o AMIGA, foram instalados na estação Coihueco três telescópios de fluorescência em uma extensão chamada HEAT, High Elevation Auger 
Telescope, que cobre uma região mais elevada no céu, dado que chuveiros de menor energia desenvolvem com um $X_{\max }$ menor.

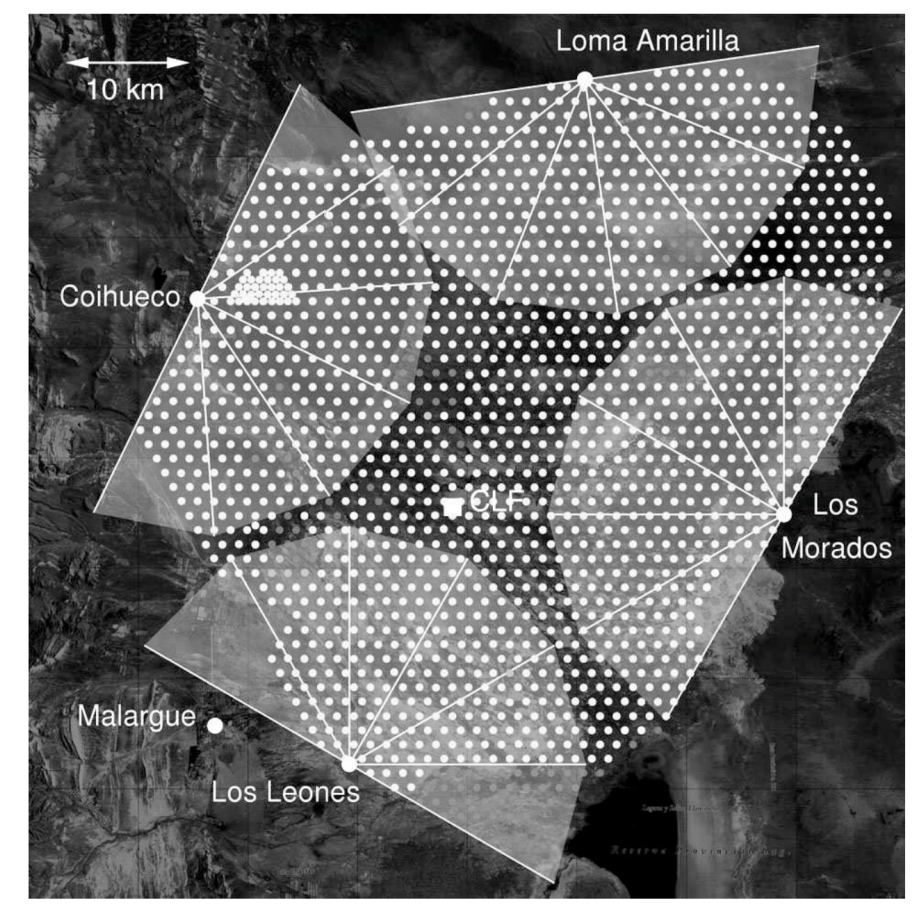

Figura 2.9: Observatório Pierre Auger em março de 2009. Extraída de [66].

Os tanques de água têm 1,2 $\mathrm{m}$ de altura e $10 \mathrm{~m}^{2}$ de área e estão espalhados numa área total de $3000 \mathrm{~km}^{2}$. Cada tanque contém três fotomultiplicadoras que medem a luz Cherenkov das partículas carregadas que passam na água. Um muon vertical com energia de $\sim 1 \mathrm{GeV}$ deposita no tanque uma energia de $\sim 240 \mathrm{MeV}(1 \mathrm{VEM})$ e elétrons depositam centenas de $1 \mathrm{keV}$.

Os tanques são equipados com um sistema de aquisição de dados (DAQ) e eletrônica front-end para controle e trigger (disparo de gravação dos dados), painel solar e duas baterias, receptor GPS para marcação de tempo e um emissor e receptor de rádio para transmissão de dados.

Cada prédio dos FD contém seis telescópios apontados na direção interna da área coberta pelos SD. Cada telescópio tem um sistema óptico equipado com um filtro que seleciona luz UV, um espelho com 3,6 m de diâmetro e uma câmera composta de 440 PMTs com um ângulo de visão de $1,5^{\circ} \times 1,5^{\circ}$, permitindo um campo de visão de $30^{\circ} \times 30^{\circ}$ em azimute e zênite. O conjunto de seis telescópios cobrem $180^{\circ} \mathrm{em}$ azimute. 


\subsection{Telescope Array}

O Telescope Array (TA) é um detector híbrido que começou a tomar dados

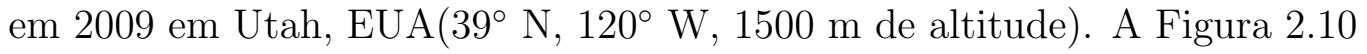
mostra um esquema do TA, onde os quadrados representam as estações de $\mathrm{SD}$ e os arcos, os FD.

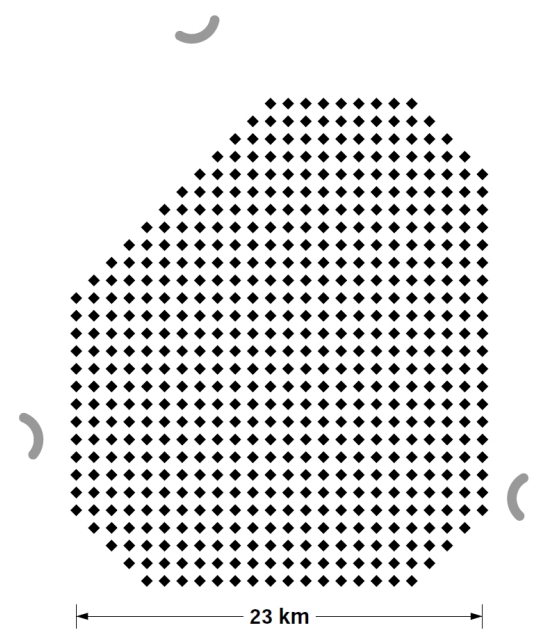

Figura 2.10: Esquema do arranjo geométrico do TA.

O SD é composto de 607 cintiladores separados por 1,2 $\mathrm{km}$ em um arranjo quadrado, cada um deles com $3 \mathrm{~m}^{2}$ de área e consistindo de duas camadas de espessura 1,2 cm. Cada estação é alimentada por baterias recarregadas por um painel solar. O TA é dividido em três partes que se comunicam com três torres de controle onde o sinal é recebido e o trigger é produzido. O SD é totalmente eficiente para chuveiros acima de $E=10^{18,7} \mathrm{eV}$ e ângulos de incidência menor do que $45^{\circ}$.

Os FD consistem de 3 estações. Duas destas consistem de 12 telescópios, com campo de visão em elevação de $3^{\circ}$ a $31^{\circ}$. O ângulo de visão horizontal total de cada estação é $108^{\circ}$. A terceira estação tem 14 telescópios que usam câmeras e eletrônica do antigo experimento HiRes.

Assim como o AMIGA do OPA, o TA também tem uma extensão para chuveiros de mais baixa energia chamado TALE, que visa analisar RC no intervalo de energia de $10^{16,5}$ a $10^{18} \mathrm{eV}[67$. 


\section{Capítulo 3}

\section{Simulação dos EAS}

Cerca de $10^{11}$ partículas são produzidas em um EAS de $E=10^{20} \mathrm{eV}$ gerado da interação de um UHECR com a atmosfera. Detectores na superfície da Terra somente podem coletar amostras dos sinais da cascata de partículas que chegam ao solo, já que os detectores se encontram espalhados numa área da alguns milhares de $\mathrm{km}^{2}$. Um conhecimento detalhado da física envolvida nos chuveiros é necessário tanto para calibrar e testar a eficiência dos detectores, quanto para analisar e interpretar os dados colhidos. Simulações de EAS baseadas no método Monte Carlo (MC) são as ferramentas mais apropriadas para esses propósitos, dado o caráter estocástico do desenvolvimento dos chuveiros, com flutuações intrínsecas inerentes às colisões e decaimentos das inúmeras partículas que o compõem.

A escala de energia característica das interações dos UHECR com a atmosfera é algumas ordens de magnitude maior do que a atingida pelas colisões geradas nos aceleradores. Os modelos das interações dos hádrons testados com os dados provenientes destes aceleradores ou dos experimentos de $\mathrm{RC}$ de energias mais baixas, são extrapolados para altíssimas energias nos algorítmos que simulam os EAS.

Neste capítulo, vamos descrever o programa de simulação MC que utilizamos para gerar os chuveiros atmosféricos. Através destas simulações, analisamos dois dos principais parâmetros dos EAS que são medidos pelos experimentos de UHECR, a densidade de múons e o $X_{\max }$, objetivando a distinção dos chuveiros atmosféricos iniciados por fótons dos iniciados por nucleons ou núcleos, tais como prótons ou ferro. Nesta análise, dois efeitos importantes nas simulações dos chuveiros iniciados por fótons são levados em consideração: o efeito Landau, Pomeranchuk [71], Midgal[72] (LPM) e o pre-shower [73]. Como descreveremos mais adiante, enquanto o efeito LPM atrasa a formação do $X_{\max }$ na atmosfera, o pre-shower adianta sua formação. O efeito pre-shower torna-se importante a energias $E>10^{19} \mathrm{eV}$ onde existe 
uma competição entre estes dois efeitos.

\subsection{Simulações através do Método MC}

O desenvolvimento de um EAS é muito complexo para ser tratado por modelos analíticos, devido às flutuações naturais da primeira interação e do grande número de partículas que o constituem. Desta forma, o método MC é a ferramenta ideal para simular os EAS. Técnicas de MC são métodos computacionais, baseados na geração de números aleatórios a partir de distribuições de probabilidade.

A simulação dos EAS pode ser dividida em duas partes principais. A primeira é o transporte das partículas geradas e a segunda é responsável pelas interações das mesmas com a atmosfera. Nesta última, a grande fonte de incertezas está nos modelos de interação dos hádrons. O algorítmo deve produzir resultados que são consistentes com as propriedades medidas nos EAS de modo a podermos interpretar os resultados experimentais consistentemente.

Entre os programas de MC utilizados para simular os EAS estão o AIRES (AIR-shower Extended Simulations) [4] e o CORSIKA (COsmic Ray SImulations for KAscade)[74]. Ambos permitem utilizar diferentes modelos de interação de hádrons, como o SIBYLL[75] e o QGSJET [76]. Em nossas simulações utilizaremos o AIRES e adotaremos o SIBYLL como modelo de interação de hádrons.

AIRES é um simulador de EAS que inclui colisões núcleos-núcleos, hádronnúcleos e fóton-núcleos. A primeira versão do AIRES (1.2.0) se baseou no código MOCCA criado por A. M. Hillas [77]. Já a versão atual do AIRES traz muitas modificações ao algorítmo original levando em consideração o perfil da densidade da atmosfera, a curvatura da Terra e o campo geomagnético.

Dado que seguir todas as partículas do chuveiro é computacionalmente inviável, métodos estatísticos de amostragens devem ser empregados para reduzir o tempo das simulações. Hillas [78] introduziu o método de statistical thinning que consiste basicamente em simular com detalhes uma fração da grande quantidade de partículas do chuveiro. Às partículas que compẽm esta fração são dados pesos estatísticos que representam aquelas que foram produzidas juntas na mesma interação e que não continuarão a ser seguidas na simulação.

Tomando $E_{A}$ como a energia de uma partícula que produz secundários de energia $E_{B_{i}}$ e $E_{t h}$ a energia fixa de thinning, cada partícula produzida em um vértice tem a probabilidade $P_{i}$ para ser seguida, de acordo com as seguintes condições: 
- se a energia $E_{A}$ do primário é maior do que a energia $E_{t h}$, e a $E_{B_{i}} \geqslant E_{t h}$ a probabilidade é $P_{i}=1$, se $E_{B_{i}} \leqslant E_{t h}$, a probabilidade é $P_{i}=E_{B_{i}} / E_{t h}$.

- se $E_{A} \leqslant E_{t h}$, significa que a partícula veio de uma operação de thinning e somente uma das partículas é selecionada com probabilidade $P_{i}=$ $E_{B_{i}} / \sum_{j=1}^{n} E_{B_{j}}$.

Apesar dos valores médios dos parâmetros simulados não dependerem da energia de thinning, o valor deste influencia as flutuações dos chuveiros. Quando este valor é próximo à energia do primário, o processo de thinning começa mais cedo no desenvolvimento longitudinal do chuveiro e um baixo número de amostras é obtido, aumentando assim as flutuações.

O algorítmo de thinning do AIRES [4] é uma extensão do criado por Hillas [78, permitindo limitar os pesos estatísticos a um valor máximo por meio de um parâmetro externo chamado fator limitante de peso $W_{f}$. O limite $W_{f} \rightarrow \infty$ corresponde ao algorítimo de Hillas, enquanto $W_{f} \rightarrow 0$ desliga a rejeição das partículas [79]. O objetivo do método de thinning do AIRES é diminuir as flutuações geradas ao utilizar um baixo valor no thinning do algorítimo de Hillas.

Um grande avanço no conhecimento que temos das interações dos hádrons vem dos experimentos em aceleradores de partículas, dando validade à interpretação de que os hádrons são compostos por partículas menores, os quarks, e seus intermediadores de força forte, os glúons [80]. A Cromodinâmica Quântica (QCD) é a teoria construída para descrever as interações entre os quarks e glúons. De forma simplificada, o processo de espalhamento entre hádrons de altas energias pode ser classificado como hard e soft, modelados diferentemente pela QCD. A parte hard descreve interações com alta transferência de momento e suas características podem ser preditas usando teoria de perturbação. Os processos na parte soft, com pequena transferência de momento, não podem ser tratados perturbativamente e modelos são utilizados para descrever essas interações. Um modelo teórico que descreve estas interações é o de Gribov e Regge(GRT) [81]. Dentre os modelos que utilizam teorias tipo GRT são [82]: QGSJET, VENUS[83] DPMJET[84] e o NEXUS[85]. Já o Sibyll é um modelo mais fenomenológico no tratamento das colisões soft.

Dentro da parte soft em uma colisão com um alvo fixo, os eventos difrativos são fenômenos de espalhamentos elásticos ou de dissociações do alvo ou do projétil. Estes devem ser levados em consideração para calcular a seção de choque total em uma colisão. Por exemplo, em uma colisão $p-\bar{p}$ no Tevatron, os eventos difrativos representam $40 \%$ da seção de choque total [86]. Os modelos de interação dos hádrons incluiem tanto a parte não difrativa 
(calculada pela teoria de perturbação) como a parte difrativa com o objetivo de reproduzir a seção de choque total dos espalhamentos determinada pelos experimentos nos aceleradores.

Estes modelos são extrapolados para energias mais altas, sendo uma grande fonte de incerteza na descrição dos EAS iniciados por UHECR.

\section{$3.2 \quad$ SIBYLL}

O Sibyll possibilita simular as interações hadrônicas, extrapolando os modelos usados na física dos aceleradores às altas energias dos EAS. O modelo deve reproduzir as características das interações dos hádrons na região de energia dos aceleradores, incluindo interações em alvos nucleares. Muitas características do modelo são emprestadas do algorítmo de Monte Carlo Lund [87] que é usado em programas como o PYTHIA para gerar eventos de física de altas energias [88, que implementa o Dual Parton Model (DPM)[89]. A principal característica do Sibyll é explicar o aumento da seção de choque total com a energia através da produção de minijets [90, 91], baseando-se também no DPM. O modelo é construído para interações hádron-hádron e é estendido para tratar das colisões núcleo-núcleo.

\subsubsection{Parte não difrativa}

A ideia central da colisão hádron-hádron é a sucessiva produção e fragmentação de cordas QCD [89]. No DPM cada nucleon é composto por um diquark (um antitripleto de cor) e um quark (tripleto de cor). Como exemplo tomemos a colisão de dois prótons. Durante a colisão eles trocam gluons (soft gluons), reorganizando o campo de cor. O diquark do projétil se combina com o quark do alvo e vice-versa, levando a formação de duas cordas esticadas, com os fragmentos dispostos nas extremidades e um par quark-antiquark entre eles. As fragmentações destas cordas formam então dois hádrons.

A energia de cada próton é dividida entre o quark e o diquark e a fração de energia do próton carregada pelo fragmento quark $x_{q}$ na colisão é escolhida de acordo com a função

$$
f_{q}(x)=\frac{(1-x)^{\alpha}}{\left(x^{2}+\mu^{2} / s\right)^{1 / 4}}
$$

onde $\mu=0,36 \mathrm{GeV}$ age como a massa efetiva do quark e $\alpha=3$ é um parâmetro de ajuste. Cada corda tem sua energia $E_{\text {str }}$ e seu momento longitudinal $p_{\text {str }}$ dados por

$$
E_{s t r}=\frac{\sqrt{s}}{2}\left(x_{1}+x_{2}\right)
$$


e

$$
p_{s t r}=\frac{\sqrt{s}}{2}\left(x_{1}-x_{2}\right) .
$$

onde $x_{1}$ corresponde ao quark do projétil enquanto $x_{2}$, ao diquark do alvo. O mesmo processo ocorre em uma colisão envolvendo mésons, onde agora o $x_{2}$ corresponde ao anti-quark. Se a colisão for entre um méson e um bárion, o quark (antiquark) do méson se combina com o diquark (quark) do nucleon.

As cordas são totalmente descritas pelos sabores dos (anti)quarks e (anti) diquarks nas extremidades. Para produzir uma partícula, uma das extremidades da corda é selecionada aleatoriamente e um par $q-\bar{q}$ (ou $q q-\overline{q q}$ ) é produzida, e os novos sabores se combinam com os sabores da partícula da corda selecionada aleatóriamente. Por exemplo, os estados $u \bar{u}, d \bar{d}$ e $s \bar{s}$ dão origem aos méson $\left(\pi^{o}, \eta, \eta^{\prime}\right)$ ou $\left(\rho^{o}, \omega, \eta^{\prime}\right)$.

Quando o par $q-\bar{q}$ e $q q-\overline{q q}$ é criado durante a fragmentação da corda, o momento transversal $p_{T}$ da nova partícula é gerado a partir de uma distribuição Gaussiana, e sua média é dada por:

$$
p_{T}=p_{o}+0,184 \ln \left(\frac{\sqrt{s}}{30 G e V}\right),
$$

onde $p_{o}=0,3 \mathrm{GeV}$ para os quarks $u$ e $d, p_{o}=0,45 \mathrm{GeV}$ para o quark $s$ e $0,6 \mathrm{GeV}$ para o diquarks. A energia das novas partículas é gerada seguindo a função de fragmentação de Lund:

$$
f(z)=\frac{(1-z)^{a}}{z} \exp \frac{-b m_{T}^{2}}{z}
$$

onde $z$ é a fração da energia do quark ou diquark "pai" carregada pela nova partícula e $m_{T}=\sqrt{p_{T}+m_{0}^{2}}$, enquanto $a=0.5$ e $b=0.8$ são parâmetros usados para ajustar a produção de partículas nas interações dos hádrons a baixas energias. Chamamos de partícula líder, ou leading particle, os bárions criados no início do chuveiro e que carregam sempre a maior parte da energia da partícula "pai". A leading particle é importante para o desenvolvimento dos EAS e tem sua energia gerada a partir de uma função de algoritmo fragmentação mais rígida. O algorítmo do processo de sucessivas criações e fragmentações de cordas para gerar hádrons continua até que a corda atinja uma massa menor do que um limiar $M_{t h}$, quando dois hádrons finais são produzidos.

\subsubsection{Parte difrativa}

A seção de choque difrativa é dividida em três partes: forward, backward e double. Estas são representadas por funções logarítmicas, sendo as partes 
forward e backward ajustadas a partir do valor de $9 \%$ da seção de choque inelástica a $30 \mathrm{GeV}$, enquanto a parte double corresponde a 4\%. Uma função logarítmica é adicionada para ajustar o crescimento das seções de choques difrativas.

Nos eventos difrativos uma ou ambas as partículas que colidem são excitadas a um estado de alta massa $X$, que decai em um grupo de partículas. A massa do estado é gerada de acordo com uma distribuição proporcional a $M_{X}^{-2}$, com limites mínimos $M_{X}^{2}[\mathrm{~min}]=1,5 \mathrm{GeV}^{2}$ para excitação de nucleons e antinucleons, 0,2 $\mathrm{GeV}^{2}$ para $\pi^{ \pm}$e 0,6 $\mathrm{GeV}^{2}$ para káons e limite máximo $M_{X}^{2}[\max ]=0,1 s$, onde $\sqrt{s}=E_{C M}$.

Dois algorítmos são utilizados para o decaimento dos estados excitados. Caso a diferença de massa seja $M_{X}-m_{h} \leq 0,6 \mathrm{GeV}$, o seguinte decaimento é simulado

$$
X \rightarrow h^{\prime}+n \pi,
$$

onde $n$ é a multipicidade de píons, enquanto $h^{\prime}$ ou é o hádron inicial $h$ ou um hádron relacionado ao $h$ por isopin. Por exemplo, se $h$ é um próton, $h^{\prime}$ pode ser um próton ou um nêutron. O número de píons produzidos é gerado por uma distribuição Gaussiana com valor médio $\left\langle n_{\pi}\right\rangle=2 \sqrt{M_{X}-m_{h}}$ e desvio padrão $\sigma_{n_{\pi}}^{2}=1 / 2\left\langle n_{\pi}\right\rangle$. Para maiores valores de massa, o decaimento é dado pela divisão do estado excitado de massa $X$, onde um méson excitado se divide em um par quark-antiquark e o bárion em um par quark-diquark. A corda QCD de massa $M_{x}$ é formada e separada de forma usual. O algorítmo reproduz as características básicas da seção de choque a baixas energias. Para estender os algorítmos a altas energias é necessário o modelo de minijets.

\subsubsection{Minijets}

A suposição básica do modelo é que o aumento da seção de choque inelástica está relacionada com a produção de minijets. Um quark do feixe realiza uma colisão hard com um quark do alvo, onde a seção de choque de produção de jets é dada pela teoria de perturbação da QCD.

Neste modelo a seção de choque inelástica que tem a parte soft não difrativa é dependente do número das interações hard que ocorrem nas colisões. O número médio de colisões destas interações hard vem dos modelos para o espalhamento hádron-hádron [92, 93], nos quais a seção de choque é determinada.

O termo da seção de choque inelástica $\sigma_{N}$ é a base para a implementação do método Monte Carlo no modelo de minijets. A seção de choque $\sigma_{N}$ é interpretada como a seção de choque para a produção de $N$ pares de minijets. A distribuição de probabilidade para a produção de minijets será 
então $P_{N}=\sigma_{N} / \sigma_{\text {inel }}$. Os eventos não difrativos são gerados escolhendo-se aleatoriamente o número de pares $N$ de minijets produzidos. O cálculo do número de minijets produzidos é somente realizado para valores acima de um momento transversal mínimo $p_{T}^{m i n}$. Com isso, a produção de minijets fica restrita ao cálculo perturbativo e, abaixo desse valor, as interações são consideradas soft, sendo tratadas separadamente.

Fenômenos difrativos não estão incluídos no modelo de minijets, dado que no limite de altas energias as interações hard são dominantes e os eventos difrativos são praticamente nulos. Para eventos de baixas energias, o termo da seção de choque inelástica que não contém a produção de jets $\sigma_{\text {nojet }}$, contém um termo que inclui eventos difrativos.

\subsection{Composição dos UHECR e EAS}

Através das simulações investigaremos as características de EAS gerados por fótons, nucleons e núcleos extremamente energéticos. Podemos descrever os EAS através de três parâmetros: a energia do primário $E_{o}$, o número de múons $N_{\mu}$ e a profundidade máxima $X_{\max }$ do desenvolvimento longitudinal dos EAS. Os parâmetros $X_{\max }$ e $N_{\mu}$ dependem da composição do primário e estão sujeitos a flutuações estatísticas [94]. Estas são inerentes aos EAS devido tanto às interações hadrônicas quanto principalmente à profundidade atmosférica da primeira interação.

\section{4 $X_{\max }$ dos EAS}

A profundidade atmosférica do máximo $X_{\max }$ dos EAS é definida como a profundidade na qual o chuveiro alcança seu tamanho máximo, ou seja, onde o número de partículas carregadas que o compẽm é máximo. Como vimos no capítulo anterior, a maior contribuição do sinal no perfil longitudinal vem da cascata eletromagnética. Obtemos o $X_{\max }$ através do ajuste da função GH (equação 2.27) ao perfil longitudinal dos EAS. No AIRES, quatro parâmetros são ajustados na função GH: $N_{\max }, X_{0}, X_{\max }$ e $\lambda$ (seção 2.2 ).

Existem dois efeitos que são responsáveis por alterar o $X_{\max }$ dos EAS iniciados por fótons. O primeiro é o efeito LPM, importante a partir de energias $E \gtrsim 10 E e V$ e o segundo é o pre-shower que ocorre a partir $E \gtrsim$ $3 \times 10^{19} \mathrm{eV}$.

No efeito LPM as seções de choque de bremsstrahlung e produção de pares são reduzidas a altas energias ou em meios altamente densos. Isto ocorre devido à supressão da produção de pares e da emisão de fótons como con- 
sequência dos espalhamentos múltiplos dos fótons. Isto implica na supressão das seções de choques destes processos. Com isso, o $X_{\max }$ é "atrasado" no desenvolvimento longitudinal e ocorre mais profundamente na atmosfera.

No pre-shower o fóton primário interage com o campo magnético da Terra antes de chegar ao topo da atmosfera. Isto gera vários $e^{ \pm}$e $\gamma$ de mais baixas energias, que ao atingirem o topo da atmosfera continuam a desenvolver o chuveiro. Neste processo, a probabilidade de conversão do fóton inicial em outras partículas aumenta com a energia. Um chuveiro iniciado por um fóton com pre-shower se desenvolve mais cedo na atmosfera, tornando o perfil longitudinal parecido com o de chuveiros iniciados por hádrons. O efeito de pre-shower é implementado no AIRES através de um programa externo chamado MaGICS [95]. É importante ressaltar que modelos de campos geomagnéticos, tais como o IGRF [96], são essenciais para cálculos precisos do efeito de pre-shower.

Na Figura 3.1 temos o perfil longitudinal do evento de $E=3 \times 10^{20}$ eV observado pelo Fly's Eye [39], que é o evento mais energético detectado até hoje, comparado com simulações $\mathrm{MC}$ de chuveiros de fótons. A linha sólida é uma simulação completa com os efeitos LPM e pre-shower, as linhas pontilhadas são simulações sem os dois efeitos, enquanto as tracejadas contêm somente efeito LPM. A Figura 3.2 apresenta a taxa de elongação com os efeitos LPM e pre-shower, onde podemos ver como o $X_{\max }$ médio é modificado devido a estes efeitos na região de altíssimas energias.

Considere agora EAS iniciados por núcleos de próton e ferro com mesma energia inicial. Chuveiros de ferro se desenvolvem mais rapidamente na atmosfera e também atingem o seu máximo antes ds chuveiros de prótons. Isto tanto porque o núcleo de ferro tem uma seção de choque maior, tornando seu caminho livre médio menor, como também porque pode ser considerado como um conjunto de 56 nucleons livres, cada um com energia correspondente a 1/56 da energia total. Com isso, o ferro leva menos gerações para distribuir sua energia em partículas secundárias. Chuveiros iniciados por elementos de massas intermediárias têm o $X_{\max }$ entre os valores dos do próton e ferro.

A Figura 3.3 (a) mostra o perfil longitudinal de EAS iniciados por fótons 1 prótons e ferro, onde foram simulados 10 chuveiros verticais de energia $E=3 \times 10^{20} \mathrm{eV}$ com thinning $10^{-6}$, já ajustados com a função GH. Em média, os chuveiros de fótons não alcançam o máximo antes de atingir a superfície (a profundidade do Auger, por exemplo é de $\sim 870 \mathrm{~g} / \mathrm{cm}^{2}$ ). Note que nesta simulação a energia é altíssima. Em (b) temos a distribuição de $X_{\text {max }}$ para 1000 EAS com energia $5 \times 10^{19} \mathrm{eV}$ e thinning $10^{-5}$ iniciados por

\footnotetext{
${ }^{1}$ Todas as nossas simulações de fótons incluíram os efeitos LPM e pre-shower, a não ser que o contrário seja indicado.
} 


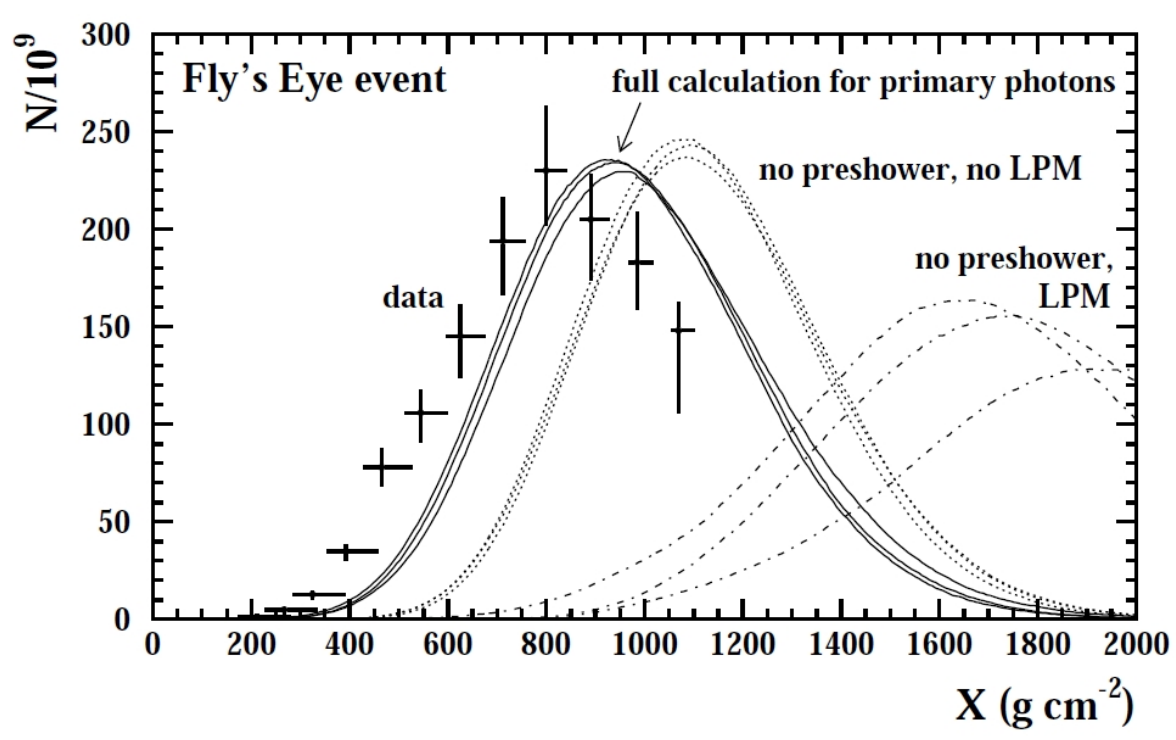

Figura 3.1: Perfil longitudinal do evento $E=3 \times 10^{20} \mathrm{eV}$ observado pelo Fly's Eye comparado com simulações MC de chuveiros iniciados por fótons primários de mesma energia com e sem os efeitos LPM e pre-shower. Extraída de [47].

prótons, ferro e fótons no intervalo de ângulo de $\left(0^{\circ}, 40^{\circ}\right)$, onde pode-se notar o efeito do pre-shower na distribuição de fótons em torno de $900 \mathrm{~g} / \mathrm{cm}^{2}$ como um pequeno máximo.

Chuveiros iniciados por prótons têm o seu máximo mais profundo na atmosfera do que os iniciados por ferro e os chuveiros de ferro flutuam menos do que chuveiros de prótons como podemos ver pela largura das distribuições. Estas características podem ser compreendidas através do modelo de superposição. Como consequência, em média é mais fácil discriminar chuveiros de fótons dos de ferro do que dos de prótons 97 .

Se o método de discriminação dos chuveiros iniciados por fótons é eficiente em relação aos prótons, ele será mais eficiente ainda para os núcleos. Os chuveiros iniciados por fótons de altíssimas energias $\left(E>5 \times 10^{18} \mathrm{eV}\right)$ incluem o efeito de pre-shower no seu desenvolvimento e, assim, se parecem com os de prótons. No entanto, os chuveiros de fótons não irão desenvolver muito a cascata hadrônica e a densidade de múons poderá ser um parâmetro adicional para discriminá-los dos iniciados por prótons. 


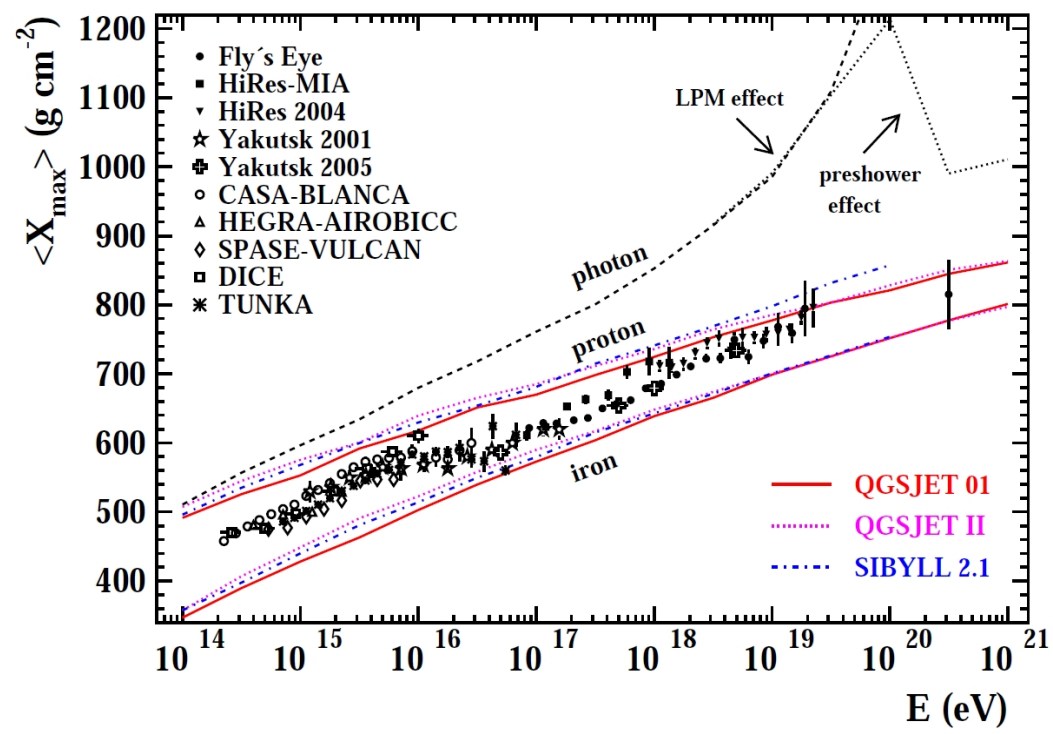

Figura 3.2: Profundidade atmosférica máxima média $X_{\max }$ em função da energia para simulações de prótons, ferro e fótons. Extraída de [47].

\subsection{Densidade de Múons}

A densidade de múons de EAS pode ser medida através dos SD espalhados na superfície da Terra. Quando um chuveiro se desenvolve na atmosfera dois processos ocorrem simultaneamente: o desenvolvimento da cascata eletromagnética e o da cascata hadrônica. Como vimos no Capítulo 2, chuveiros iniciados por fótons desenvolvem quase que somente a cascata eletromagnética, composta principalmente por $e^{-}, e^{+}$e $\gamma$. Chuveiros atmosféricos compostos tanto pela cascata eletromagnética como pela cascata hadrônica são, na sua grande maioria, iniciados por hádrons. Desta forma, o número de múons pode auxiliar na discriminação entre chuveiros de nucleons e de fótons.

A Figura 3.4 mostra o perfil lateral da densidade média de múons de EAS iniciados por núcleos de ferro, próton e fótons a energias (a) $5 \times 10^{19} \mathrm{eV}$ e (b) $3 \times 10^{20} \mathrm{eV}$ e ângulos de incidência que variam isotropicamente entre $0^{\circ}$ a $40^{\circ}$. Pode-se notar uma clara diferença na densidade de múons produzidos pelos chuveiros iniciados por estes primários.

Podemos estudar a média da densidade de múons em função dos vários ângulos de incidência $(\theta)$ e de sua energia para descobrir as melhores maneiras de utilizar esse parâmetro para separar a natureza primária dos UHECR. Esta análise está representada na Figura 3.5 para prótons com $E=5 \times 10^{19} \mathrm{eV}$. Podemos notar que próximo ao núcleo do chuveiro existe uma grande variação 


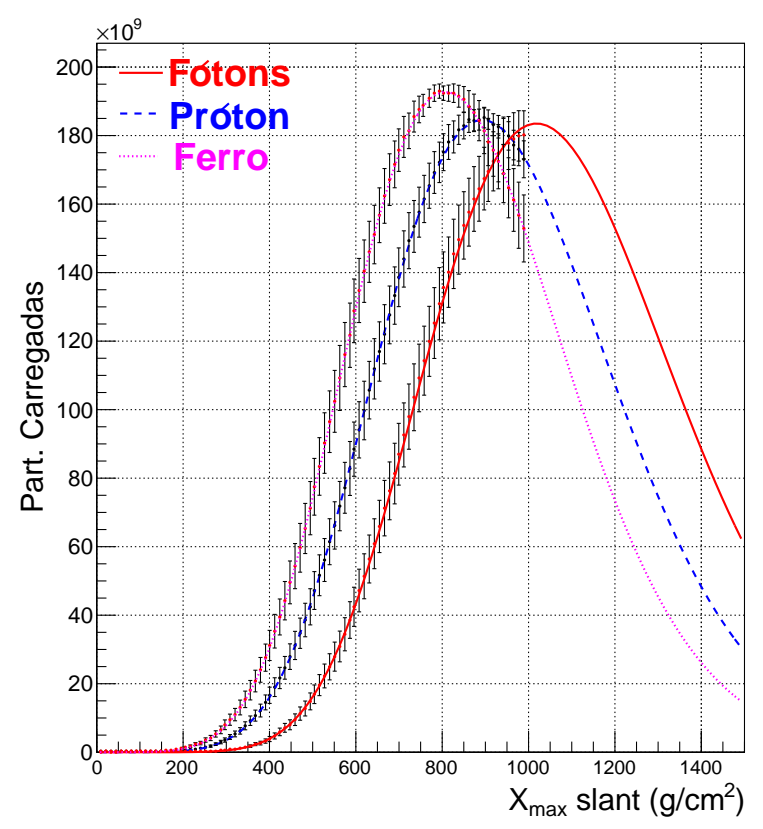

(a)

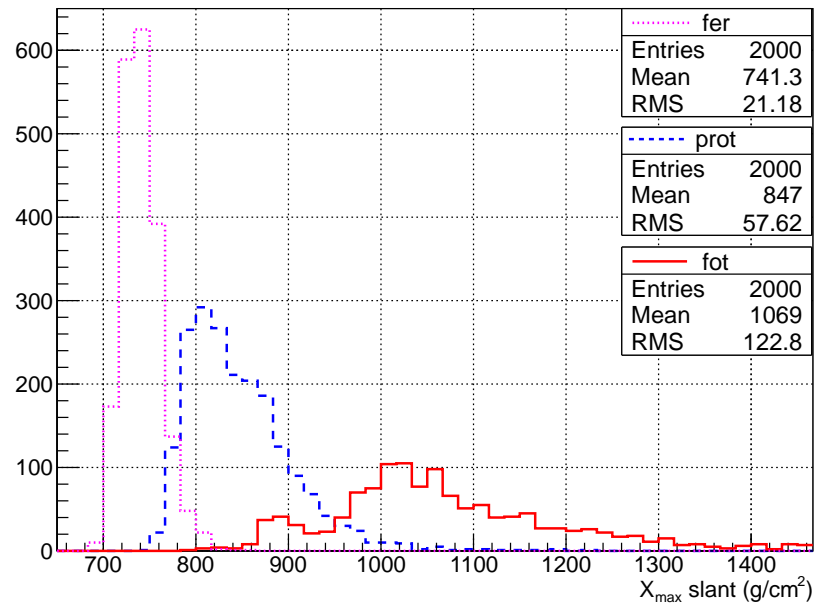

(b)

Figura 3.3: (a) Perfil longitudinal de chuveiros verticais com $E=3 \times 10^{20} \mathrm{eV}$ $\left(E_{t h}=10^{-6}\right)$ iniciados por prótons, ferro e fótons. (b) Distribuição do $X_{\max }$ para 1000 chuveiros de $E=5 \times 10^{19} \mathrm{eV}\left(E_{t h}=10^{-5}\right.$ e $\left.\left(0^{\circ}, 40^{\circ}\right)\right)$ iniciados por prótons, ferro e fótons. 
na densidade de múons em função do ângulo de incidência. Já a grandes distâncias, tais como $1000 m$, não há tanta variação.

Vamos investigar a densidade média de múons a uma distância fixa do chuveiro. A largura da distribuição de múons varia com a distância ao núcleo do chuveiro. Foram simulados 5000 eventos de fótons e prótons com energia inicial de $5 \times 10^{19} \mathrm{eV}$ e ângulo de incidência entre $0^{\circ}<\theta<20^{\circ}$. Na Figura 3.6 mostramos as distribuições das densidades de múons a 100, 1000 e 3000 metros do núcleo dos chuveiros. A $3000 \mathrm{~m}$ a flutuação é muito grande impedindo uma distinção das componentes. Por outro lado, a alta concentração de partículas de vários tipos próximo ao núcleo do chuveiro torna inviável a discriminação de múons nesta região, como é visto na distribuição a 100 m. No OPA, $1000 \mathrm{~m}$ do núcleo é a distância onde a soma das flutuações é mínima o que é evidenciado na figura. Assim, tomaremos a densidade de múons na distância de $1000 \mathrm{~m}$ do núcleo do chuveiro para investigar a composição primária. 


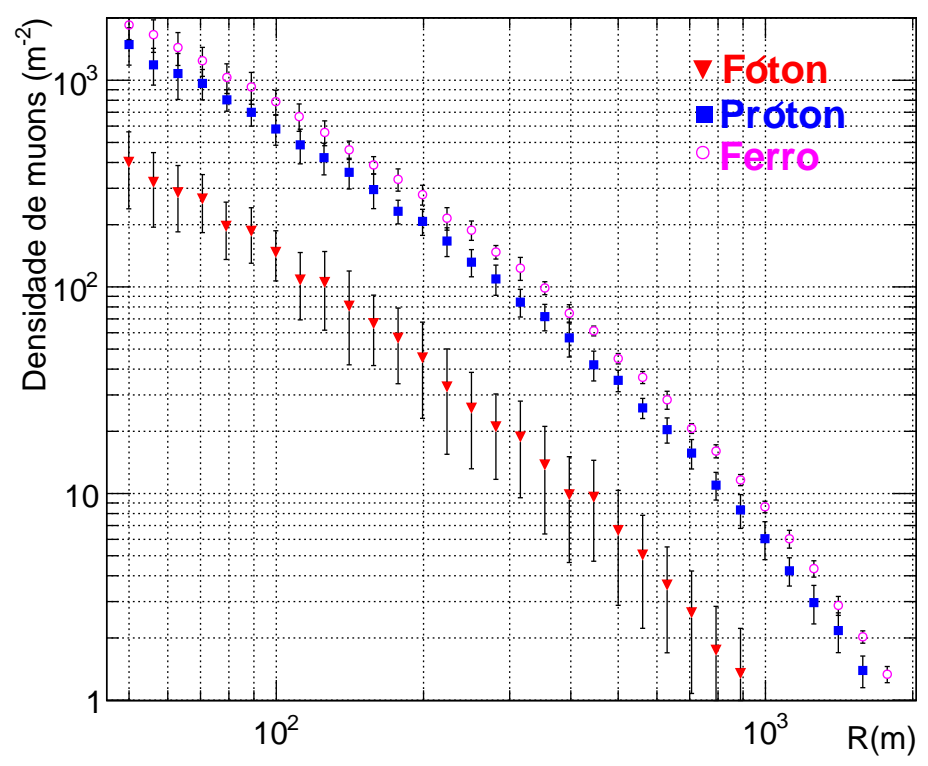

(a)

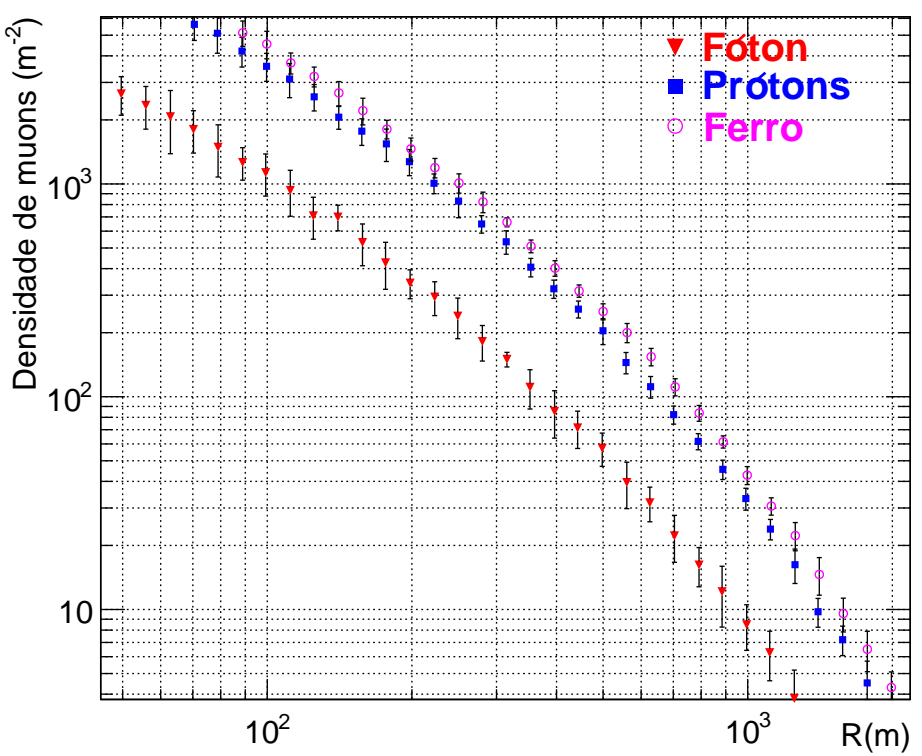

(b)

Figura 3.4: Densidade média de múons para chuveiros iniciados por ferro, próton e fóton à energia (a) $10^{19} \mathrm{eV}$ e (b) $10^{20} \mathrm{eV}$. Os ângulos de incidência do primário variam entre $0^{\circ}$ e $40^{\circ}$. 


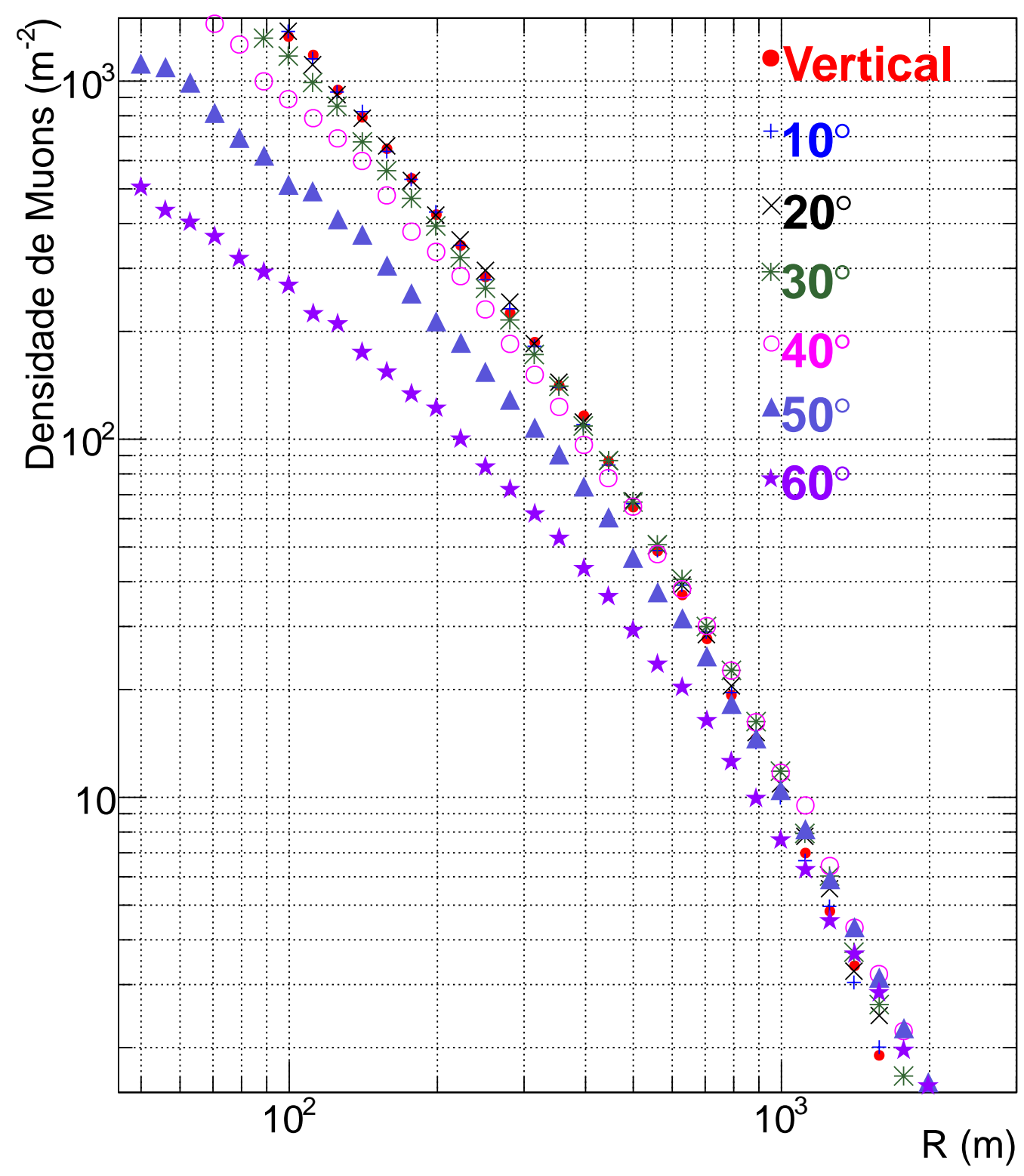

Figura 3.5: Densidade de múons para simulações de prótons de $5 \times 10^{19} \mathrm{eV}$ em função do ângulo zenital. 


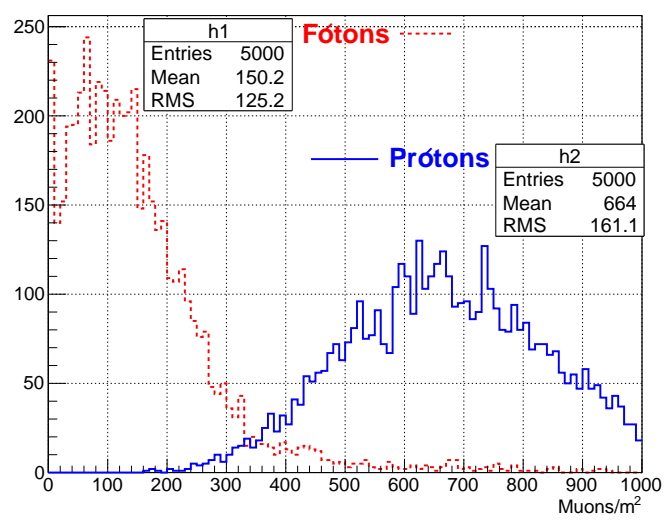

(a)

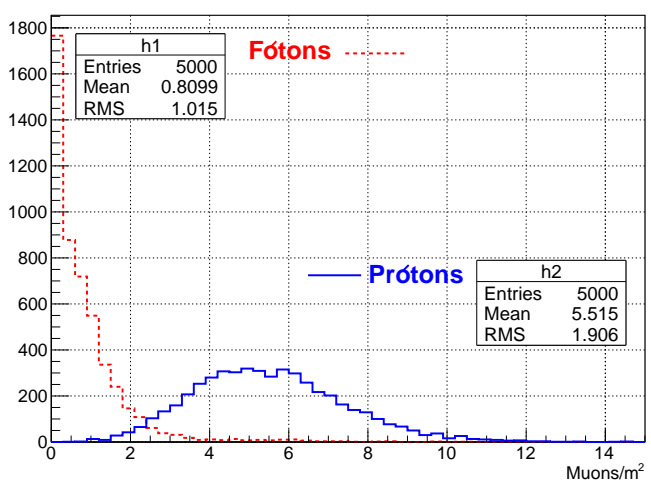

(b)

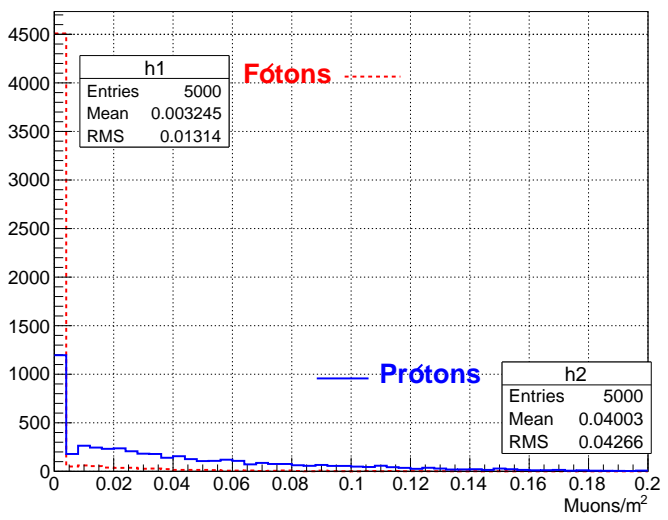

(c)

Figura 3.6: Distribuição da densidade de múons a $100 \mathrm{~m}, 1000 \mathrm{~m}$ e $3000 \mathrm{~m}$ do núcleo para chuveiro de prótons (azul-linha) e fótons (vermelho-traço), ambos com $E=5 \times 10^{19} \mathrm{eV}$. 


\section{Capítulo 4}

\section{Método de distinção dos EAS}

A profundidade atmosférica máxima $X_{\max }$ e a densidade de múons a 1000 $m$ do núcleo do chuveiro $\left(\rho_{1000}\right)$ são parâmetros que podem ser eficientes na distinção entre chuveiros iniciados por fótons dos por núcleos e nucleons, tal como apresentado no capítulo anterior nas análises feitas com simulações MC. Porém, como visto nas Figuras 3.3 e 3.6, as distribuições de cada um destes parâmetros quando resultantes de chuveiros iniciados por prótons, se sobrepõem às respectivas distribuições dos iniciados por fótons. Isto dificulta a determição dos primários dos EAS utilizando um baixo número de eventos, ou num caso extremo, em obter a composição primária de um único evento. Determinar métodos de distinção de chuveiros baseados em alta estatística pode ser um primeiro passo para encontrarmos uma combinação de parâmetros que nos auxilie na determinação da natureza primária dos UHECR em amostras com baixo número de eventos.

Nesta dissertação desenvolvemos um método simples para distinguir entre primários a partir de um número de eventos estatisticamente significativo. Este é ainda um primeiro passo e as incertezas, relacionadas tanto à detecção como à reconstrução dos dados, não serão levados em consideração. Esperamos num futuro próximo, partir deste método simples para um mais robusto, que possibilite esta distinção com um número mais baixo de eventos.

Iremos analisar chuveiros iniciados por prótons e fótons, buscando sua distinção primeiramente através das distribuições de um único parâmetro. Para tal, escolheremos um determinado valor para este parâmetro na região na qual as distribuições dos parâmetros dos chuveiros de fóton e do próton se sobrepõem. A região abaixo ou acima deste valor terá uma pureza de fótons otimizada. No caso da $\rho_{1000}$ valores acima do escolhido serão descartados, pois esperamos que os chuveiros de fótons desenvolvam menos múons do que os iniciados por prótons. No caso do $X_{\max }$ ocorre o contrário, onde eventos com valores abaixo do escolhido serão descartados, já que chuveiros iniciados 
por fótons têm a probabilidade maior de ter seu $X_{\max }$ mais profundo na atmosfera do que os iniciados por prótons.

Depois buscaremos um método que combine ambos os parâmetros. Neste caso, se os parâmetros do chuveiro obedecerem a condição de terem seu $X_{\max }$ maior e seu $\rho_{1000}$ menor do que os valores otimizados, ele é contado como um candidato a um chuveiro iniciado por fóton.

Iremos analisar conjuntos de chuveiros que geramos com o AIRES [4], buscando otimizar estes parâmetros de forma a separar uma amostra final com a melhor pureza possível de chuveiros de fótons. Inicialmente compararemos o método que analisa cada parâmetro individualmente com o método combinado determinando qual destes é mais eficiente. Utilizaremos a palavra "corte" para indicar o valor otimizado de cada parâmetro.

O nosso foco está nos eventos mais energéticos $\left(E>5 \times 10^{19} \mathrm{eV}\right)$, para os quais o limite superior para a fração de fótons é de $\sim 30 \%$, tendo sido determinada pelo OPA [1] e TA[3]. Assim, o nosso método deve ser eficiente para componentes fotônicas que correspondam a uma fração $\lesssim 30 \%$. Geramos, então, vários conjuntos de eventos contendo cada um diferentes frações de fótons. Por exemplo, um conjunto de chuveiros poderia ser formado por 5000 chuveiros dentro dos quais existem 250 iniciados fótons, correspondendo uma fração de $5 \%$ de chuveiros iniciados por fótons. Outra amostra poderia ser formada por 1000 chuveiros com 10\% de chuveiros iniciados por fótons e assim por diante.

Como o $\rho_{1000}$ varia com o ângulo de incidência separamos as amostras em cinco intervalos de ângulos: $\left(0^{\circ}, 20^{\circ}\right),\left(20^{\circ}, 30^{\circ}\right),\left(30^{\circ}, 40^{\circ}\right),\left(40^{\circ}, 50^{\circ}\right)$ e $\left(50^{\circ}, 60^{\circ}\right)$. Assim, dentro de cada um destes intervalos teremos diversas amostras com diferentes frações de chuveiros iniciados por fótons, como por exemplo $2 \%, 5 \%, 7 \%$... e 30\%, cada uma contendo 5000 chuveiros, onde a fração restante é constituída de chuveiros iniciados por prótons.

Os principais parâmetros utilizados para regular as simulações dos EAS no AIRES são: tipo de partícula, energia do primário, ângulo zenital (de incidência) e azimutal, sítio de observação e número de eventos a serem simulados, podendo também simular um conjunto de chuveiros com distintos primários, aos quais temos que estipular pesos estatísticos. Estabelecemos a energia de $E=5 \times 10^{19} \mathrm{eV}$, pois o número de eventos é alto comparado com os poucos eventos com energias acima de $10^{20} \mathrm{eV}$. O ângulo azimutal de cada evento varia isotropicamente entre o intervalo de $0^{\circ}<\phi<360^{\circ}$ e o zenital varia isotropicamente dentro dos intervalos citados acima. O sítio de observação será Malargüe, local onde se encontra o OPA, localizado geograficamente a $1416 \mathrm{~m}$ de altitude, $-35.47^{\circ}$ de latitude e $-69.58^{\circ}$ de longitude. Os chuveiros iniciados por fótons contém os efeitos LPM e preshower. 
Uma vez estabelecido nosso método, este será aplicado em amostras de chuveiros simulados para as quais desconhecemos a fração de chuveiros iniciados por fótons. Para tal, iremos gerar esta fração a partir de uma distribuição linear entre 0 e 30\%, fração esta encoberta e não conhecida. Ao final de nossa análise, após aplicarmos nosso método, verificaremos o valor desta fração, que foi guardada num arquivo, e compararemos nossa previsão com este valor.

\subsection{Cortes Individuais e Vinculados}

Nesta seção vamos apresentar e comparar os dois métodos de separação que discutimos acima, ou seja, a análise individual de cada parâmetro e da combinação destes. Os cortes otimizados para cada uma destas análises serão chamados, respectivamente, de cortes individuais e vinculados.

Considere uma amostra com 5000 chuveiros, ou eventos, no intervalo de ângulo zenital de $\left(0^{\circ}, 20^{\circ}\right)$. Nesta amostra temos $\sim 60 \%$ de prótons $\left(N_{p}=\right.$ 3016 eventos) e $\sim 40 \%$ de fótons $\left(N_{\gamma}=1984\right.$ eventos). Saímos do intervalo de $0 \%$ à $30 \%$ da fração de fótons, mas nossos resultados são válidos neste intervalo de fração como também para todos os ângulos de incidência. Estas amostras serão usadas apenas para comparar os dois métodos de análise dos parâmetros e não serão utilizadas na análise final.

A Figura 4.1 mostra as distribuições do $X_{\max }$ e do $\rho_{1000}$ construídas a partir da amostra considerada. Os cortes individuais otimizados foram definidos de forma a excluir o máximo número de prótons e minimizar a exclusão de fótons. A linha tracejada vertical verde representa o valor do corte em cada uma das distribuições.

O corte que maximiza e minimiza, respectivamente, a exclusão de prótons e de fótons é encontrado através da contagem dos eventos acima e abaixo do corte. No caso da distribuição do $X_{\max }$, variamos o valor do corte $\left(X_{c}\right)$ no intervalo $700 \mathrm{~g} / \mathrm{cm}^{2}<X_{c}<1100 / \mathrm{cm}^{2}$ que é a região de encontro das componentes em passos de $5 \mathrm{~g} / \mathrm{cm}^{2}$. Assim, ao varrer este intervalo, encontramos o valor $X_{c}$ para o qual o máximo e o mínimo de eventos de prótons e fótons são excluídos, respectivamente.

O corte para a densidade de múons $\rho_{c}$ também é feito através da contagem de eventos, como anteriormente, varrendo o intervalo 0 múons $/ m^{2}<\rho_{c}<$ 8 múons $/ m^{2}$ em passos de 0,2 múons $/ m^{2}$, onde agora excluímos os eventos acima deste valor.

Com este procedimento, o corte no $X_{\max }$ deve ser feito em $X_{c}=845$ $\mathrm{g} / \mathrm{cm}^{2}$ excluindo os eventos com $X_{\max }<X_{c}$. Isto resulta em $N_{\gamma}^{\prime}=1971$ fótons e $N_{p}^{\prime}=974$ prótons sobrevivendo ao corte, totalizando $N^{\prime}=2945$ eventos acima de $X_{c}$ e excluindo 2042 prótons e 13 fótons. Assim, na amostra 


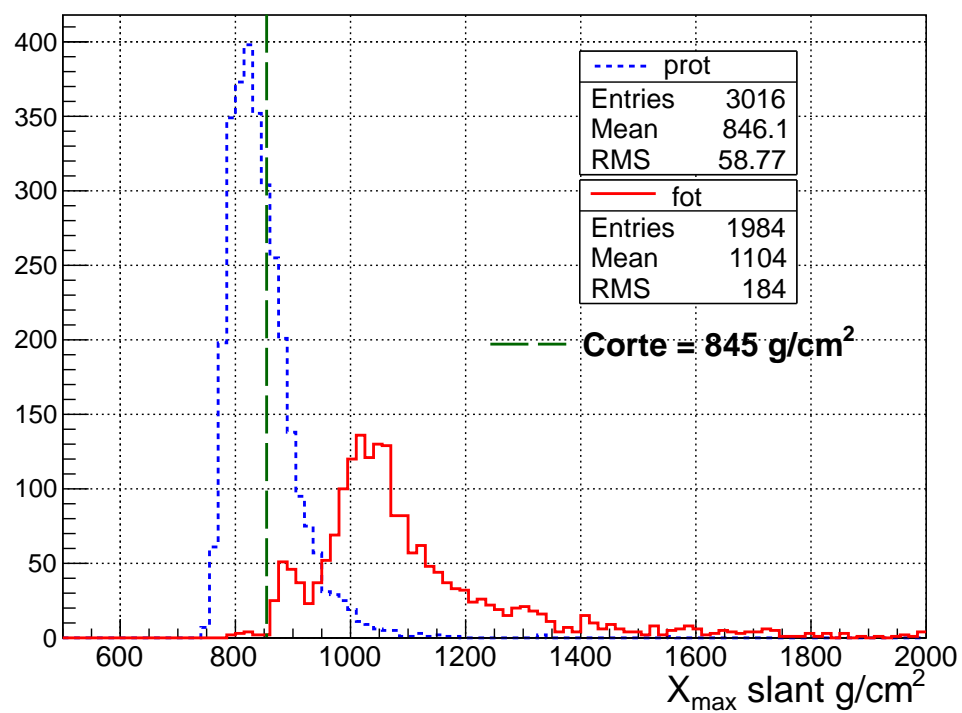

(a)

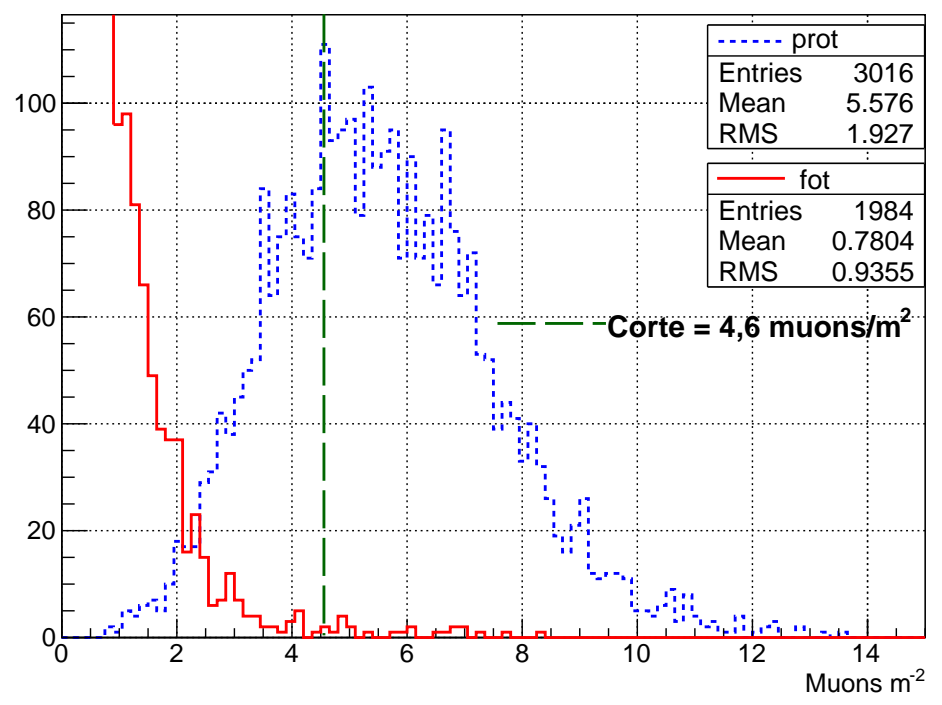

(b)

Figura 4.1: Distribuições do (a) $X_{\max }$ e (b) $\rho_{1000}$ de fótons (vermelho-sólido) e prótons (azul-tracejado). A linha verde-vertical tracejada indica o corte individual.

final temos uma contaminação relativa de $c=33 \%$ de prótons e uma pureza de $p=67 \%$ de fótons. 
Já para a $\rho_{1000}$ obtemos o corte em $4,6 m^{-2}$, com $N_{\gamma}^{\prime}=1963$ fótons e $N_{p}^{\prime}=$ 1026 prótons, totalizando em $N^{\prime}=2989$ eventos abaixo do $\rho_{c}$. Excluímos 1990 eventos de prótons e 20 de fótons, sendo a contaminação da amostra final de $c=34 \%$ de prótons e uma pureza $p=66 \%$. Estes procedimentos definem os cortes individuais.

Agora vamos apresentar os cortes vinculados, que são definidos como anteriormente mas exigindo condições simultâneas. Quando, para cada chuveiro, o $X_{\max }>X_{c}$ e o $\rho_{1000}<\rho_{c}$, este evento é considerado como um provável chuveiro iniciado por um fóton.

Para entendermos melhor este procedimento, considere a mesma amostra que utilizamos para aplicar os cortes individuais. Na Figura 4.2 (a) mostramos o $X_{\max }$ em função do $\rho_{1000}$, onde cada ponto representa um chuveiro da amostra de 5000 eventos. Os pontos vermelhos, mais concentrados na parte esquerda do gráfico, representam os fótons e os pontos azuis, centrados na parte de baixo à direita, os prótons. Os intervalos em que o $X_{\max }$ e $\rho_{1000}$ do próton e do fóton se encontram são respectivamente $700 \mathrm{~g} / \mathrm{cm}^{2}<X_{\max }<$ $1110 \mathrm{~g} / \mathrm{cm}^{2}$ e 0 múons $/ \mathrm{m}^{2}<\rho_{1000}<8$ múons $/ \mathrm{m}^{2}$, que define um retângulo no gráfico (a).

Fixamos, então, o valor mais baixo de $X_{\max }=X_{c}$ e varremos $\rho_{1000}$ no seu respectivo intervalo de passos de 0,2 múons $/ m^{2}$. A partir deste procedimento, geramos uma tabela com o número de eventos obtidos para cada valor do par $\left(X_{c}, \rho_{c}\right)$. O corte ótimo encontrado foi de $\left(850 \mathrm{~g} / \mathrm{cm}^{2}, 1 \mathrm{~m}^{-2}\right)$ e mostramos os eventos que a eles sobreviveram na Figura 4.2 (b). Estes totalizam $N^{\prime}=1416$ eventos, onde $N_{\gamma}^{\prime}=1413$ deles são fótons e $N_{p}^{\prime}=3$ são prótons, com 571 fótons perdidos.

Com o método combinado, conseguimos excluir a maioria dos eventos de prótons à custa de excluirmos cerca de $11 \%$ dos eventos de fótons (em relação ao totol de chuveiros iniciais), conseguindo uma pureza de $p=99,8 \%$ na amostra após o corte vinculado.

Neste método poderíamos também escolher um corte não otimizado. Este nos permitiria manter mais chuveiros de fótons na amostra final, mas às custas de diminuir a pureza da amostra. Por exemplo, poderíamos ter escolhido o par $\left(845 \mathrm{~g} / \mathrm{cm}^{2}, 4.6 \mathrm{~m}^{-2}\right)$, ao qual sobrevivem $N^{\prime}=2520$ eventos, com $N_{\gamma}^{\prime}=1960$ e $N_{p}^{\prime}=560$ prótons. Teríamos excluído apenas 24 eventos de fótons, mas a pureza se degradaria para $p=77,8 \%$.

Assim, os cortes vinculados nos fornecem duas possibilidades de refinar nossa análise: a pureza $p$ das amostras após os cortes e o número de eventos de fótons perdidos. Concluímos que os cortes vinculados são não apenas mais eficientes como mais flexíveis que os cortes individuais. Utilizaremos então os cortes vinculados, dado que este método consegue alcançar uma alta pureza de fótons na amostra final. 


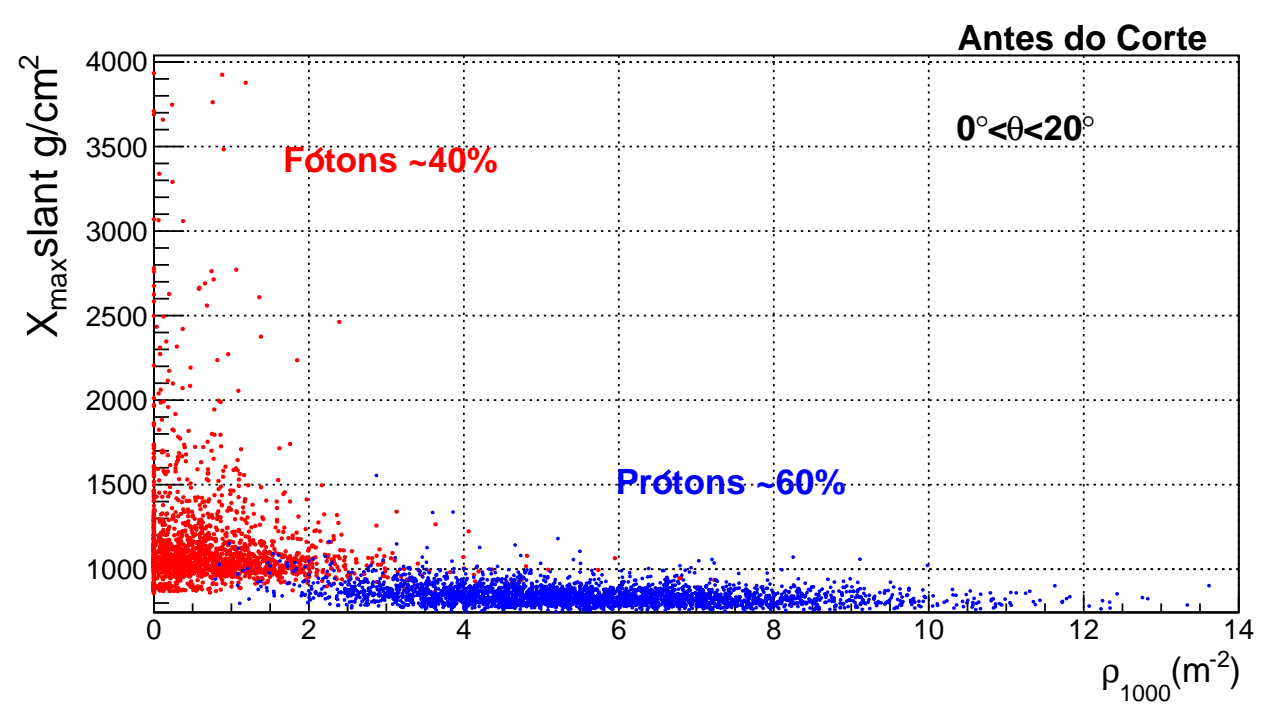

(a)

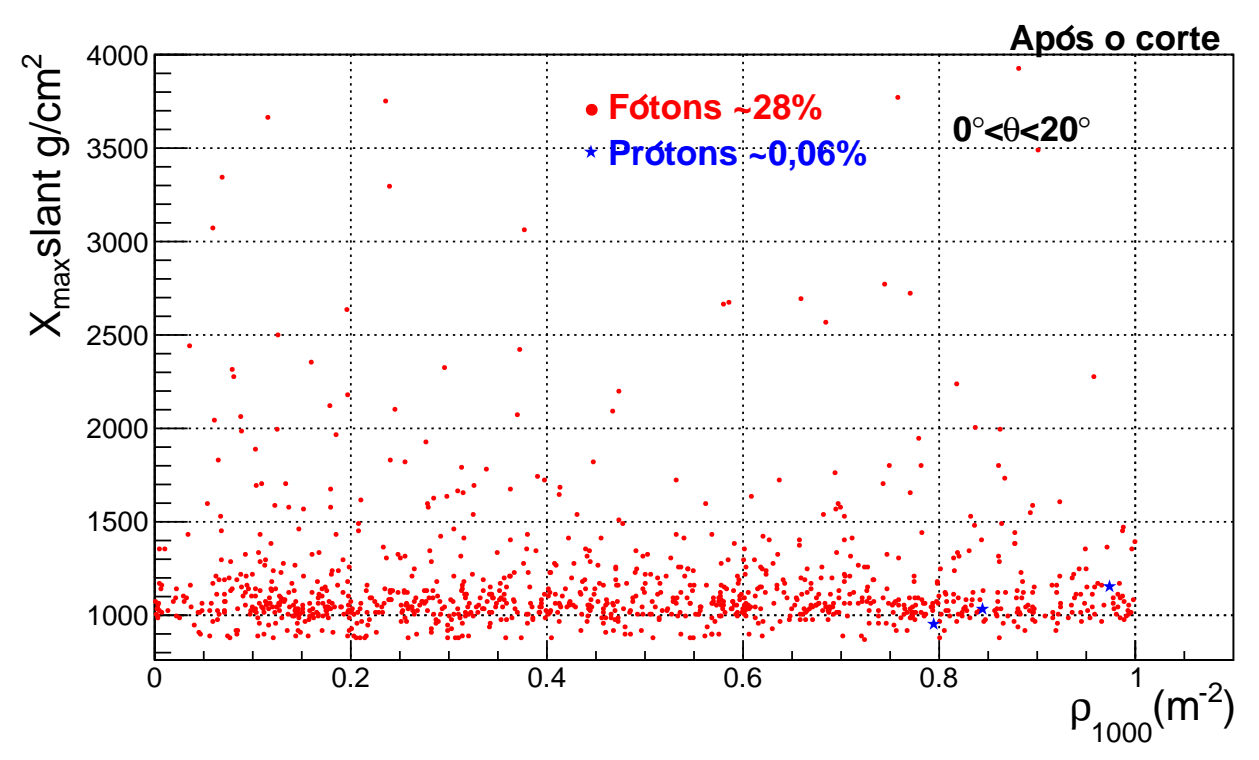

(b)

Figura 4.2: Gráficos do $X_{\max }$ em função da $\rho_{1000}$, onde cada ponto representa um evento: (a) antes de aplicarmos o corte e (b) após o corte. Dos fótons iniciais (a), sobreviveram $28 \%$ ao corte, mas reduzimos os prótons de 60 para 0,06\% (3 chuveiros iniciados por prótons). 


\subsection{Fator de qualidade e Otimização dos Cor- tes Vinculados}

Como descrito anteriormente, todos os chuveiros atmosféricos com o $X_{\max }>$ $X_{c}$ e $\rho_{1000}<\rho_{c}$ serão contados como prováveis EAS iniciados por fótons. Como um exemplo, a Tabela 4.1 mostra o número de eventos que sobrevivem a um corte específico $\left(940 \mathrm{~g} / \mathrm{cm}^{2}, 2.4\right.$ múons $\left./ \mathrm{m}^{2}\right)$, para amostras com diferentes frações de chuveiros iniciados por fótons, no intervalo de ângulo de incidência $\left(0^{\circ}, 20^{\circ}\right)$.

Tabela 4.1: Número ou fração de eventos que sobrevivem a um corte específico $\left(940 \mathrm{~g} / \mathrm{cm}^{2}, 2.4\right.$ múons $\left./ \mathrm{m}^{2}\right)$, para amostras de 5000 chuveiros com diferentes frações iniciais $f_{\gamma}$ de fótons no intervalo de ângulo $\left(0^{\circ}, 20^{\circ}\right) . N_{\gamma}^{\prime}$ e $N_{p}^{\prime}$ são, respectivamente, o número de fótons e de prótons sobreviventes ao corte e $p$ é a pureza de fótons na amostra final.

\begin{tabular}{lllll}
\hline \hline$f_{\gamma} \%$ & $N_{\gamma}^{\prime}$ & $N_{p}^{\prime}$ & $p \%$ & $N_{\gamma}^{\prime} / N_{\gamma}(\%)$ \\
\hline 1,7 & 79 & 48 & 62,2047 & 92,94 \\
4,42 & 191 & 44 & 81,2766 & 86,43 \\
7,12 & 303 & 46 & 86,8195 & 85,11 \\
9,88 & 416 & 49 & 89,4624 & 84,21 \\
20,74 & 900 & 33 & 96,463 & 86,79 \\
29,12 & 1245 & 32 & 97,4941 & 85,51 \\
\hline
\end{tabular}

Vamos agora investigar a pureza $p$ das amostras finais. Esta é mostrada em função de $f_{\gamma}$ na Figura 4.3 no intervalo de ângulo $\left(0^{\circ}, 20^{\circ}\right)$, para $\rho_{c}=2.4$ múons $/ \mathrm{m}^{2}$ e $X_{c}$ variando em passos de $2 \mathrm{~g} / \mathrm{cm}^{2}$ a partir de $940 \mathrm{~g} / \mathrm{cm}^{2}$. O gráfico no topo à esquerda é referente à Tabela 4.1. Os gráficos mostram que o valor da pureza depende da fração inicial de eventos e cai bastante quando a amostra inicial tem pouca fração de fótons. Isto ocorre para todos os ângulos de incidência.

Dado que, em uma amostra com eventos reais não sabemos a priori a fração de fótons, seremos obrigados a usar o mesmo corte, independente da fração de fótons da amostra inicial. Devemos, então, otimizar o corte, ou seja, o par $\left(X_{c}, \rho_{c}\right)$, que forneça em média a melhor pureza $p$ de fótons, de forma independente do $f_{\gamma}$.

Para este propósito usaremos o fator de qualidade " $q$ " [46], desenvolvido inicialmente para investigar a distinção entre chuveiros iniciados por prótons 

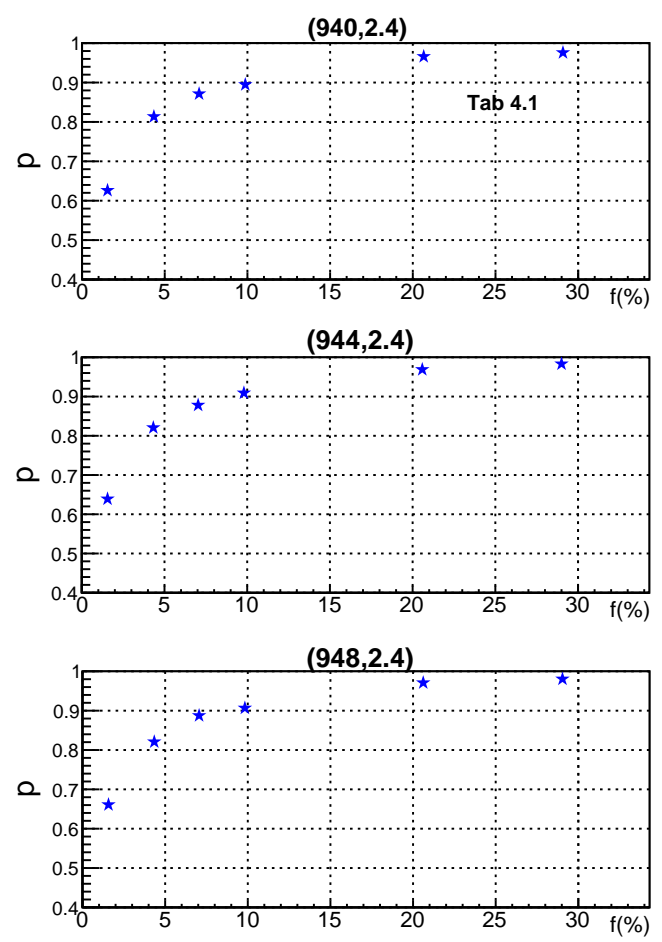
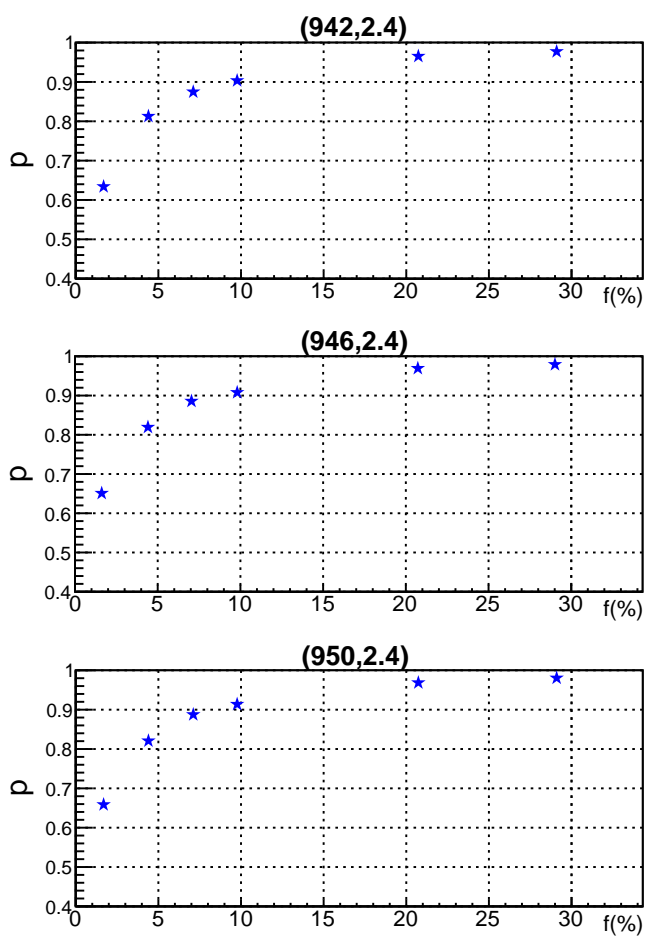

Figura 4.3: Gráficos da fração de eventos de fótons na amostra $f_{\gamma}$ versus o parâmetro de pureza $p$ para diversos cortes.

e uhecrons [45]. Este é dado por

$$
q=\frac{N_{\gamma}^{\prime}}{N_{\gamma}^{\prime}+N_{p}^{\prime}} N_{\gamma}^{\prime \alpha},
$$

onde $\alpha$ está relacionado com a pureza e a um número mínimo de eventos de fótons que queremos garantir na amostra final. Valores pequenos de $\alpha$ priorizam alta pureza na amostra final, enquanto que valores altos degradam a pureza, mas garantem um número significativo de fótons na amostra final. O corte ótimo é aquele que maximiza o fator $q$. Após variarmos este parâmetro, decidimos que um $\alpha$ baixo é mais adequado para o nosso método e escolhemos $\alpha=0.05$.

Submetemos, então, nossas amostras de chuveiros simulados, para os diferentes ângulos de incidência, a uma análise fina com passos de $5 \mathrm{~g} / \mathrm{cm}^{2}$ para o $X_{\max }$ e de 0.2 múons $/ m^{2}$ para o $\rho_{1000}$. Mostramos na Tabela 4.2 , para diferentes $f_{\gamma}$ iniciais e cortes otimizados (ambos na primeira coluna), os valores obtidos para o fator de qualidade $q$. Por exemplo, na primeira coluna, a amostra de $30 \%$ de fótons tem os cortes otimizados em $(850,1.2)$ com fator de qualidade $q=1.42$. Ao aplicar este corte em uma amostra com, 
por exemplo, $f_{\gamma}=20 \%$, teremos um $q=1.37$.

Note que dentro da precisão mostrada existe uma degenerescência nos valores dos cortes otimizados. Para sanarmos este problema, usamos todas as amostras em conjunto, totalizando 25000 chuveiros. Maximizamos, então, o fator de qualidade $q_{t}$ após aplicarmos os cortes descritos em cada linha desta coluna na amostra total. O resultado é o fator de qualidade total $q_{t}$ dado pela última coluna.

Tabela 4.2: Comparação entre os fatores de qualidade nas amostras, para o intervalo $\left(0^{\circ}, 20^{\circ}\right)$. Na $1^{\text {a }}$ coluna temos a fração inicial de fótons $f_{\gamma}$ e os cortes otimizados para $X_{\max }$ e $\rho_{1000}$, respectivamente. As outras colunas mostram o fator de qualidade destes cortes ao serem aplicados em amostras com diversos $f_{\gamma}$ conforme indicado no topo de cada coluna. Note que dentro da precisão usada, existem valores degenerados para o fator de qualidade. Na última coluna temos o fator de qualidade calculado para todas as frações.

\begin{tabular}{lllllll}
\hline$\left[f_{\gamma}(\%)\right]\left(\mathrm{g} / \mathrm{cm}^{2}\right.$, múons $\left./ \mathrm{m}^{2}\right)$ & $30 \%$ & $20 \%$ & $10 \%$ & $5 \%$ & $2 \%$ & $q_{t}$ \\
\hline$[30 \%](850,1,2)$ & 1.42 & 1.37 & 1.32 & 1.23 & 1.08 & 1.46 \\
{$[30 \%](855,1.2)$} & 1.42 & 1.37 & 1.32 & 1.23 & 1.08 & 1.46 \\
{$[30 \%](860,1.2)$} & 1.42 & 1.37 & 1.32 & 1.23 & 1.08 & 1.46 \\
{$[30 \%](865,1.2)$} & 1.42 & 1.37 & 1.32 & 1.23 & 1.08 & 1.46 \\
{$[20 \%](955,1.4)$} & 1.41 & 1.39 & 1.32 & 1.23 & 1.11 & 1.46 \\
{$[10 \%](840,1.0)$} & 1.41 & 1.37 & 1.33 & 1.25 & 1.13 & 1.46 \\
{$[10 \%](845,1.0)$} & 1.41 & 1.38 & 1.33 & 1.25 & 1.13 & 1.47 \\
{$[2 \%](930,0.9)$} & 1.40 & 1.37 & 1.32 & 1.25 & 1.22 & 1.46 \\
{$[2 \%](935,0.9)$} & 1.40 & 1.37 & 1.32 & 1.25 & 1.22 & 1.45 \\
\hline
\end{tabular}

O maior $q_{t}$ nos fornece o corte otimizado de $(845,1)$. O mesmo procedimento é feito para outros intervalos de ângulos de incidência. Na Tabela 4.3 mostramos os cortes otimizados para todos os intervalos de ângulos. Na Figura 4.4 mostramos a pureza em função da fração inicial de fótons para os cortes e ângulos mostrados na Tabela 4.3 .

Tabela 4.3: Cortes otimizados para diferentes intervalos de ângulos, tendo o $X_{c}$ $\left(\mathrm{g} / \mathrm{cm}^{2}\right)$ e o $\rho_{c}$ (múons $\left./ \mathrm{m}^{2}\right)$ entre parênteses.

\begin{tabular}{ll}
\hline Ângulos & Cortes otimizados \\
\hline $0^{\circ}<\theta<20^{\circ}$ & $(845,1.0)$ \\
$20^{\circ}<\theta<30^{\circ}$ & $(975,1.9)$ \\
$30^{\circ}<\theta<40^{\circ}$ & $(1030,2.3)$ \\
$40^{\circ}<\theta<50^{\circ}$ & $(1025,3.4)$ \\
$50^{\circ}<\theta<60^{\circ}$ & $(1015,3.1)$ \\
\hline
\end{tabular}



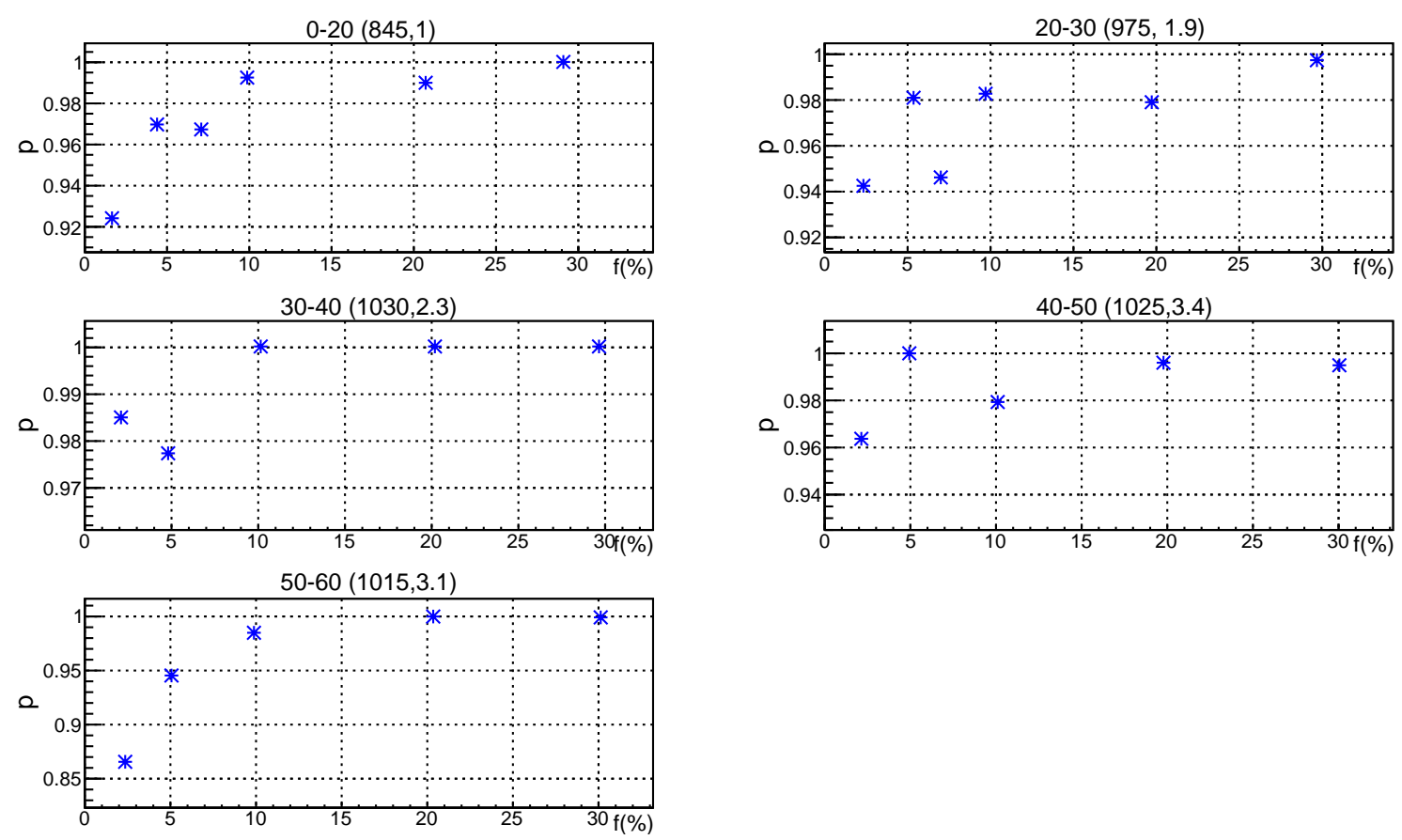

Figura 4.4: Pureza $p$ em função da fração inicial de fótons $f_{\gamma}$ na amostra. Os cortes otimizados e os intervalos de ângulos estão descritos no topo de cada gráfico.

Podemos notar nesta figura que a pureza, para os cortes otimizados, podem variar em 1\%. Na nossa análise, usaremos o valor médio da pureza no intervalo de fração 0 a 30\%. Estes valores estão listados na Tabela 4.4.

\section{3 "Blind" Analysis}

Em um conjunto de chuveiros reais não conhecemos a sua fração correspondente aos iniciados por fótons, sabemos apenas que, para energias acima de $5 \times 10^{19} \mathrm{eV}$, o seu limite superior é de $\sim 30 \%$. Com o objetivo de testar o nosso método sobre amostras com frações de fótons desconhecidas, vamos realizar uma blind analysis.

Simulamos $\mathrm{N}$ chuveiros contendo uma fração inicial $f_{\gamma}$ de fótons. A $f_{\gamma}$ é gerada aleatóriamente a partir da distribuição linear que vai de $0 \%$ à $30 \%$, e então guardada no arquivo que dará as instruções para simular os N chuveiros. Neste procedimento, o valor da fração inicial de fótons é encoberta ("blinded") e não conhecemos o seu valor. Aplicaremos então os cortes otimizados pré-estabelecidos através do fator de qualidade e, assim, estimaremos a fração de fótons inicial da amostra. Ao final, iremos "desmascarar" $f_{\gamma}$, 
verificaremos este valor no arquivo e compararemos este à nossa estimativa. Descreveremos abaixo cada passo desta análise.

Construímos a nossa amostra final a partir dos cortes listados na Tabela 4.3. Lembramos que os eventos que constituem a amostra final têm $X_{\max }>$ $X_{c}$ e $\rho_{1000}<\rho_{c}$. Devemos estimar o número de fótons contidos nesta amostra, lembrando que ela está contaminada por prótons. Esta estimativa será feita através da pureza média que está listada na Tabela 4.4 para os diferentes ângulos de incidência.

Tabela 4.4: Valores da pureza $p$ utilizadas para estimar a fração de fótons em uma amostra final.

\begin{tabular}{ll}
\hline$\hat{\text { Angulo }}$ & $\mathrm{p}$ \\
\hline $0^{\circ}<\theta<20^{\circ}$ & 0.96 \\
$20^{\circ}<\theta<30^{\circ}$ & 0.94 \\
$30^{\circ}<\theta<40^{\circ}$ & 0.98 \\
$40^{\circ}<\theta<50^{\circ}$ & 0.96 \\
$50^{\circ}<\theta<60^{\circ}$ & 0.86 \\
\hline
\end{tabular}

O número de fótons estimados na amostra final será dado por

$$
N_{\gamma e}^{\prime}=p N^{\prime}
$$

onde $N^{\prime}$ é o número de eventos na amostra final, a partir do qual determinamos a fração de fótons $f_{e}$.

Como exemplo, tomemos uma amostra de 1000 eventos com $f_{\gamma}=14 \%$, no intervalo de ângulo de incidência de $\left(0^{\circ}, 20^{\circ}\right)$. Aplicados os cortes otimizados, $N^{\prime}=93$ eventos são selecionados. Com isso, estimamos que temos na amostra final,

$$
N_{\gamma e}^{\prime}=(0,96) \cdot(93) \simeq 89
$$

fótons, e a fração correspondente é de

$$
f_{e}=89 / 1000=0,089 .
$$

Se compararmos o valor $f_{e}$ com a fração real $f_{\gamma}=0,14$, temos que

$$
\Delta f=f_{e}-f_{\gamma}=0,089-0,14=-0,051,
$$

ou seja, a fração estimada é $5 \%$ menor que a real. Como veremos abaixo, este é um efeito sistemático de nossa análise e será levado em consideração.

Para a nossa "blind" analysis simulamos quatro conjuntos com $N=$ 10.000 chuveiros cada um, com $f_{\gamma}$ escolhido aleatóriamente no intervalo de 
ângulo $\left(0^{\circ}, 20^{\circ}\right)$. Já no intervalo de ângulo $\left(20^{\circ}, 30^{\circ}\right)$ simulamos um conjunto contendo $N=10.000$ eventos. A Tabela 4.5 abaixo mostra o resultado de nossa análise, onde as quatro primeiras colunas se referem ao intervalo de ângulo $\left(0^{\circ}, 20^{\circ}\right)$ e cortes $(845,1)$ conforme a Tabela 4.3 . A quinta análise se refere ao intervalo $\left(20^{\circ}, 30^{\circ}\right)$ com corte $(975,1.9)$. Porém, a fração esperada $f_{e}$ ainda não corresponde ao nosso resultado final, dado que esta está sistematicamente abaixo da real. Descreveremos os próximos passos, onde consideraremos a fração sistemática na próxima seção. Lembramos que até este estágio da análise ainda não conhecemos a fração de fótons inicial de cada amostra.

Tabela 4.5: Tabela das nossas análises. Somente os valores acessíveis após o corte são conhecidos.

\begin{tabular}{llllll}
\hline Análise & $1^{\mathrm{a}}$ & $2^{\mathrm{a}}$ & $3^{\mathrm{a}}$ & $4^{\mathrm{a}}$ & $5^{\mathrm{a}}$ \\
$\mathrm{N}^{\mathrm{o}}$ eventos iniciais & 10000 & 10000 & 10000 & 10000 & 10000 \\
$\mathrm{~N}^{\mathrm{o}}$ eventos finais & 730 & 575 & 1429 & 149 & 1296 \\
$\mathrm{~N}^{\mathrm{o}}$ de fótons estimados & 701 & 552 & 1372 & 143 & 1218 \\
\hline$f_{e}(\%)$ & 7,01 & 5,52 & 13,72 & 1,43 & 12,18 \\
\hline
\end{tabular}

\subsubsection{Erros Inerentes à Análise}

Como vimos na seção anterior, ao aplicarmos os cortes otimizados sobre a amostra inicial de chuveiros simulados, muitos eventos de fótons são perdidos, pois o nosso método foi construído para manter a pureza nas amostras finais. Como descreveremos a seguir, simulamos novos conjuntos de chuveiros para analisar este erro sistemático.

Simulamos $N=1000$ chuveiros com $2 \%$ de fótons, outros $N=1000 \mathrm{com}$ $5 \%$, e assim por diante até o último conjunto com $30 \%$, todos estes conjuntos no intervalo de ângulo de incidência $\left(0^{\circ}, 20^{\circ}\right)$. Aplicamos os cortes otimizados $(845,1)$ sobre estas amostras e estimamos a fração de fótons $f_{e}$ como descrito na seção anterior. Comparamos a fração $f_{e}$ com a fração inicial de fótons $f_{\gamma}$, lembrando que, neste caso, $f_{\gamma}$ é conhecido. Repetimos este procedimento várias vezes com novos conjuntos de 1000 chuveiros para diversas frações iniciais de fótons, totalizando 78.000 chuveiros.

A Figura 4.5 mostra os resultados desta análise através da distribuição relativa de erros. Ajustamos, com método dos mínimos quadrados, uma gaussiana a esta distribuição. Em média, o valor da fração estimada $f_{e}$ está $41,6 \%$ abaixo da fração inicial $f_{\gamma}$. Assim, para estimarmos a fração inicial $f_{\gamma}$ devemos corrigir a fração esperada $f_{e}$ por este valor, que será denotada 
por $f_{e c}$. A Figura 4.6 mostra a distribuição dos erros relativos, agora entre a fração estimada corrigida pelo erro sistemático em relação à fração inicial.

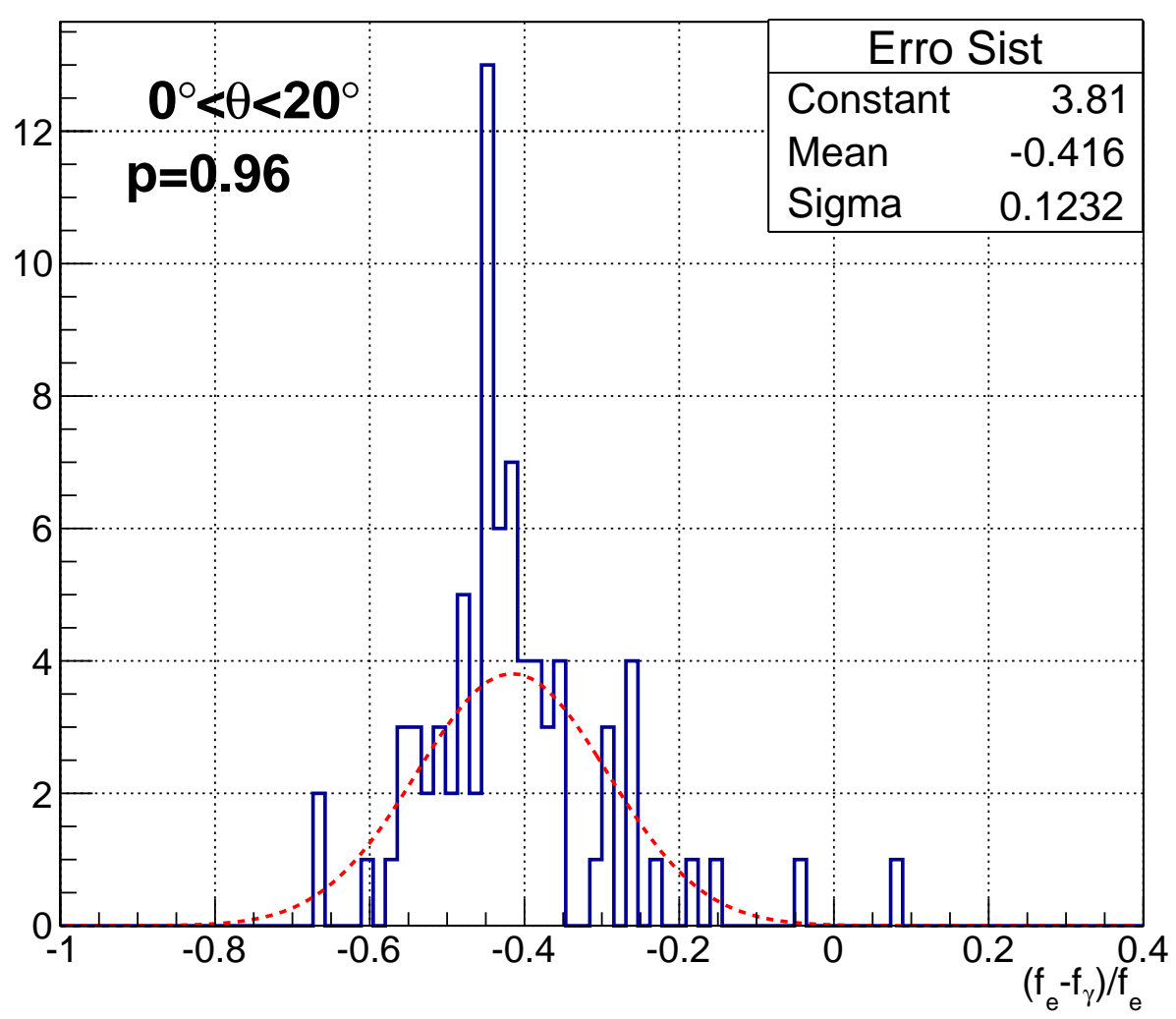

Figura 4.5: Distribuição relativa de erros correspondente à fração de fótons das amostras iniciais e finais. Foram utilizado 78.000 chuveiros nesta análise.

Ajustamos a esta nova distribuição de erros outra gaussiana obtendo então o erro intrínseco ao nosso método. Este é dado em função do desvio padrão, de $\sigma_{m e t} \simeq 12 \%$. Notamos que a distribuição é dada em relação à $f_{e c}$, pois conhecemos $f_{e c}$ e não $f_{\gamma}$. Assim, a incerteza do método será dado por $\sigma_{m e t}=$ $12,23 \% f_{e c}$.

Por último, temos o erro estatístico, dado por $1 / \sqrt{N}$. Como temos na "blind" analysis $N=10.000$, o erro estatístico relativo é de $1 \%$. Como este valor relativo é muito baixo não o expressaremos nos resultados finais. 


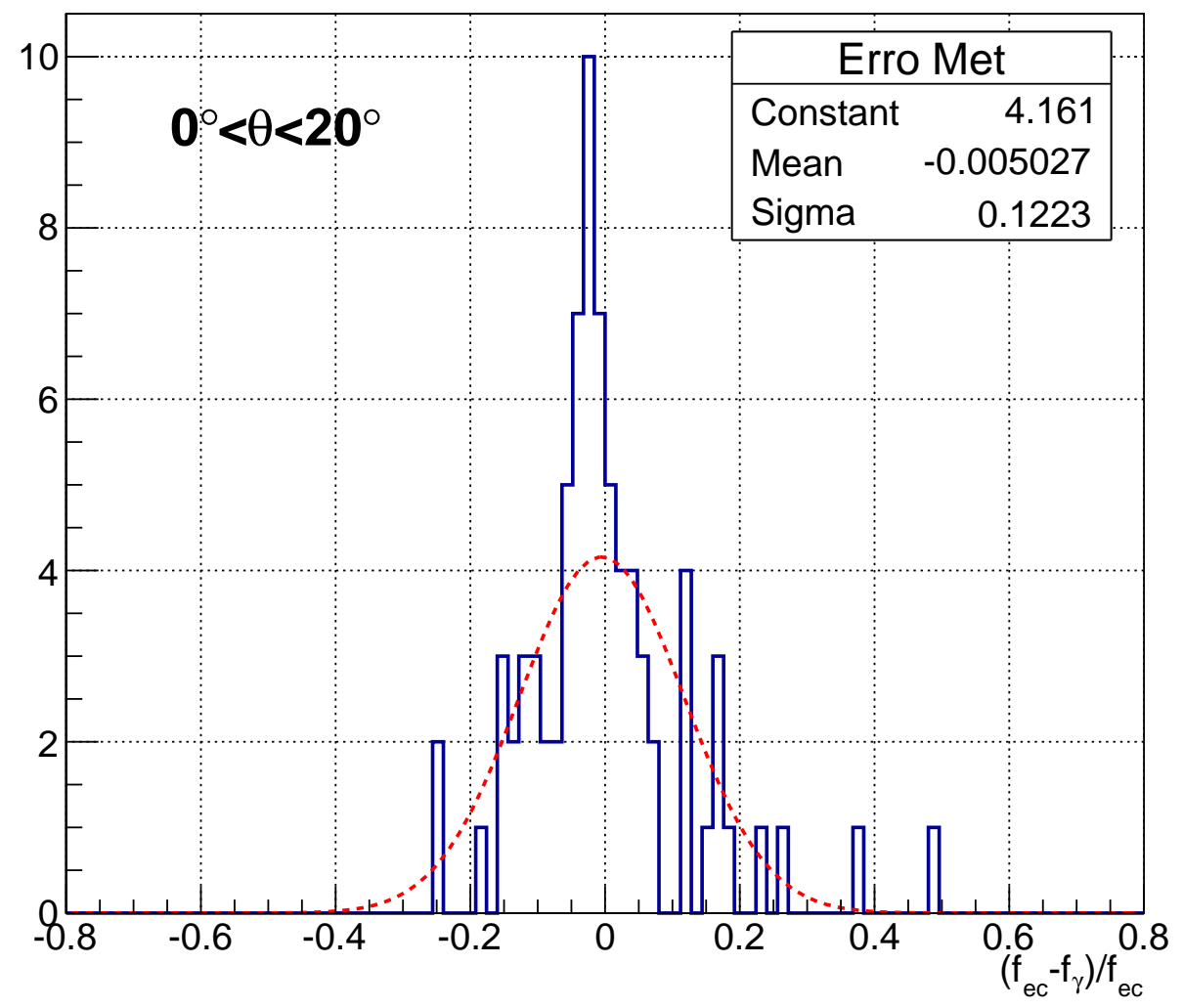

Figura 4.6: Idem à Figura 4.5, mas agora com a fração de fótons estimada corrigida pelo erro sistemático. 


\subsubsection{Resultados}

Munidos dos erros, voltamos às nossas "blind" analysis da Tablela 4.5. Estas análises contêm somente dois intervalos de ângulos de incidência, de $\left(0^{\circ}, 20^{\circ}\right)$, as quatro primeiras análises, e de $\left(20^{\circ}, 30^{\circ}\right)$, a quinta análise. Na seção anterior encontramos a incerteza para o intervalo de $\left(0^{\circ}, 20^{\circ}\right)$ e o mesmo procedimento é realizado para o outro intervalo de ângulo de incidência.

A Tabela 4.6 lista os resultados das nossas análises, onde a fração de fótons estimada foi corrigida sistematicamente $f_{e c}$, com $f_{c e}=1,416 f_{e}$. Este resultado tem uma incerteza de $\sigma_{m e t}=12,23 \% f_{\text {ec }}$.

Tabela 4.6: Tabela das amostras finais.

\begin{tabular}{llllll}
\hline Análise & $1^{\mathrm{a}}$ & $2^{\mathrm{a}}$ & $3^{\mathrm{a}}$ & $4^{\mathrm{a}}$ & $5^{\mathrm{a}}$ \\
$\mathrm{N}^{\mathrm{o}}$ eventos iniciais & 10000 & 10000 & 10000 & 10000 & 10000 \\
$\mathrm{~N}^{\mathrm{o}}$ eventos finais & 730 & 575 & 1429 & 149 & 1296 \\
$\mathrm{~N}^{\mathrm{o}}$ de Fótons Estimados & 701 & 552 & 1372 & 143 & 1218 \\
\hline$f_{e}$ & 7,01 & 5,52 & 13,72 & 1,43 & 12,2 \\
$f_{c e} \pm \sigma_{\text {met }}$ & $9,93 \pm 1,21$ & $7,82 \pm 0,96$ & $19,43 \pm 2,38$ & $2,02 \pm 0,25$ & $16,21 \pm 0,83$ \\
$f_{\gamma}$ & 10,02 & 8,14 & 19,74 & 1,91 & 16,23 \\
\hline
\end{tabular}

Agora que determinamos os valores estimados para a fração de fótons referentes aos conjuntos de chuveiros simulados, vamos revelar as $f_{\gamma}$ da entrada de nossas análises. Estas são mostradas na última linha da tabela. Todas as nossas estimativas para $f_{e c} \pm \sigma_{m e t}$ são compatíveis com as frações $f_{\gamma}$ de entrada, dentro de $1 \sigma_{m e t}$. Iremos discutir estes resultados no próximo capítulo. 


\section{Capítulo 5}

\section{Conclusões}

As distribuições dos parâmetros $X_{\max }$ e $\rho_{1000}$ foram utilizadas para analisar duas formas de discriminação entre chuveiros iniciados por fótons dos por prótons. Chamamos estas duas formas de método individual e vinculado.

Enquanto o método individual mantém uma alta contaminação de fótons na amostra final, o método vinculado permite obter uma alta pureza de fótons. Outra vantagem deste último método é que ele não exclui um grande número de chuveiros de fótons ou, no máximo, exclui a mesma quantidade que no método individual. Desta forma, o segundo método é mais eficiente.

Nossos resultados, a partir de uma "blind" analysis, mostram a compatibilidade entre nossas estimativas e as $f_{\gamma}$ de entrada. Assim, apesar do nosso método ser bastante simples, ele é bastante eficiente. É claro que para tornarmos nosso método mais robusto, teremos que incluir as incertezas referentes à detecção e reconstrução. Veremos, então, que enquanto o $X_{\max }$ é uma medida bem estabelecida e de acesso direto pelo FD, a densidade de múons não é acessível diretamente. Ela é medida através de amostragens na superfície da Terra e a sua estimativa depende dos modelos das interações dos hádrons. Desta forma, a eficiência de um método baseado no nosso, mas mais robusto, depende de determinar eficientemente o parâmetro $\rho_{1000}$. Existe uma esforço das colaborações nos experimentos de UHECR para conseguir determinar este parâmetro, tal como o AMIGA do OPA. Este esforço se dá tanto ao nível de desenvolvimento de detectores, como no desenvolvimento de técnicas de análise.

Outro ponto a ressaltar é que simulamos os conjuntos de chuveiros somente para $E=5 \times 10^{19} \mathrm{eV}$. A mais altas energias os efeitos LPM e preshower influenciam cada vez mais os chuveiros iniciados por fótons. Necessitamos, portanto, testar o nosso método para energias maiores que $5 \times 10^{19}$ $e V$, verificando a dependência da eficiência de nosso método em relação à energia. 
Daremos continuidade às nossas análises com o objetivo de encontrar as incertezas do método nos intervalos de ângulos restantes e para diferentes energias do primário maiores que $E>5 \times 10^{19} \mathrm{eV}$. Levaremos também em consideração tanto os efeitos de detecção do SD e do FD como da reconstrução de dados.

A informação do $X_{\max }$ combinado com $\rho_{1000}$ é bastante eficiente na distinção entre fótons e prótons e, consequentemente, por núcleos, quando houver um número significativo de eventos. Assim, este método de análise constitue um primeiro passo para a obtenção de um método mais robusto para distinguir chuveiros iniciados por fótons daqueles iniciados por prótons e núcleos e que seja eficiente para um número baixo de eventos. 


\section{Referências Bibliográficas}

[1] Auger Collab., Upper limit on the cosmic-ray photon fraction at EeV energies from the Pierre Auger Observatory, Astroparticle Physics 31 (2009) 399-406, doi:10.1016/j.astropartphys.2009.04.003

[2] The Pierre Auger Collaboration, Upper limit on the cosmic-ray photon flux above $10^{19} \mathrm{eV}$ using the surface detector of the Pierre Auger Observatory, arXiv:0712.1147, Astropart.Phys.29:243-256,2008.

[3] Telescope Array Collaboration, Upper limit on the flux of photons with energies above $10^{19} \mathrm{eV}$ using Telescope Array surface detector, arXiv:1304.5614.

[4] S. J. Sciutto, AIRES: A system for air shower simulations, User's guide and reference manual, Versão 2.6.0., 11 de Julho de 2002,

[5] http://www.cdcc.usp.br/ciencia/artigos/art_50/raios_ cosmicos.html, 15 de janeiro de 2013.

[6] Bruno Rossi, Cosmic Rays, New York: McGraw-Hill, 1964.

[7] From Ultra Rays to Astroparticles: A Historical Introduction to Astroparticle Physics, editado por Brigitte Falkenburg, Wolfgang Rhode, Springer, December 29, 2012.

[8] Bothe, W. 1929. Zur Vereinfachung von Koinzidenzzählungen. Z. Phys. 59: $1-5$

[9] Rossi, B. 1930. Method of Registering Multiple Simultaneous Impulses of Several Geiger's Counters. Nature 125: 636

[10] Karl-Heinz Kampert and Alan A. Watson, Extensive air showers and ultra high-energy cosmic rays: a historical review, Eur. Phys. J. H 37, 359-412 (2012). 
[11] Bhabha, H. and W. Heitler. 1937. The passage of fast electrons and the theory of cosmic showers. Proc. Roy. Soc. A 159: 432-458

[12] Blackett, P.M.S. and G. Occhialini. 1932. Photography of penetrating corpuscular radiation. Nature 130: 363

[13] Fretter, W.B. 1949. Proceedings of Echo Lake Cosmic Ray Symposium.

[14] Rossi, B. 1934. Misure sulla distribuzione angolare di intensita della radiazione penetrante all' Asmara. Supplemento a la Ricerca Scientifica 1: 579

[15] Mariangela Settimo, Hybrid Detection of Ultra High Energy Cosmic Rays with Pierre Auger Observatory. Tese, 2009/2010. Pierre Auger Collaboration Technical Note. GAP-2010-130

[16] V. L. Ginzburg, S. I. Syrovatskii, The Orign of Cosmic Rays, New York: Macmillan, 1964

[17] J. Abraham et al. The Pierre Auger Collaboration,Observation of the Suppression of the Flux of Cosmic Rays above $4 \times 1019 \mathrm{eV}$, Phys. Rev. Lett. 101, 061101 (2008).

[18] R. U. Abbasi et al. High Resolution Fly's Eye Collaboration, First Observation of the Greisen-Zatsepin-Kuzmin Suppression, Phys. Rev. Lett. 100, 101101 (2008).

[19] Greisen, K., End to the Cosmic-Ray Spectrum?, Phys. Rev. Lett., 16, $748,1966$.

[20] Zatsepin, G.T. and Kuz'min, V.A., Upper Limit of the Espectrum of Cosmic Rays, J. Exp. Theor. Phys. Lett. 4,78 (1966).

[21] http://www-conf.slac.stanford.edu/ssi/2004/lec_notes/ stanev/

[22] F. A. Aharonian, J. W. Cronin, Influence of the universal microwave background radiation on the extragalactic cosmic-ray spectrum, Phys. Rev. D, 50,3.

[23] Auger Project Design Report, Second Edition - November 1996, Revised - March 1997.

[24] J.W. Cronin, The highest-energy cosmic rays, Nuclear Physics B (Proc. Suppl.) 138 (2005) 465-491. 
[25] Pijushpani Bhattacharjee, Günter Sigl, Origin and propagation of extremely high-energy cosmic rays, Physics Reports 327 109-247 (2000).

[26] E. Fermi, On the Origin of the Cosmic Radiation, Phys. Rev. 75 (1949) 1169.

[27] Axford, W., E. Lear, and G. Skadron, Proceedings of the 15th ICRC (Plovdiv, Bulgaria) (Bulgarian Academy of Sciences, Sofia, Bulgaria), Vol. 11, p. 132.

[28] Krymsky, G. F., Docl. Akad. Nauk SSSR 243, 973, 1977.

[29] Bell, A. R., 1978, Mon. Not. R. Astron. Soc. 182, 443.

[30] Blandford, R., and D. Eichler, Particle Acceleration by Astrophysical Shocks, 1987, Phys. Rep. 154, 1.

[31] Antoine Letessier-Selvon and Todor Stanev. Ultrahigh Energy Cosmic Rays. Rev. Mod. Phys., 83:907-942, 2011.

[32] Hillas A. M., The Origin of Ultra-High-Energy Cosmic Rays, Ann. Rev. Astr. Astrophys. 22,425., 1984.

[33] P Sommers and S Westerhoff, Cosmic ray astronomy, 2009 New J. Phys. 11055004 doi:10.1088/1367-2630/11/5/055004

[34] Waxman, E., Cosmological Gamma-Ray Bursts and the Highest Energy Cosmic Rays, Phys. Rev. Lett. 75, 386 (1995).

[35] Vietri, M., The Acceleration of Ultra-High-Energy Cosmic Rays in Gamma-Ray Bursts, Astrophys. J. 453, 883 (1995).

[36] Milgrom, M., and V. Usov, Possible Association of Ultra-High-Energy Cosmic-Ray Events with Strong Gamma-Ray Bursts, Astrophys. J. 449, L37 (1995).

[37] Linsley, John, Evidence for a Primary Cosmic-Ray Particle with Energy $10^{20} \mathrm{eV}$, PhysRevLett. 10, 146, 1963.

[38] M. Takeda et al., Astrophys. J. 522, 225 (1999)

[39] D. J. Bird et al., Detection of a cosmic ray with measured energy well beyond the expected spectral cutoff due to cosmic microwave radiation, Astrophys. J. 441, 144-150 (1995).

[40] http://pdg.lbl.gov/2012/figures/figures.html, 22 de outubro de 2012. 
[41] The Pierre Auger Collaboration, Measurement of the Depth of Maximum of Extensive Air Showers above $10^{18} \mathrm{eV}$, Phys.Rev.Lett.104:091101,2010, arXiv:1002.0699

[42] Hires Collaboration, Indications of Proton-Dominated Cosmic Ray Composition above 1.6 EeV, Phys.Rev.Lett.104:161101, 2010, arXiv:0910.4184.

[43] The Pierre Auger Collaboration, Anisotropy and chemical composition of ultra-high energy cosmic rays using arrival directions measured by the Pierre Auger Observatory, JCAP06 (2011) 022, arXiv:1106.3048

[44] Albuquerque, Ivone F.M. and Chou, Aaron, A Faraway Quasar in the Direction of the Highest Energy Auger Event, Journal of Cosmology and Astroparticle Physics, 08, 016, 2010.

[45] Albuquerque, Ivone F. M. and Farrar, Glennys R. and Kolb, Edward W., Exotic massive hadrons and ultrahigh energy cosmic rays, Phys. Rev. D 59, 015021 (1998).

[46] Albuquerque, Ivone F. M. and Carvalho, Washington R., Detection of exotic massive hadrons in ultrahigh energy cosmic ray telescopes, Phys. Rev. D 80, 023006 (2009).

[47] Markus Risse, Piotr Homola, Search for Ultra-High Energy Photons Using Air Showers, Modern Physics Letters A, Vol. 22, No. 11(2007) 749-766.

[48] Floyd W. Stecker, Tests of Lorentz Invariance Using High Energy Astrophysics Observations, arXiv:1307.5212.

[49] S. T. Scully, F. W. Stecker, Lorentz Invariance Violation and the Observed Spectrum of Ultrahigh Energy Cosmic Rays, Astroparticle Phys. 31 (2009) 220-225 arXiv:0811.2230v4

[50] H. Kawai and others, Telescope Array Experiment, Nuclear Physics B (Proc. Suppl.) 175-176 (2008) 221-226. Departamento de Física da Universidade Nacional de La Plata,Argentina.

[51] W. Heitler, The Quantum Theory of Radiation, third ed., Oxford University Press, London, 1954, p. 386 (Section 38).

[52] Pierre Billor, Phenomenology of Ultra-High-Energy Atmospheric Showers, Physics and Astrophysics of Ultra-High-Energy, Cosmic Rays Lecture Notes in Physics Volume 576, 2001, pp 27-44. 
[53] Matthews, J., A Heitler model of extensive air showers, Astroparticle Physics, Volume 22, Issue 5-6, p. 387-397.

[54] Stanev, T., 2010, High Energy Cosmic Rays, Springer Praxis Books (Springer-Verlag, Berlin).

[55] Alvarez-Muniz, J., R. Engel, T. K. Gaisser, J. A. Ortiz, and T. Stanev, Hybrid simulations of extensive air showers, Phys. Rev. D66, 033011, arXiv:astro-ph/0205302, 2002.

[56] Ulrich, R., et al., On the measurement of the proton-air cross section using air shower data, New J. Phys. 11, 065018, 2009.

[57] Particle Data Group, Review of particle physics, Phys.Rev. D 66 (2002) 258, Fig. 39-5.

[58] Linsley, J., 1977, Proc. 15th ICRC (Plovdiv, Bulgaria) 12, 89.

[59] Ralf Ulrich, Ralph Engel, Steffen Müller, Fabian Schüssler, Michael Unger, Proton-Air Cross Section and Extensive Air Showers, Nucl.Phys.Proc.Suppl.196:335-340,2009.

[60] Markus Roth, The Lateral Distribution Function of Shower Signals in the Surface Detector of the Pierre Auger Observatory, arXiv:astroph/0308392, 2003.

[61] D. Barnhill, P. Bauleo, M.T. Dova, J. Harton, R. Knapik, J. Knapp, J. Lee, M. Mancenido, A.G. Mariazzi, I.C. Maris, D. Newton, M. Roth, T. Schmidt, A.A. Watson for the Pierre Auger Collaboration, Measurement of the Lateral Distribution Function of UHECR Air Showers with the Pierre Auger Observatory, arXiv:astro-ph/0507590, 2005.

[62] Kamata, K. and J. Nishimura, Progress of Theoretical Physics Supplement 6, 93, 1958.

[63] Greisen, K. Ann. Rev. Nucl. Part.Sci. 10, 63, 1960.

[64] http://auger/colostate.edu/ED (Maio, 2013)

[65] Hillas, A.M., Proceedings of 11th ICRC, Budapest, Hungary, 3, 539, 1970.

[66] The Pierre Auger Collaboration, The Fluorescence Detector of the Pierre Auger Observatory, Nucl. Instr. and Methods in Physics Research A620 (2010) 227; arXiv:0907.4282v1 [astro-ph.IM] 
[67] http://www.telescopearray.org/

[68] Gaisser, T., and Hillas, A., Proc 15th ICRC, Plovdiv, Bulgária, 8, 353, 1977.

[69] Pierog, T., and Werner, K., Proc 30th ICRC, Merida, Mexico, 4, 629, $102,2007$.

[70] Surface Detector Array design-Cap 6, Auger Project Design Report, Second Edition - November 1996.

[71] L.D. Landau and I. Ya. Pomeranchuk, Dokl. Akad. Nauk SSSR 92, 535 (1953).

[72] A. B. Migdal, Phys. Rev. 103, 1811 (1956).

[73] B. McBreen and C.J. Lambert, Phys. Rev. D 24, (1981) 2536

[74] D. Heck and T. Pierog, Extensive Air Shower Simulation with CORSIKA: A User's Guide (Version 737xx from April 18, 2013), http://wwwik.fzk.de/ corsika/usersguide/usersguide.pdf

[75] R. S.Fletcher, T. K. Gaisser, P. Lipari, T. Stanev, Phys. Rev. D 50 (1994) 5710.

[76] N.N Kalmykov, S.S Ostapchenko,A. I. Pavlov, Bull. Russ. Acad. Sci. (Physics)58(1994) 1966.

[77] Hillas, A. M. 1997, Nucl. Phys. B(Proc. Suppl.) 52B, 29.

[78] Hillas, A.M., Proc $17^{\text {th }}$ Int. Cosmic Ray Conf., Paris (France), 8 (1981) 193. Proc $19^{\text {th }}$ Int. Cosmic Ray Conf., La Jolla (USA), 1 (1985) 155.

[79] S.J. Sciutto, Aires Shower Simulation with AIRES System, arXiv:astroph/9905185 (1999).

[80] David Griffiths, Introduction to elementary Particles, John Wiley and Sons, inc, 1942 (ISBN 0-471-60386-4).

[81] L.V. Gribov et al., Phys. Rep. 100 (1983) 1.

[82] J. Knapp, D. Heck, S.J. Sciutto, M.T. Dova, M. Risse, Extensive Air Shower Simulations at the Highest Energies, arXiv:astro-ph/0206414, Astropart.Phys. 19 (2003) 77-99.

[83] K.Werner, Phys Rep. 232 (1993)87. 
[84] J. Ranft, Phys. Rev. D51 (1995)64.

[85] H.J. Drescher et al., Phys. Rep. 350 (2001) 93.

[86] V.A. Khoze, A.D. Martin and M.G. Ryskin, Soft diffraction and the elastic slope at Tevatron and LHC energies: a multi-Pomeron approach, Eur.Phys.J.C18:167-179,2000, arXiv:hep-ph/0007359v2.

[87] H. Bengtsson and T. Sjostrand, Comput. Phys. Commun. 46, 43 (1987).

[88] http://home.thep.lu.se/ torbjorn/Pythia.html

[89] A. Capella and A. Krzywicki, Phys. Rev. D 18, 3357 (1978); A. Capella and J. Tran Thanh Van, Z. Phys. C 10, 249 (1981).

[90] T.K. Gaisser and F. Halzen, Phys. Rev. Lett. 54, 1754(1985); G. Pancheri and Y. Srivastava, Phys. Lett. 159B, 69 (1985).

[91] Loyal Durand and Pi Hong, Phys. Rev. Lett. 58, 303 (1987); Phys. Rev. D 38, 78 (1988).

[92] L. Durand and R. Lipes, Phys. Rev. Lett. 20, 637 (1968).

[93] T.T. Chou and C.N. Yang, Phys. Lett. 128B,457 (1983).

[94] Fabian Schmidt, Maximo Ave, Lorenzo Cazon, Aaron Chou, A ModelIndependent Method of Determining Energy Scale and Muon Number in Cosmic Ray Surface Detectors, 10.1016/j.astropartphys.2008.03.004, arXiv:0712.3750.

[95] D. Badagnani, S.J. Sciutto, Proc. 29th Intern. Cosmic Ray Conf., Pune, 9, 1 (2005).

[96] National Geophysical Data Center, USA, http://www.ngdc.noaa.gov.

[97] Maximo Ave, Nicolas Busca, Lorenzo Cazon, Fabian Schmidt, Tokonatsu Yamamoto, Discrimination between Photons, Protons and Iron in Atmospherics Showers, GAPNOTE 2003 - 086.

[98] J. Allen, A. Castellina, R. Engel, K. Kasahara, S. Knurenko, T. Pierog, A. Sabourov, B. T. Stokes, R. Ulrich for the Pierre Auger, Telescope Array, Yakutsk Collaborations, S. Ostapchenko, T. Sako, Air Shower Simulation and Hadronic Interactions, arXiv:1306.6090v1 ,EPJ Web of Conferences 53, 01007 (2013) 
[99] Ralph Engel, for the Pierre Auger Collaboration, Test of hadronic interaction models with data from the Pierre Auger Observatory, arXiv:0706.1921, Contribution to the 30th International Cosmic Ray Conference, Merida, Mexico, July 2007. 